DO NOT DESTROY

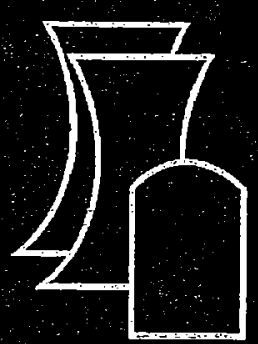

Review of the Margins for ASME Code Fatigue Design

Curve - Effects of Surface

Roughness and Material

Variability

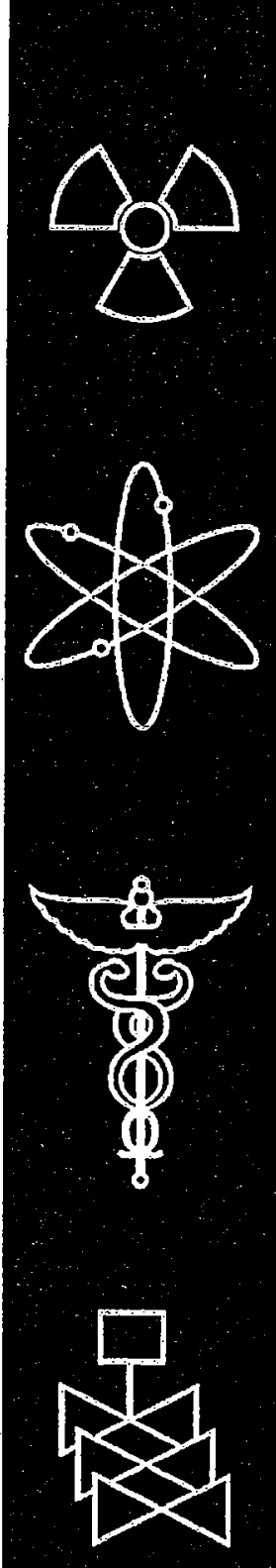

Argonne National Laboratory

U.S. Nuclear Regulatory Commission Office of Nuclear Regulatory Research Washington, DC 20555-0001

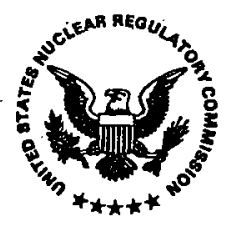




\section{Review of the Margins for ASME Code Fatigue Design Curve - Effects of Surface Roughness and Material Variability}

Manuscript Completed: December 2002

Date Published: September 2003

Prepared by

O. K. Chopra, W. J. Shack

Argonne National Laboratory

9700 South Cass Avenue

Argonne, IL 60439

W. H. Cullen, Jr., NRC Project Manager

\section{Prepared for}

Division of Engineering Technology

Office of Nuclear Regulatory Research

U.S. Nuclear Regulatory Commission

Washington, DC 20555-0001

NRC Job Code Y6388

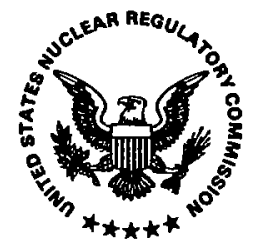




\section{AVAILABILITY OF REFERENCE MATERIALS IN NRC PUBLICATIONS}

\section{NRC Reference Material}

As of November 1999, you may electronically access NUREG-series publications and other NRC records at NRC's Public Electronic Reading Room at http://mww.nrc.gov/reading-rm.html. Publicly released records include, to name a few, NUREG-series publications; Federal Register notices; applicant, licensee, and vendor documents and correspondence; NRC correspondence and internal memoranda; bulletins and information notices; inspection and investigative reports; licensee event reports; and Commission papers and their attachments.

NRC publications in the NUREG series, NRC regulations, and Title 10, Energy, in the Code of Federal Regulations may also be purchased from one of these two sources.

1. The Superintendent of Documents

U.S. Government Printing Office

- Mail Stop SSOP

Washington, DC 20402-0001

Internet: bookstore.gpo.gov

Telephone: 202-512-1800

Fax: 202-512-2250

2. The National Technical Information Service Springfield, VA 22161-0002

wuw.ntis.gov

1-800-553-6847 or, locally, 703-605-6000

A single copy of each NRC draft report for comment is available free, to the extent of supply, upon written request as follows:

Address: Office of the Chief Information Officer, Reproduction and Distribution Services Section

U.S. Nuclear Regulatory Commission

Washington, DC 20555-0001

E-mail: DISTRIBUTION@nrc.gov

Facsimile: 301-415-2289

Some publications in the NUREG series that are posted at NRC's Web site address http://www.nrc.gov/reading-rm/doc-collections/nuregs are updated periodically and may differ from the last printed version. Although references to material found on a Web site bear the date the material was accessed, the material available on the date cited may subsequently be removed from the site.

\section{Non-NRC Reference Material}

Documents available from public and special technical libraries include all open literature items, such as books, joumal articles, and transactions, Federal Register notices, Federal and State legislation, and congressional reports. Such documents as theses, dissertations, foreign reports and translations, and non-NRC conference proceedings may be purchased from their sponsoring organization.

Copies of industry codes and standards used in a substantive manner in the NRC regulatory process are maintained at-

The NRC Technical Library

Two White Flint North

11545 Rockville Pike

Rockville, MO 20852-2738

These standards are available in the library for reference use by the public. Codes and standards are usually copyrighted and may be purchased from the originating organization or, if they are American National Standards, from-

American National Standards Institute

11 West $42^{\text {nd }}$ Street

New York, NY 10036-8002

wuw.ansi.org

212-642-4900

Legally binding regulatory requirements are stated only in laws; NRC regulations; licenses, including technical specifications; or orders, not in NUREG-series publications. The views expressed in contractor-prepared publications in this series are not necessarily those of the NRC.

The NUREG series comprises (1) technical ahd administrative reports and books prepared by the staff (NUREG- $X X X X$ ) or agency contractors (NUREG/CR-XXXX), (2) proceedings of conferences (NUREG/CP-XXXX), (3) reports resulting from international agreements (NUREG/IA-XXXX), (4) brochures

(NUREG/BR- $X X X X$ ), and (5) compilations of legal decisions and orders of the Commission and Atomic and Safety Licensing Boards and of Directors' decisions under Section 2.206 of NRC's regulations (NUREG-0750).

DISCLAIMER: This report was prepared as an account of work sponsored by an agency of the U.S. Government. Neither the U.S. Government nor any agency thereof, nor any employee, makes any warranty, expressed or implied, or assumes any legal liability or responsibility for any third party's use, or the results of such use, of any information, apparatus, product, or process disclosed in this publication, or represents that its use by such third party would not infringe privately owned rights. 


\title{
Review of the Margins for ASME Code Fatigue Design Curve - Effects of Surface Roughness and Material Variability
}

by

O. K. Chopra and W. J. Shack

\begin{abstract}
The ASME Boiler and Pressure Vessel Code provides rules for the construction of nuclear power plant components. The Code specifies fatigue design curves for structural materials. However, the effects of light water reactor (LWR) coolant environments are not explicitly addressed by the Code design curves. Existing fatigue strain-vs.-life $(\varepsilon-N)$ data illustrate potentially significant effects of LWR coolant environments on the fatigue resistance of pressure vessel and piping steels. This report provides an overview of the existing fatigue $\varepsilon-\mathrm{N}$ data for carbon and low-alloy steels and wrought and cast austenitic SSs to define the effects of key material, loading, and environmental parameters on the fatigue lives of the steels. Experimental data are presented on the effects of surface roughness on the fatigue life of these steels in air and LWR environments. Statistical models are presented for estimating the fatigue $\varepsilon-\mathrm{N}$ curves as a function of the material, loading, and environmental parameters. Two methods for incorporating environmental effects into the ASME Code fatigue evaluations are discussed. Data available in the literature have been reviewed to evaluate the conservatism in the existing ASME Code fatigue evaluations. A critical review of the margins for ASME Code fatigue design curves is presented.
\end{abstract}




\section{Contents}

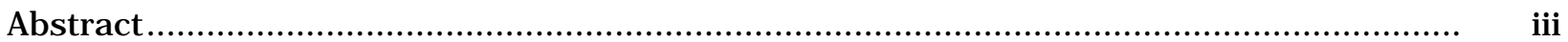

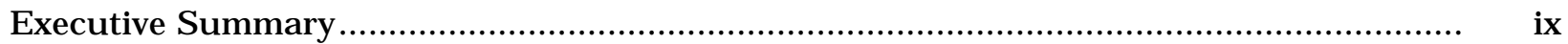

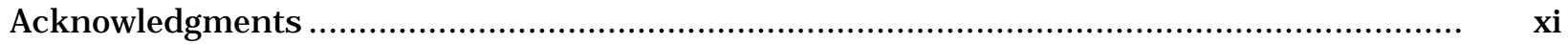

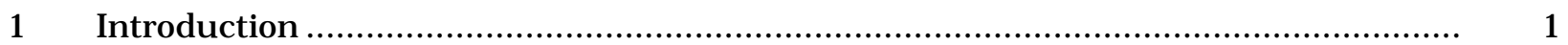

$2 \quad$ Experimental .......................................................................................

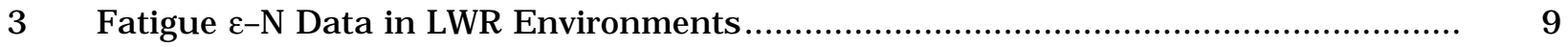

3.1 Carbon and Low-Alloy Steels....................................................... 10

$3.2 \quad$ Austenitic Stainless Steels.......................................................

Effects of Surface Finish ............................................................ 19

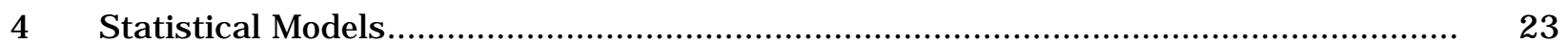

5 Incorporating Environmental Effects into Fatigue Evaluations .......................... 25

$5.1 \quad$ Fatigue Design Curves.............................................................

5.2 Fatigue Life Correction Factor ...................................................... 28

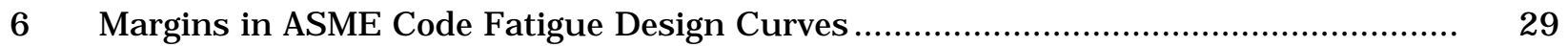

6.1 Material variability and data scatter ............................................. 31

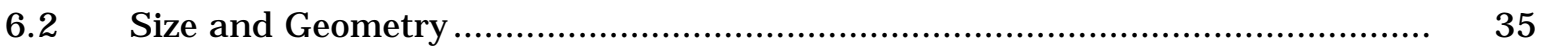

Surface Finish ....................................................................... 35

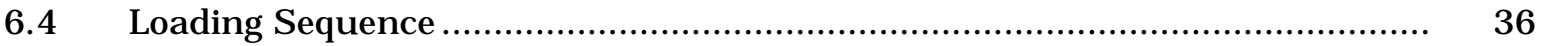

6.5 Moderate or Acceptable Environmental Effects .................................... 37

Fatigue Design Curve Margins ........................................................ 38

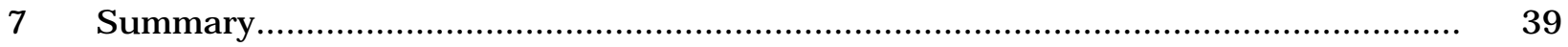

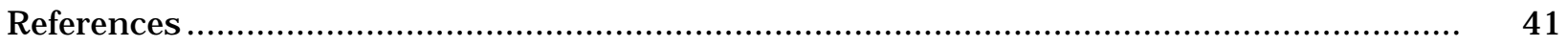




\section{Figures}

1. Fatigue $\varepsilon-\mathrm{N}$ data for carbon steels and austenitic stainless steels in water............... 2

2. Configuration of fatigue test specimen.............................................................. 5

3. Surface roughness profile of fatigue test specimen. ........................................ 6

4. Autoclave system for fatigue tests in water................................................... 6

5. Dependence of fatigue lives of carbon and low-alloy steels on strain rate. ............... 11

6. Change in fatigue life of A333-Gr 6 carbon steels with temperature ........................ 12

7. Dependence on dissolved oxygen of fatigue life of carbon steels at 288 and $250^{\circ} \mathrm{C}$

8. Effect of water flow rate on fatigue life of A333-Gr 6 carbon steel in high-purity water at $289^{\circ} \mathrm{C}$ and strain amplitude and strain rates of $0.3 \%$ and $0.01 \% / \mathrm{s}$ and $0.6 \%$ and $0.001 \% / \mathrm{s}$

9. Effect of flow rate on low-cycle fatigue of carbon steel tube bends in high-purity water at $240^{\circ} \mathrm{C}$

10. Dependence of fatigue life of austenitic stainless steels on strain rate in low-DO water

11. Dependence of fatigue life of Types 304 and $316 \mathrm{NG}$ stainless steel on strain rate in high- and low-DO water at $288^{\circ} \mathrm{C}$

12. Dependence of fatigue life of two heats of Type 316NG SS on strain rate in high- and low-DO water at $288^{\circ} \mathrm{C}$.

13. Effects of conductivity of water and soaking period on fatigue life of Type 304 $\mathrm{SS}$ in high-DO water.

14. Change in fatigue lives of austenitic stainless steels in low-DO water with temperature

15. Fatigue life of Type 316 stainless steel under constant and varying test temperature.....

16. Effect of surface roughness on fatigue life of A106 Gr. B carbon steel and A533 low-alloy steel in air and high-purity water at $289^{\circ} \mathrm{C}$

17. Effect of surface roughness on fatigue life of Type 316NG and Type 304 stainless steels in air and high-purity water at $289^{\circ} \mathrm{C}$

18. Cyclic stress response of A106-Gr B carbon steel, A533-Gr B low-alloy steel, Type $316 \mathrm{NG}$, and Type $304 \mathrm{SS}$, in air and LWR environments at $289^{\circ} \mathrm{C}$. 
19. Fatigue design curves developed from statistical model for carbon steels and low-alloy steels under service conditions where one or more critical threshold values are not satisfied.

20. Fatigue design curves developed from statistical model for carbon steels and low-alloy steels in high-DO water at 200, 250, and 288C and under service conditions where all other threshold values are satisfied.

21. Fatigue design curves developed from the statistical model for austenitic stainless steels in air at room temperature, LWR environments under service conditions where one or more critical threshold values are not satisfied, and LWR environments under service conditions where all threshold values are satisfied.

22. Fatigue data for carbon and low-alloy steel and Type 304 stainless steel components.....

23. Estimated cumulative distribution of Parameter A in statistical models for fatigue life for heats of carbon and low-alloy steels and austenitic SSs in air and water environments.

24. Schematic illustration of growth of short cracks in smooth specimens as a function of fatigue life fraction and crack velocity as a function of crack length 


\section{Tables}

1. Composition of austenitic and ferritic steels for fatigue tests

2. Fatigue test results for smooth and rough specimens of austenitic SSs and carbon and low-alloy steels in air and LWR environments at $288^{\circ} \mathrm{C}$.

3. Values of parameter A in statistical model for carbon steels as a function of confidence level and percentage of population bounded

4. Values of parameter A in statistical model for low-alloy steels as a function of confidence level and percentage of population bounded

5. Values of parameter A in statistical model for austenitic stainless steels as a function of confidence level and percentage of population bounded

6. Margins on life for carbon steels corresponding to various confidence levels and percentile values of Parameter A

7. Margins on life for low-alloy steels corresponding to various confidence levels and percentile values of Parameter A

8. Margins on life for austenitic stainless steels corresponding to various confidence levels and percentile values of Parameter A .....

9. Factors on cycles and strain to be applied to mean $\varepsilon-\mathrm{N}$ curve 


\section{Executive Summary}

Section III, Subsection NB, of the ASME Boiler and Pressure Vessel Code contains rules for the design of Class 1 components of nuclear power plants. Figures I-9.1 through I-9.6 of Appendix I to Section III specify the Code fatigue design curves for applicable structural materials. However, Section III, Subsection NB-3121, of the Code states that the effects of the coolant environment on fatigue resistance of a material were not intended to be addressed in these design curves. Therefore, the effects of environment on the fatigue resistance of materials used in operating pressurized water reactor and boiling water reactor plants, whose primary-coolant pressure boundary components were designed in accordance with the Code, are uncertain.

The current Section-III fatigue design curves of the ASME Code were based primarily on strain-controlled fatigue tests of small polished specimens at room temperature in air. Best-fit curves to the experimental test data were first adjusted to account for the effects of mean stress and then lowered by a factor of 2 on stress and 20 on cycles (whichever was more conservative) to obtain the fatigue design curves. These factors are not safety margins but rather adjustment factors that must be applied to experimental data to obtain estimates of the lives of components. They were not intended to address the effects of the coolant environment on fatigue life. Recent fatigue-strain-vs.-life $(\varepsilon-\mathrm{N})$ data obtained in the U.S. and Japan demonstrate that light water reactor (LWR) environments can have potentially significant effects on the fatigue resistance of materials. Specimen lives obtained from tests in simulated LWR environments can be much shorter than those obtained from corresponding tests in air.

The existing fatigue $\varepsilon-\mathrm{N}$ data for carbon and low-alloy steels and wrought and cast austenitic stainless steels (SSs) have been evaluated to define the effects of key material, loading, and environmental parameters on the fatigue lives of these steels. The fatigue lives of carbon and low-alloy steels and austenitic SSs are decreased in LWR environments; environmental effects are significant only when certain critical parameters, e.g., temperature, strain rate, dissolved oxygen (DO) level, and strain amplitude, meet certain threshold values. Environmental effects are moderate when any one of the threshold conditions is not satisfied. The threshold values of the critical parameters and the effects of other parameters, such as water conductivity, water flow rate, and material heat treatment, on the fatigue life of the steels are summarized.

Experimental data are presented on the effects of surface roughness on the fatigue life of carbon and low-alloy steels and austenitic SSs in air and LWR environments. For austenitic SSs, the fatigue life of roughened specimens is a factor of $\approx 3$ lower than it is for the smooth specimens in both air and low-DO water. The fatigue life of roughened specimens of carbon and low-alloy steels in air is lower than that of smooth specimens; but, in high-DO water the fatigue life of roughened and smooth specimens is the same. In low-DO water, the fatigue life of the roughened specimens of carbon and low-alloy steels is slightly lower than that of smooth specimens.

Statistical models are presented for estimating the fatigue life of carbon and low-alloy steels and wrought and cast austenitic SSs as a function of material, loading, and environmental parameters. Also, two approaches are presented for incorporating the effects of LWR environments into ASME Section III fatigue evaluations. In the first approach, 
environmentally adjusted fatigue design curves have been developed by adjusting the best-fit experimental curve for the effect of mean stress and by setting margins of 20 on cycles and 2 on strain to account for the uncertainties in life associated with material and loading conditions. These curves provide allowable cycles for fatigue crack initiation in LWR coolant environments. The second approach considers the effects of reactor coolant environments on fatigue life in terms of an environmental correction factor $\mathrm{F}_{\mathrm{en}}$, which is the ratio of fatigue life in air at room temperature to that in water under reactor operating conditions. To incorporate environmental effects into the ASME Code fatigue evaluations, the fatigue usage factor for a specific load set, based on the current Code design curves, is multiplied by the correction factor.

Data available in the literature have been reviewed to evaluate the conservatism in the existing ASME Code fatigue evaluations. Much of the conservatism in these evaluations arises from current design procedures, e.g., stress analysis rules, and cycle counting. However, the ASME Code permits alternative approaches, such as finite-element analyses, fatigue monitoring, and improved $\mathrm{K}_{\mathrm{e}}$ factors, that can significantly decrease the conservatism in the current fatigue evaluation procedures.

Because of material variability, data scatter, and component size and surface, the fatigue life of actual components differs from that of laboratory test specimens under a similar loading history, and the mean $\varepsilon-\mathrm{N}$ curves for laboratory test specimens must be adjusted to obtain design curves for components. These design margins are another source of possible conservatism. The factors of 2 on stress and 20 on cycles, used in the Code, were intended to cover the effects of variables that can influence fatigue life but were not investigated in the tests that provided the data for the curves. Although these factors were intended to be somewhat conservative, they should not be considered safety margins because they were intended to account for variables that are known to have effects on fatigue life. This report presents a critical review of the ASME Code fatigue design curve margins. Data available in the literature have been reviewed to evaluate the margins on cycles and stress that are needed to account for the effects of size and surface finish and the uncertainties due to material variability and data scatter. The results indicate that the current ASME Code requirements of a factor of 2 on stress and 20 on cycle are quite reasonable, but do not contain excess conservatism that can be assumed to account for the effects of LWR environments. They thus provide appropriate design margins for the development of design curves from mean data curves for small specimens in LWR environments. 


\section{Acknowledgments}

The authors thank T. M. Galvin, J. Tezak, and E. J. Listwan for their contributions to the experimental effort. This work is sponsored by the Office of Nuclear Regulatory Research, U.S. Nuclear Regulatory Commission, under Job Code Y6388; Program Manager: W. H. Cullen, Jr. 


\section{Introduction}

Cyclic loadings on a structural component occur because of changes in mechanical and thermal loadings as the system goes from one load set (e.g., pressure, temperature, moment, and force loading) to another. For each load set, an individual fatigue usage factor is determined by the ratio of the number of cycles anticipated during the lifetime of the component to the allowable cycles. Figures I-9.1 through I-9.6 of the mandatory Appendix I to Section III of the ASME Boiler and Pressure Vessel Code specify fatigue design curves that define the allowable number of cycles as a function of applied stress amplitude. The cumulative usage factor (CUF) is the sum of the individual usage factors, and ASME Code Section III requires that the CUF at each location must not exceed 1.

The ASME Code fatigue design curves, given in Appendix I of Section III, are based on strain-controlled tests of small polished specimens at room temperature in air. The design curves have been developed from the best-fit curves to the experimental fatigue-strain-vs.-life $(\varepsilon-\mathrm{N})$ data that are expressed in terms of the Langer equation ${ }^{1}$ of the form

$$
\varepsilon_{\mathrm{a}}=\mathrm{A} 1(\mathrm{~N})^{-\mathrm{n} 1}+\mathrm{A} 2
$$

where $\varepsilon_{\mathrm{a}}$ is the applied strain amplitude, $\mathrm{N}$ is the fatigue life, and $\mathrm{A} 1, \mathrm{~A} 2$, and $\mathrm{n} 1$ are coefficients of the model. Equation 1 may be written in terms of stress amplitude $\mathrm{S}_{\mathrm{a}}$ instead of $\varepsilon_{\mathrm{a}}$. The stress amplitude is the product of $\varepsilon_{\mathrm{a}}$ and elastic modulus E, i.e., $\mathrm{S}_{\mathrm{a}}=\mathrm{E} \cdot \varepsilon_{\mathrm{a}}$. The current ASME Code best-fit or mean curve for various steels is given by

$$
\mathrm{S}_{\mathrm{a}}=\frac{\mathrm{E}}{4 \sqrt{\mathrm{N}}} \ln \left(\frac{100}{100-\mathrm{A}}\right)+\mathrm{B}
$$

where $\mathrm{E}$ is the elastic modulus, $\mathrm{N}$ is the number of cycles to failure, and $\mathrm{A}$ and $\mathrm{B}$ are constants related to reduction in area in a tensile test and endurance limit of the material at $10^{7}$ cycles, respectively. In the fatigue tests performed during the last three decades, fatigue life is defined in terms of the number of cycles for tensile stress to decrease $25 \%$ from its peak or steady state value. For a typical specimen diameter used in these studies, this corresponds to the number of cycles needed to produce an $\approx 3$-mm-deep crack in the test specimen. Thus, the fatigue life of a material is actually represented by three parameters, e.g., strain or stress, cycles, and crack length. The best-fit curve to the existing fatigue $\varepsilon-\mathrm{N}$ data represents, for a given strain or stress amplitude, the number of cycles needed to develop a 3-mm crack.

The ASME Code fatigue design curves have been obtained from the best-fit curves by first adjusting for the effects of mean stress on fatigue life and then reducing the fatigue life at each point on the adjusted curve by a factor of 2 on strain (or stress) or 20 on cycles, whichever is more conservative. As described in the Section III criteria document, ${ }^{2}$ these factors were intended to account for data scatter (including material variability) and differences in surface condition and size between the test specimens and actual components. In comments by Cooper ${ }^{3}$ about the initial scope and intent of the Section III fatigue design procedures it is stated that the factor of 20 on life was regarded as the product of three subfactors: 
Scatter of data (minimum to mean)

Size effect

Surface finish, atmosphere, etc.
2.0

2.5

4.0

The factors of 2 and 20 are not safety margins but rather adjustment factors that should be applied to the small-specimen data to obtain reasonable estimates of the lives of actual reactor components. Although the Section III criteria document ${ }^{2}$ states that these factors were intended to cover such effects as environment, Cooper ${ }^{3}$ further states that the term "atmosphere" was intended to reflect the effects of an industrial atmosphere in comparison with an air-conditioned laboratory, not the effects of a specific coolant environment. Subsection NB-3121 of Section III of the Code explicitly notes that the data used to develop the fatigue design curves (Figs. I-9.1 through I-9.6 of Appendix I to Section III) did not include tests in the presence of corrosive environments that might accelerate fatigue failure. Article B-2131 in Appendix B to Section III states that the owner's design specifications should provide information about any reduction to fatigue design curves that is necessitated by environmental conditions.

Existing fatigue strain-vs.-life $(\varepsilon-\mathrm{N})$ data illustrate potentially significant effects of light water reactor (LWR) coolant environments on the fatigue resistance of carbon and low-alloy steels $^{4-17}$ and austenitic stainless steels (SSs) ${ }^{16-28}$ (Fig. 1). The key parameters that influence fatigue life in these environments are temperature, dissolved-oxygen (DO) level in water, strain rate, strain (or stress) amplitude, and, for carbon and low-alloy steels, S content of the steel. Under certain environmental and loading conditions, fatigue lives of carbon and low-alloy steels can be a factor of 70 lower in the coolant environment than in air. ${ }^{5,14}$ Therefore, the margins in the ASME Code may be less conservative than originally intended.

Two approaches have been proposed for incorporating the environmental effects into ASME Section III fatigue evaluations for primary pressure boundary components in operating nuclear power plants: (a) develop new fatigue design curves for LWR applications, or (b) use an environmental correction factor to account for the effects of the coolant environment. In the first approach, following the same procedures used to develop the current fatigue design curves of the ASME Code, environmentally adjusted fatigue design curves are developed from fits to

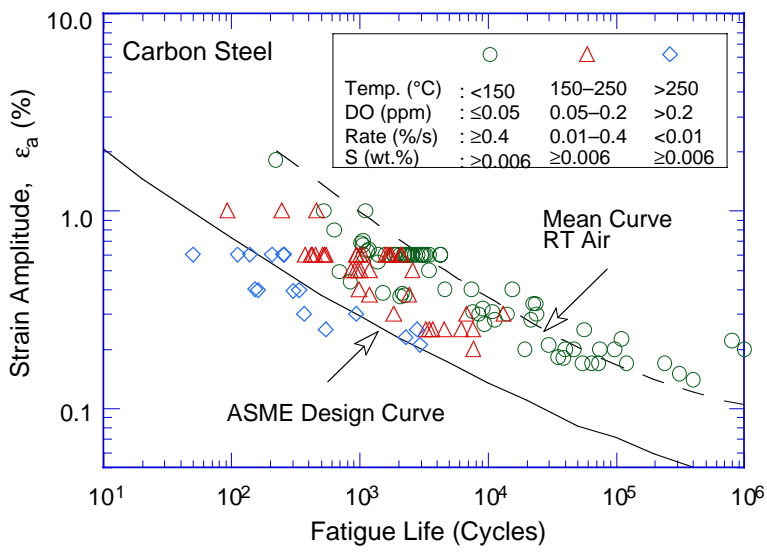

(a)

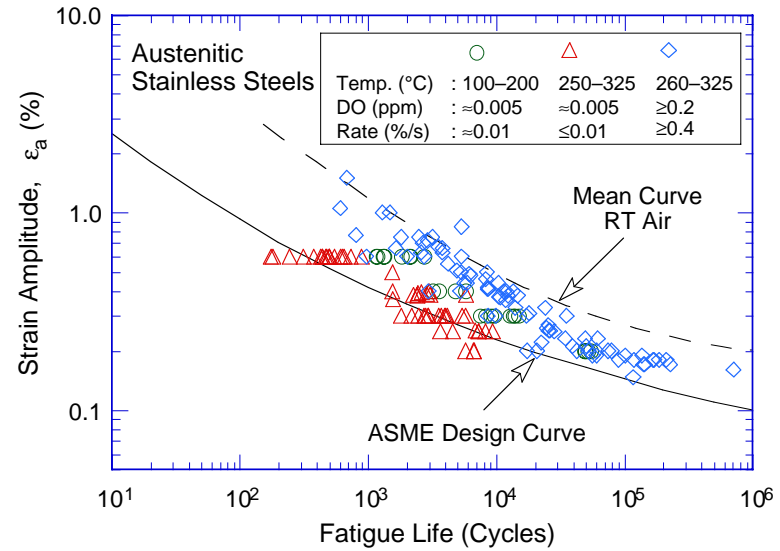

(b)

Figure 1. Fatigue $\varepsilon-\mathrm{N}$ data for (a) carbon steels and (b) austenitic stainless steels in water; $\mathrm{RT}=$ room temperature. 
experimental data obtained in LWR environments. Interim fatigue design curves that address environmental effects on the fatigue life of carbon and low-alloy steels and austenitic SSs were first proposed by Majumdar et al. ${ }^{29}$ Fatigue design curves based on a more rigorous statistical analysis of experimental data were developed by Keisler et al. ${ }^{30}$ These design curves have subsequently been updated on the basis of updated statistical models. ${ }^{14,17,26}$

The second approach, proposed by Higuchi and Iida, ${ }^{5}$ considers the effects of reactor coolant environments on fatigue life in terms of an environmental correction factor $\mathrm{F}_{\mathrm{en}}$, which is the ratio of fatigue life in air at room temperature to that in water under reactor operating conditions. To incorporate environmental effects into fatigue evaluations, the fatigue usage factor for a specific load set, based on the current Code design curves, is multiplied by the environmental correction factor. Specific expressions for $\mathrm{F}_{\mathrm{en}}$, based on the Argonne National Laboratory (ANL) statistical models $14,17,26$ and on the correlations proposed by the Ministry of International Trade and Industry (MITI) of Japan, ${ }^{11}$ have been proposed.

A pressure vessel research council (PVRC) working group has also been compiling and evaluating fatigue $\varepsilon-\mathrm{N}$ data related to the effects of LWR coolant environments on the fatigue lives of pressure boundary materials. ${ }^{31}$ One of the tasks in the PVRC activity was to define a set of values for material, loading, and environmental variables that lead to "moderate" or "acceptable" effects of environment on fatigue life. A factor of 4 on the ASME mean life was chosen as a working definition of "moderate" or "acceptable" effects of environment, i.e., up to a factor of 4 decrease in fatigue life due to the environment is considered acceptable and does not require further fatigue evaluation. The basis for this choice was the above-listed third subfactor, for surface finish, atmosphere, etc. The criterion for "acceptable" environmental effects assumes that the current Code design curve includes a factor of 4 to account for the effects of environment.

This report presents a critical review of the ASME Code fatigue design margins and assesses the conservatism in the current choice of design margins. The existing fatigue $\varepsilon-\mathrm{N}$ data for carbon and low-alloy steels and wrought and cast austenitic SSs have been evaluated to define the effects of key material, loading, and environmental parameters on the fatigue lives of these steels. Statistical models are presented for estimating their fatigue life as a function of material, loading, and environmental parameters. Both approaches to incorporating the effects of LWR environments into ASME Section III fatigue evaluations are considered. 


\section{Experimental}

Fatigue tests have been conducted to establish the effects of surface finish on the fatigue life of austenitic SSs and carbon and low-alloy steels in LWR environments. Tests were conducted on Types 304 and 316NG SS, A106-Gr B carbon steel, and A533-Gr B low-alloy steel; the composition and heat treatments of the steels are given in Table 1. The A106-Gr B material was obtained from a 508-mm-diameter, Schedule 140 pipe fabricated by the Cameron Iron Works of Houston, TX. The A533-Gr B material was obtained from the lower head of the Midland reactor vessel, which was scrapped before the plant was completed. The product form for Types 304 and 316NG SS materials was 76 x 25-mm bar and 25-mm plate, respectively.

Table 1. Composition (wt.\%) of austenitic and ferritic steels for fatigue tests

\begin{tabular}{|c|c|c|c|c|c|c|c|c|c|}
\hline Material & Source & $\mathrm{C}$ & $\mathrm{P}$ & $\mathrm{S}$ & $\mathrm{Si}$ & $\mathrm{Cr}$ & $\mathrm{Ni}$ & $\mathrm{Mn}$ & Mo \\
\hline \multicolumn{10}{|c|}{ Carbon Steel } \\
\hline A106-Gr Ba & ANL & 0.290 & 0.013 & 0.015 & 0.25 & 0.19 & 0.09 & 0.88 & 0.05 \\
\hline \multicolumn{10}{|c|}{ Low-Alloy Steel } \\
\hline A533-Gr B ${ }^{b}$ & ANL & 0.220 & 0.010 & 0.012 & 0.19 & 0.18 & 0.51 & 1.30 & 0.48 \\
\hline \multicolumn{10}{|c|}{$\begin{array}{l}\text { Supplier } \\
\text { Austenitic Stainless Steel }\end{array}$} \\
\hline Type $304^{c}$ & Supplier & 0.060 & 0.019 & 0.007 & 0.48 & 18.99 & 8.00 & 1.54 & 0.44 \\
\hline Type $316 \mathrm{NG}^{\mathrm{d}}$ & Supplier & 0.015 & 0.020 & 0.010 & 0.42 & 16.42 & 10.95 & 1.63 & 2.14 \\
\hline
\end{tabular}

Smooth cylindrical specimens, with a 9.5-mm diameter and a 19-mm gauge length, were used for the fatigue tests (Fig. 2). The gauge section of the specimens was oriented along the axial directions of the carbon steel pipe and along the rolling direction for the bar and plates. The gauge length of all specimens was given a $1-\mu \mathrm{m}$ surface finish in the axial direction to prevent circumferential scratches that might act as sites for crack initiation. Some specimens

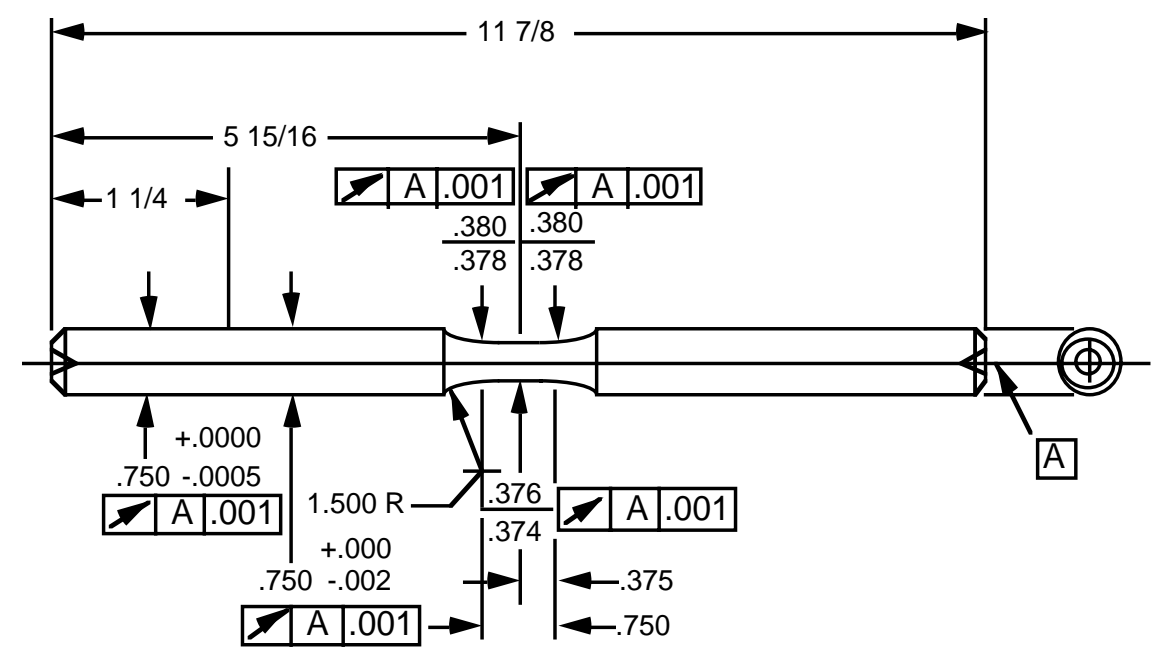

Figure 2. Configuration of fatigue test specimen (all dimensions in inches). 


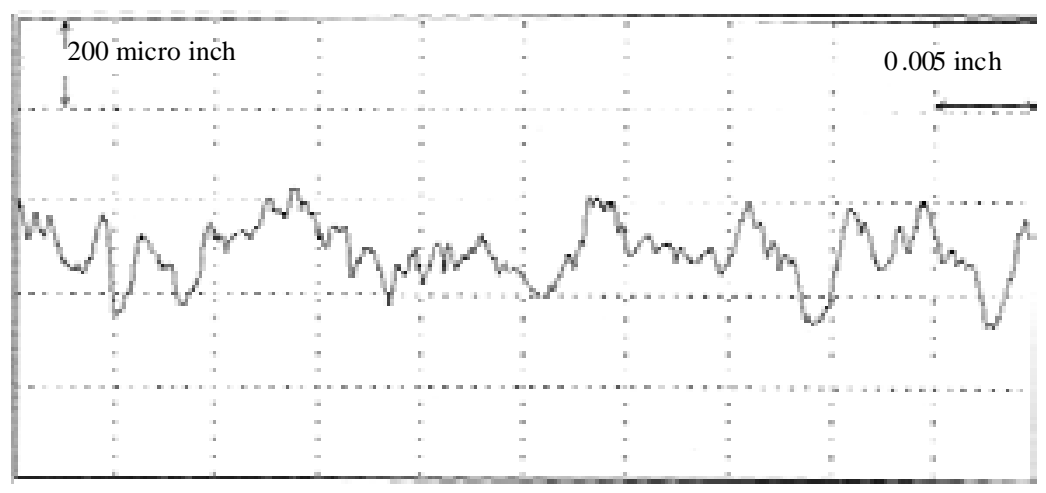

Figure 3. Surface roughness profile of fatigue test specimen.

were intentionally roughened in a lathe, under controlled conditions, with 50-grit sandpaper to produce circumferential scratches. The measured surface roughness of the specimen is shown in Fig. 3. The average surface roughness $\left(R_{a}\right)$ was $1.2 \mu \mathrm{m}$, and the root-mean-square (RMS) value of surface roughness $\left(\mathrm{R}_{\mathrm{q}}\right)$ was $1.6 \mu \mathrm{m}$ (61.5 micro-inch).

Tests in water were conducted in a 12-mL autoclave (Fig. 4) equipped with a recirculating water system that consisted of a 132-L closed feedwater storage tank, Pulsafeeder ${ }^{\mathrm{TM}}$ high-pressure pump, regenerative heat exchanger, autoclave preheater, test autoclave, electrochemical potential (ECP) cell, back-pressure regulator, ion exchange bed, 0.2-micron filter, and return line to the tank. Water was circulated at a rate of $\approx 10 \mathrm{~mL} / \mathrm{min}$. Water quality was maintained by circulating water in the feedwater tank through an ion exchange cleanup system. An Orbisphere meter and CHEMetrics ${ }^{\mathrm{TM}}$ ampules were used to measure the DO concentrations in the supply and effluent water. The redox and open-circuit corrosion potentials were monitored at the autoclave outlet by measuring the ECPs of platinum and an electrode of the test material, respectively, against a $0.1-\mathrm{M} \mathrm{KCl} / \mathrm{AgCl} / \mathrm{Ag}$ external (cold)

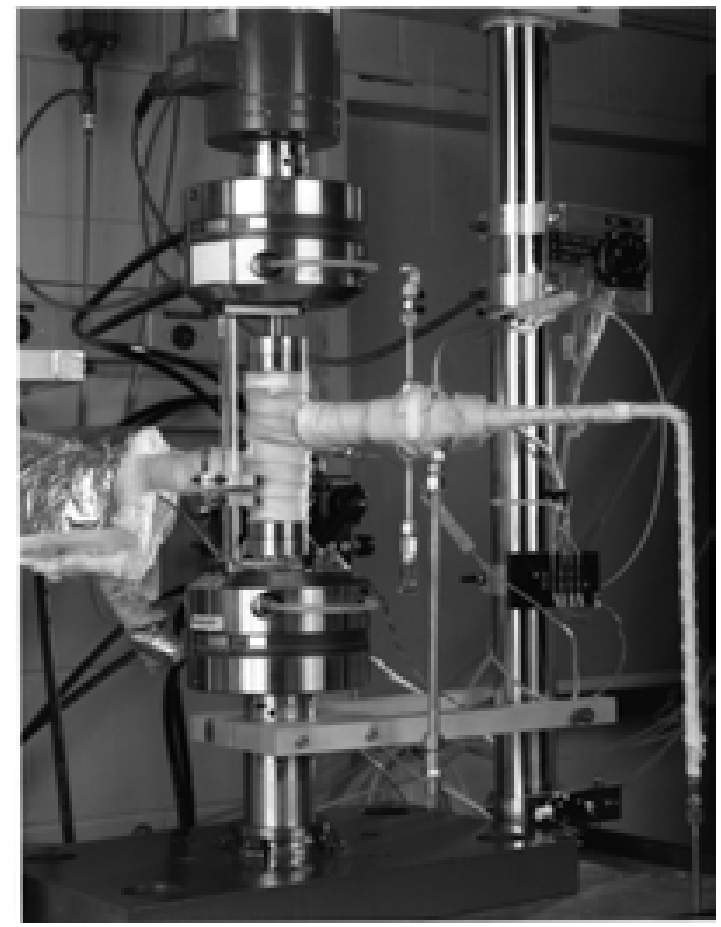

Figure 4.

Autoclave system for fatigue tests in water. 
reference electrode. A detailed description of the test facility has been presented earlier. ${ }^{26,32}$

Boiling water reactor (BWR) conditions were established by bubbling $\mathrm{N}_{2}$ that contained $1-2 \% \mathrm{O}_{2}$ through deionized water in the supply tank. The deionized water was prepared by passing purified water through a set of filters that comprise a carbon filter, an Organex- $\mathrm{Q}$ filter, two ion exchangers, and a $0.2-\mathrm{mm}$ capsule filter. Water samples were taken periodically to measure $\mathrm{pH}$, resistivity, and DO concentration. When the desired concentration of DO was attained, the $\mathrm{N}_{2} / \mathrm{O}_{2}$ gas mixture in the supply tank was maintained at a $20-\mathrm{kPa}$ overpressure. After an initial transition period during which an oxide film developed on the fatigue specimen, the DO level and the ECP in the effluent water remained constant. Test conditions are described in terms of the DO in effluent water.

Simulated pressurized water reactor (PWR) water was obtained by dissolving boric acid and lithium hydroxide in $20 \mathrm{~L}$ of deionized water before adding the solution to the supply tank. The DO in the deionized water was reduced to $<10 \mathrm{ppb}$ by bubbling $\mathrm{N}_{2}$ through the water. A vacuum was drawn on the tank cover gas to speed deoxygenation. After the DO was reduced to the desired level, a $34-\mathrm{kPa}$ overpressure of hydrogen was maintained to provide $\approx 2 \mathrm{ppm}$ dissolved $\mathrm{H}$ ( or $\approx 23 \mathrm{cc}^{3} / \mathrm{kg}$ ) in the feedwater.

All tests were conducted at $288^{\circ} \mathrm{C}$, with fully reversed axial loading (i.e., $\mathrm{R}=-1$ ) and a triangular or sawtooth waveform. During the tests in water, performed under stroke control, the specimen strain was controlled between two locations outside the autoclave. Companion tests in air were performed under strain control with an axial extensometer; during the test the stroke at the location used to control the water tests was recorded. Information from the air tests was used to determine the stroke required to maintain constant strain in the specimen gauge. To account for cyclic hardening of the material, the stroke that was needed to maintain constant strain was gradually increased during the test, based on the stroke measurements from the companion strain-controlled tests. The fatigue life $\mathrm{N}_{25}$ is defined as the number of cycles for tensile stress to decrease $25 \%$ from its peak or steady-state value. 


\section{Fatigue $\varepsilon-N$ Data in LWR Environments}

The existing fatigue $\varepsilon-\mathrm{N}$ data developed at various establishments and research laboratories worldwide have been compiled and categorized according to test conditions. The fatigue data were obtained on smooth specimens tested under a fully reversed loading condition, i.e., load ratio $\mathrm{R}=-1$; tests on notched specimens or at values of $\mathrm{R}$ other than -1 were excluded. Unless otherwise mentioned, all tests were conducted on gauge specimens in strain control. In nearly all tests, fatigue life is defined as the number of cycles $\mathrm{N}_{25}$ necessary for tensile stress to drop $25 \%$ from its peak or steady-state value; in some tests, life is defined as the number of cycles for peak tensile stress to decrease by $1-5 \%$. Also, for fatigue tests on tube specimens, life was represented by the number of cycles to develop a leak.

For carbon and low-alloy steels, the primary sources of $\varepsilon-\mathrm{N}$ data include the tests performed by General Electric Co. (GE) at the Dresden 1 reactor, ${ }^{33,34}$ work sponsored by the Electric Power Research Institute (EPRI) at GE, ${ }^{4,35}$ the work of Terrell at Materials Engineering Associates (MEA), ${ }^{36,37}$ the present work at ANL, ${ }^{12-17}$ the JNUFAD* database, and recent studies at Ishikawajima-Harima Heavy Industries Co., (IHI), Hitachi, and Mitsubishi Heavy Industries (MHI) in Japan. ${ }^{5-10}$ The database is composed of results from $\approx 1400$ tests, $\approx 650$ in air and $\approx 750$ in water. Carbon steels include 8 heats of A333-Grade 6,3 heats of A106-Grade B, and a heat each of A516-Grade 70 and A508-Class 1 steel, while the low-alloy steels include 8 heats of A533-Grade B, 10 heats of A508-Class 2 and 3 steels, and a heat of A302-Grade B.

The relevant fatigue $\varepsilon-\mathrm{N}$ data for austenitic SSs in air include the data compiled by Jaske and $\mathrm{O}^{\prime}$ Donnell ${ }^{38}$ for developing fatigue design criteria for pressure vessel alloys, the JNUFAD database from Japan, and the results of Conway et al. ${ }^{39}$ and Keller. ${ }^{40}$ In water, the existing data include the tests performed by GE at the Dresden 1 reactor, ${ }^{33}$ the JNUFAD database, studies at MHI, 18,21-23 $\mathrm{IHI},{ }^{19}$ and Hitachi ${ }^{41,42}$ in Japan, and the present work at ANL. ${ }^{24-28}$

In air, the fatigue $\varepsilon-\mathrm{N}$ database for austenitic SSs is composed of 500 tests: 240 on 26 heats of Type 304 SS, 170 on 15 heats of Type 316 SS, and 90 on 4 heats of Type 316NG. Most of the tests have been conducted on cylindrical gauge specimens with fully reversed axial loading; $\approx 75$ tests were on hourglass specimens, and $\approx 40$ data points were from bending tests on flat-sheet specimens with rectangular cross section. The results indicate that specimen geometry has little or no effect on the fatigue life of austenitc SSs; the fatigue lives of hourglass specimens are comparable to those of gauge specimens.

In water, the database for austenitic SSs consists of 310 tests: 150 on 9 heats of Type 304 SS, 60 on 3 heats of Type 316 SS, and 100 on 4 heats of Type 316 NG. Nearly 90\% of the tests in water were conducted at temperatures between 260 and $325^{\circ} \mathrm{C}$. The data on Type $316 \mathrm{NG}$ in water have been obtained primarily at DO levels $\geq 0.2 \mathrm{ppm}$ and those on Type 316 SS, at $\leq 0.005$ ppm DO; half of the tests on Type 304 SS were at low DO levels, the remaining half, at high DO levels. The existing $\varepsilon-\mathrm{N}$ data for cast SS are very limited, i.e., a total of 64 tests on 5 heats of CF-8M SS. ${ }^{17,21,22}$ Nearly $90 \%$ of the tests on cast SSs have been conducted in simulated PWR water at $325^{\circ} \mathrm{C}$.

* Private communication from M. Higuchi, Ishikawajima-Harima Heavy Industries Co., Japan, to M. Prager of the Pressure Vessel Research Council, 1992. The old data base "FADAL" has been revised and renamed "JNUFAD." 
The existing fatigue $\varepsilon-\mathrm{N}$ data, both foreign and domestic, are consistent with each other, and are also consistent with the large database for fatigue crack growth rates (CGRs) obtained on fracture mechanics specimens. In LWR environments, data on both fatigue crack initiation and fatigue crack growth show similar trends. For example, the effects of loading and environmental parameters, such as strain rate, DO level in water, or S content in carbon and low-alloy steels, are similar for fatigue crack initiation and fatigue crack growth.

The fatigue life of a material, i.e., cycles required to form an $\approx 3-\mathrm{mm}$-deep crack in the material, has traditionally been divided into two stages: an initiation stage that involves the growth of microstructurally small cracks (i.e., cracks smaller than $\approx 200 \mu \mathrm{m}$ ), and a propagation stage that involves the growth of mechanically small cracks. ${ }^{15,17,27,43,44}$ A fracture mechanics approach and CGR data have been used to predict fatigue crack initiation in carbon and lowalloy steels in air and LWR environments. ${ }^{17}$

The decrease in fatigue lives of carbon and low-alloy steels and austenitic SSs in LWR environments is caused primarily by the effects of the environment on the growth of microstructurally small cracks and, to a lesser extent, on enhanced growth rates of mechanically small cracks. ${ }^{17,43,44}$ In LWR environments, the growth of small cracks in carbon and low-alloy steels occurs by a slip oxidation/dissolution process, and in austenitic SSs, most likely, by mechanisms such as H-enhanced crack growth.

\subsection{Carbon and Low-Alloy Steels}

In air, the fatigue lives of carbon and low-alloy steels depend on steel type, temperature, orientation (rolling or transverse), and strain rate. The fatigue life of carbon steels is a factor of $\approx 1.5$ lower than that of low-alloy steels. For both steels, life is decreased by a factor of $\approx 1.5$ when temperature is increased from room temperature to $288^{\circ} \mathrm{C}$. Carbon steels, which have a pearlite and ferrite structure and low yield stress, exhibit significant initial hardening. The low-alloy steels, which have a tempered bainite and ferrite structure and relatively high yield stress, exhibit little or no initial hardening and may exhibit softening. In the temperature range of dynamic strain aging $\left(200-370^{\circ} \mathrm{C}\right)$, these steels show negative sensitivity to strain rate, i.e., cyclic stresses increase with decreasing strain rate. Cyclic-stress-vs.-strain curves for carbon and low-alloy steels at $288^{\circ} \mathrm{C}$ have been developed as a function of strain rate. ${ }^{12-17}$ The effect of strain rate on fatigue life is not clear; for some heats, life may be unaffected or decrease, for other heats, it may increase. Also, depending on the distribution and morphology of sulfides, fatigue properties in the transverse orientation may be inferior to those in the rolling orientation. The ASME mean curve for low-alloy steels is in good agreement with the experimental data. The corresponding curve for carbon steels is somewhat conservative, especially at strain amplitudes $<0.2 \%$.

The fatigue lives of carbon and low-alloy steels are reduced in LWR environments. Although the microstructures and cyclic-hardening behavior of carbon steels and low-alloy steels differ significantly, the effects of the environment on the fatigue life of these steels are very similar. The magnitude of the reduction depends on temperature, strain rate, DO level in water, and S content of the steel. The decrease is significant only when four conditions are satisfied simultaneously, viz., when the strain amplitude, temperature, and DO in water are above certain threshold values, and the strain rate is below a threshold value. For both steels, only a moderate decrease in life (by a factor of $<2$ ) is observed when any one of the threshold conditions is not satisfied. The $\mathrm{S}$ content of the steel is also important; its effect on life appears 
to depend on the DO level in water. The threshold values and the effects of the critical parameters on fatigue life are summarized below.

Strain: A minimum threshold strain is required for an environmentally assisted decrease in the fatigue lives of carbon and low-alloy steels. ${ }^{13-17}$ The threshold strain is defined as the minimum total applied strain above which environmental effects on fatigue life are significant. Even within a given loading cycle, environmental effects are significant at strain levels greater than the threshold value. Limited data suggest that the threshold value is $\approx 20 \%$ higher than the fatigue limit for the steel. The results also indicate that, within a given loading cycle, environmental effects are significant primarily during the tensile-loading cycle. This can be important if the strain rate varies over the loading cycle. Thus, for example, low strain rates at strains lower than the threshold strain and high strain rates for those portions of the cycle at strains greater than the threshold strain would not lead to significant reductions in life. Consequently, it is the loading and environmental conditions, e.g., strain rate, temperature, and DO level, during the tensile-loading cycle that are important for estimating environmental effects. Limited data indicate that hold periods during peak tensile or compressive strain have no effect on the fatigue life of these steels. ${ }^{14}$

Strain Rate: When all other threshold conditions are satisfied, fatigue life decreases logarithmically with decreasing strain rate below $1 \% /$ s. $^{5,7,9}$ The effect of environment on life saturates at $\approx 0.001 \% / \mathrm{s}$ (Fig. 5). ${ }^{12-17}$ When any one of the threshold conditions is not satisfied, e.g., DO $<0.04 \mathrm{ppm}$ or temperature $<150^{\circ} \mathrm{C}$, the effects of strain rate are consistent with those observed in air. Therefore, heats that are sensitive to strain rate in air show a decrease in life in water, although the decreases are much smaller than those observed when the threshold conditions are met.

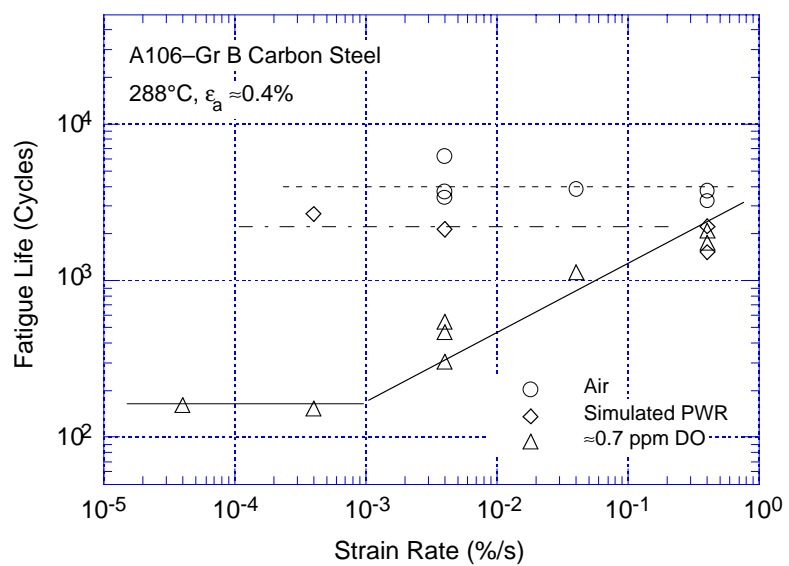

(a)

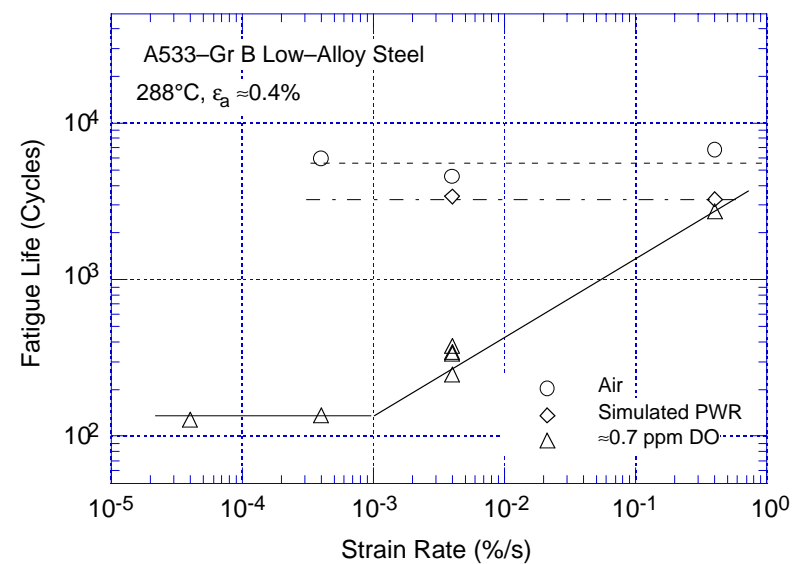

(b)

Figure 5. Dependence of fatigue lives of (a) carbon and (b) low-alloy steels on strain rate (Refs. 12-17).

Temperature: Experimental data indicate a threshold temperature of $150^{\circ} \mathrm{C}$, below which environmental effects on life either do not occur or are insignificant. When other threshold conditions are satisfied, fatigue life decreases linearly with temperature above $150^{\circ} \mathrm{C}$ and up to $320^{\circ} \mathrm{C}$ (Fig. 6). ${ }^{5,7,9}$ Fatigue life is insensitive to temperatures below $150^{\circ} \mathrm{C}$ or higher temperatures when any other threshold condition is not satisfied. Analyses of the fatigue $\varepsilon-\mathrm{N}$ data using artificial neural networks also show a similar effect of temperature on the fatigue lives of carbon and low-alloy steels. ${ }^{45}$ For service histories that involve variable loading 

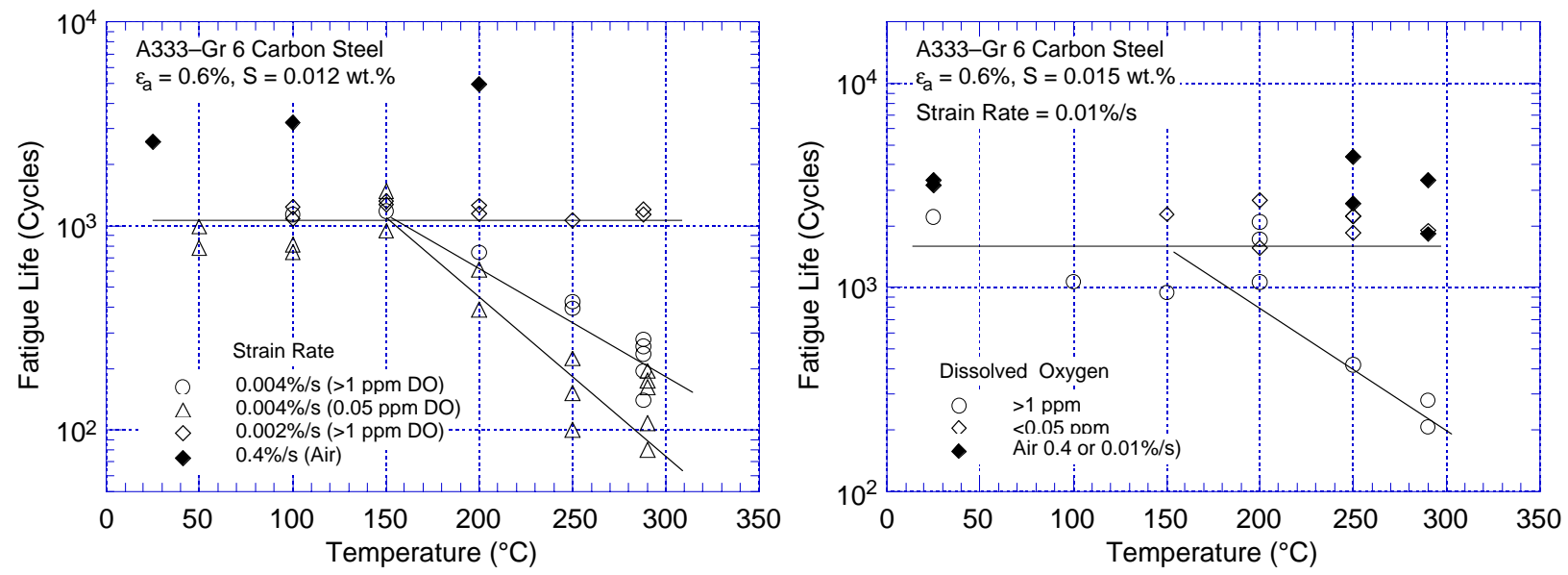

Figure 6. Change in fatigue life of A333-Gr 6 carbon steels with temperature (Refs. 5,7,9).

conditions, service temperature may be represented by the average of the maximum temperature and higher of the minimum temperature or $150^{\circ} \mathrm{C} .8$

Dissolved Oxygen in Water: When the other threshold conditions are satisfied, fatigue life decreases logarithmically with DO above $0.04 \mathrm{ppm}$; the effect saturates at $\approx 0.5 \mathrm{ppm}$ DO (Fig. 7). ${ }^{7,9}$ Only a moderate decrease in life, i.e., less than a factor of 2 , is observed at DO levels below $0.04 \mathrm{ppm}$. In contrast, environmental enhancement of CGRs has been observed in low-alloy steels even in low-DO environments. ${ }^{46}$ This apparent inconsistency of fatigue $\varepsilon-\mathrm{N}$ data with the CGR data may be attributed to differences in the environment at the crack tip. The initiation of environmentally assisted enhancement of CGRs in low-alloy steels requires a critical level of sulfides at the crack tip. ${ }^{46}$ The development of this critical sulfide concentration requires a minimum crack extension of $0.33 \mathrm{~mm}$ and CGRs of $1.3 \times 10^{-4}-4.2 \times 10^{-7} \mathrm{~mm} / \mathrm{s}$. These conditions are not achieved under typical $\varepsilon-\mathrm{N}$ tests. Thus, environmental effects on fatigue life are expected to be insignificant in low-DO environments.

Water Conductivity: In most studies the DO level in water has generally been considered the key environmental parameter that affects fatigue life of materials in LWR environments.

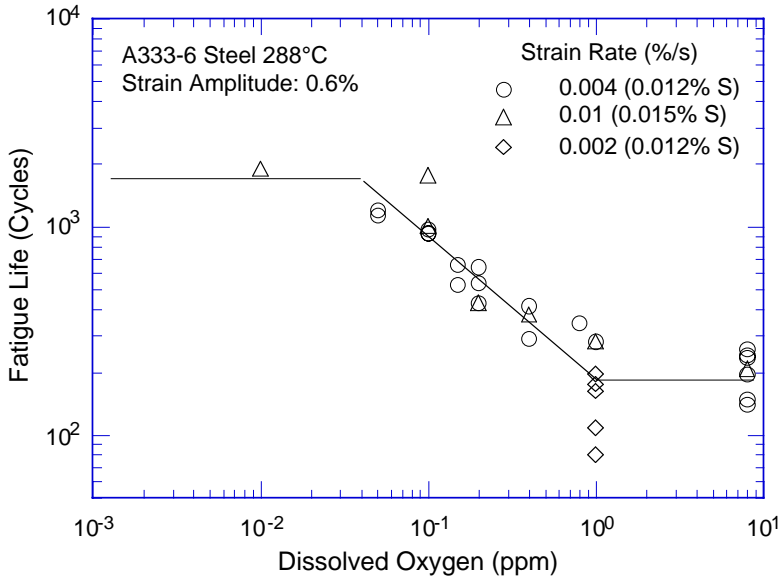

(a)

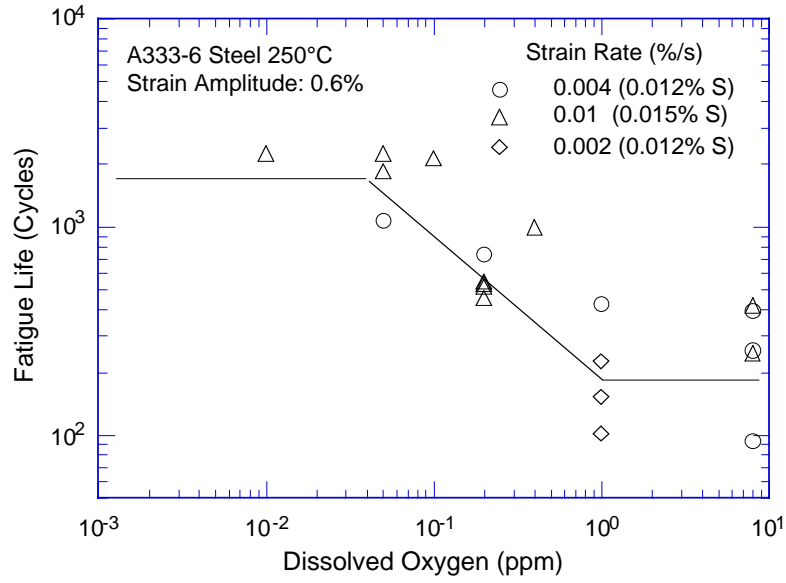

(b)

Figure 7. Dependence on dissolved oxygen of fatigue life of carbon steels at (a) 288 and (b) $250^{\circ} \mathrm{C}$ (Refs. 7,9). 
Studies on the effect of other parameters, such as the concentration of anionic impurities in water (expressed as the overall conductivity of water), are somewhat limited. Studies on the effect of conductivity on the fatigue life indicate that the fatigue life of WB36 low-alloy steel at $177^{\circ} \mathrm{C}$ in water with $\approx 8 \mathrm{ppm}$ DO decreased by a factor of $\approx 6$ when the conductivity of water was increased from 0.06 to $0.5 \mu \mathrm{S} / \mathrm{cm} .{ }^{47,48}$ A similar behavior has also been observed in another study of the effect of conductivity on the initiation of short cracks. ${ }^{49}$

Sulfur Content of Steel: The effect of S content on fatigue life appears to depend on the DO content of the water. When the threshold conditions are satisfied, the fatigue life decreases with increasing $\mathrm{S}$ content for DO levels $\leq 1.0 \mathrm{ppm}$. Limited data suggest that environmental effects on life saturate at a S content of $\approx 0.015 \mathrm{wt} . \% .{ }^{14}$ For DO levels $>1.0 \mathrm{ppm}$, fatigue life seems to be relatively insensitive to $\mathrm{S}$ content in the range of $0.002-0.015 \mathrm{wt} . \% .{ }^{11}$

Flow Rate: Nearly all of the fatigue $\varepsilon-\mathrm{N}$ data for LWR environments have been obtained at very low water flow rates. Recent data indicate that, under the environmental conditions typical of operating BWRs, environmental effects on the fatigue life of carbon steels are at least a factor of 2 lower at high flow rates $(7 \mathrm{~m} / \mathrm{s})$ than at $0.3 \mathrm{~m} / \mathrm{s}$ or lower. ${ }^{50-52}$ The beneficial effects of increased flow rate are greater for high-S steels and at low strain rates. 50,51 The effect of water flow rate on the fatigue life of high-S (0.016 wt.\%) A333-Gr 6 carbon steel in high-purity water at $289^{\circ} \mathrm{C}$ is shown in Fig. 8 . At $0.3 \%$ strain amplitude, $0.01 \% / \mathrm{s}$ strain rate, and all DO levels, fatigue life is increased by a factor of $\approx 2$ when the flow rate is increased from $\approx 10^{-5}$ to $7 \mathrm{~m} / \mathrm{s}$. At $0.6 \%$ strain amplitude and $0.001 \% / \mathrm{s}$ strain rate, fatigue life is increased by a factor of $\approx 6$ in water with $0.2 \mathrm{ppm}$ DO and by a factor of $\approx 3$ in water with 1.0 or $0.05 \mathrm{ppm}$ DO. Under similar loading conditions, i.e., $0.6 \%$ strain amplitude and $0.001 \% / \mathrm{s}$ strain rate, a low-S (0.008 wt.\%) heat of A333-Gr 6 carbon steel showed only a factor of $\approx 2$ increase in fatigue life with increased flow rates. Note that the beneficial effects of flow rate are determined from a single test on each material at very low flow rates; data scatter in LWR environments is typically a factor of $\approx 2$.

A factor of 2 increase in fatigue life was observed (Fig. 9) at Kraftwerk Union laboratories (KWU) during component tests with $180^{\circ}$ bends of carbon steel tubing (0.025 wt.\% S) when

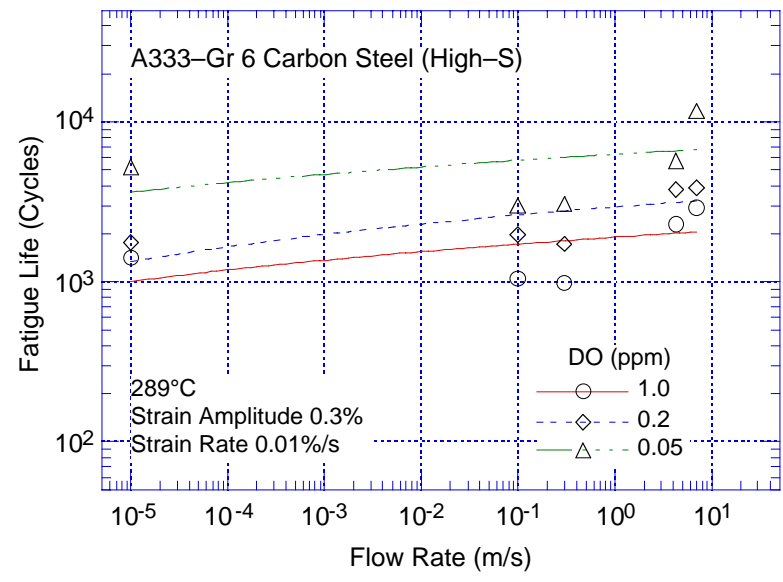

(a)

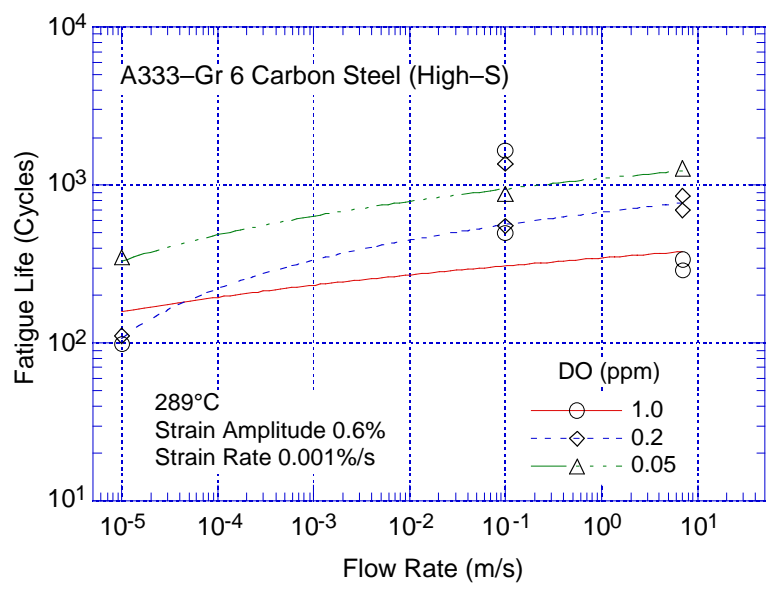

(b)

Figure 8. Effect of water flow rate on fatigue life of A333-Gr 6 carbon steel in high-purity water at $289^{\circ} \mathrm{C}$ and strain amplitude and strain rates of (a) $0.3 \%$ and $0.01 \% / \mathrm{s}$ and (b) $0.6 \%$ and $0.001 \% / s$ (Ref. 50,51). 


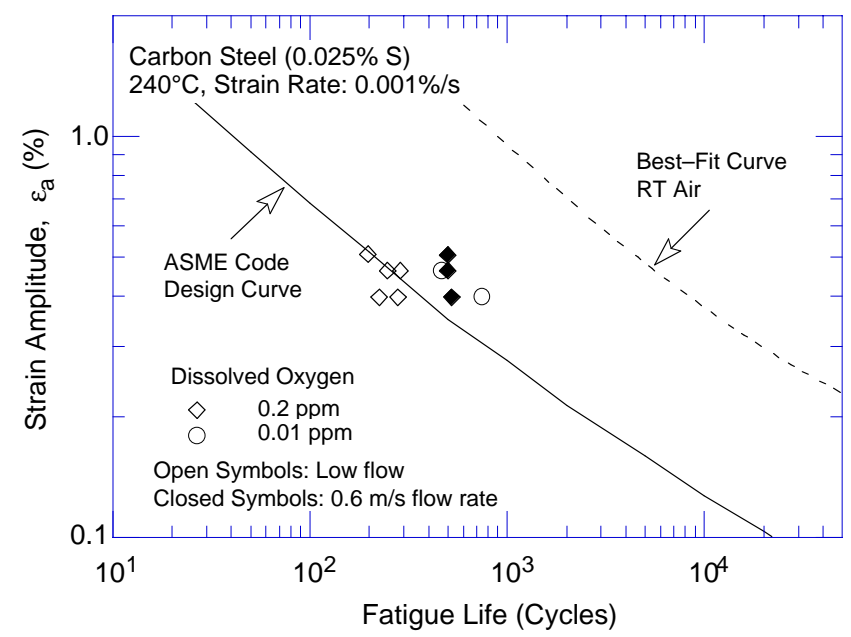

Figure 9.

Effect of flow rate on low-cycle fatigue of carbon steel tube bends in high-purity water at $240^{\circ} \mathrm{C}$ (Ref. 52 ).

internal flow rates of up to $0.6 \mathrm{~m} / \mathrm{s}$ were established. ${ }^{52}$ The tests were conducted at $240^{\circ} \mathrm{C}$ in water that contained $0.2 \mathrm{ppm} \mathrm{DO}$.

\subsection{Austenitic Stainless Steels}

In an air environment, the fatigue life of Type 304 SS is comparable to that of Type 316 SS; the fatigue life of Type 316NG is slightly higher than that of Types 304 and 316 SS, particularly at high strain amplitudes. The results also indicate that the fatigue life of austenitic SSs in air is independent of temperature from room temperature to $427^{\circ} \mathrm{C}$. Although the effect of strain rate on fatigue life seems to be significant at temperatures above $400^{\circ} \mathrm{C}$, variations in strain rate in the range of $0.4-0.008 \% / \mathrm{s}$ have no effect on the fatigue lives of SSs at temperatures up to $400^{\circ} \mathrm{C} .53$ The fatigue $\varepsilon-\mathrm{N}$ behavior of cast $\mathrm{CF}-8$ and $\mathrm{CF}-8 \mathrm{M}$ SSs is similar to that of wrought austenitic SSs. ${ }^{26}$ Under cyclic loading, austenitic SSs exhibit rapid hardening during the first 50-100 cycles; the extent of hardening increases with increasing strain amplitude and decreasing temperature and strain rate. ${ }^{26,53}$ The initial hardening is followed by softening and a saturation stage at high temperatures, and by continuous softening at room temperature. The ASME Code mean curve is not consistent with the existing fatigue $\varepsilon-\mathrm{N}$ data for austenitic SSs. At strain amplitudes $<0.5 \%$, the mean curve predicts significantly longer fatigue lives than those observed experimentally.

The fatigue lives of austenitic SSs are also decreased in LWR environments. The magnitude of this reduction depends on strain amplitude, strain rate, temperature, DO level in the water, and, possibly, the composition and heat treatment of the steel. ${ }^{16-28}$ The effects of LWR environments on the fatigue lives of wrought materials are comparable for Types 304, 316, and 316NG SSs; effects on cast materials differ somewhat. As in the case of the carbon and low-alloy steels, fatigue life is reduced significantly only when certain critical parameters meet certain threshold values. The critical parameters that influence fatigue life and the threshold values that are required for environmental effects to be significant are summarized below.

Strain Amplitude: As in the case of the carbon and low-alloy steels, a minimum threshold strain is required for the environmentally induced decrease in fatigue lives of SS to occur. The threshold strain appears to be independent of material type (weld or base metal) and temperature in the range of $250-325^{\circ} \mathrm{C}$, but it tends to decrease as the strain amplitude of the 
cycle is decreased. ${ }^{23}$ The threshold strain appears to be related to the elastic strain range of the material ${ }^{23}$ and does not correspond to the rupture strain of the surface oxide film.

Hold-Time Effects: For a given loading cycle, environmental effects are significant primarily during the tensile-loading cycle, and at strain levels greater than the threshold value. Consequently, loading and environmental conditions, e.g., strain rate, temperature, and DO level, during the tensile-loading cycle are important for environmentally assisted reduction of the fatigue lives of these steels. Limited data indicate that hold periods during peak tensile or compressive strain have no effect on the fatigue life of austenitic SSs. The fatigue lives of Type 304 SS tested in high-DO water with a trapezoidal waveform (i.e., hold periods at peak tensile and compressive strain) ${ }^{33}$ are comparable to those tested with a triangular waveform. ${ }^{19}$

Strain Rate: Fatigue life decreases with decreasing strain rate. In low-DO PWR environments, fatigue life decreases logarithmically with decreasing strain rate below $\approx 0.4 \% / \mathrm{s}$; the effect of environment on life saturates at $\approx 0.0004 \% / \mathrm{s}$ (Fig. 10). ${ }^{17-27}$ Only a moderate decrease in life is observed at strain rates $>0.4 \% / \mathrm{s}$. A decrease in strain rate from 0.4 to $0.0004 \% / \mathrm{s}$ decreases the fatigue life of austenitic SSs by a factor of $\approx 10$. For some SSs, the effect of strain rate may be less pronounced in high- than in low-DO water (Fig. 11). For cast
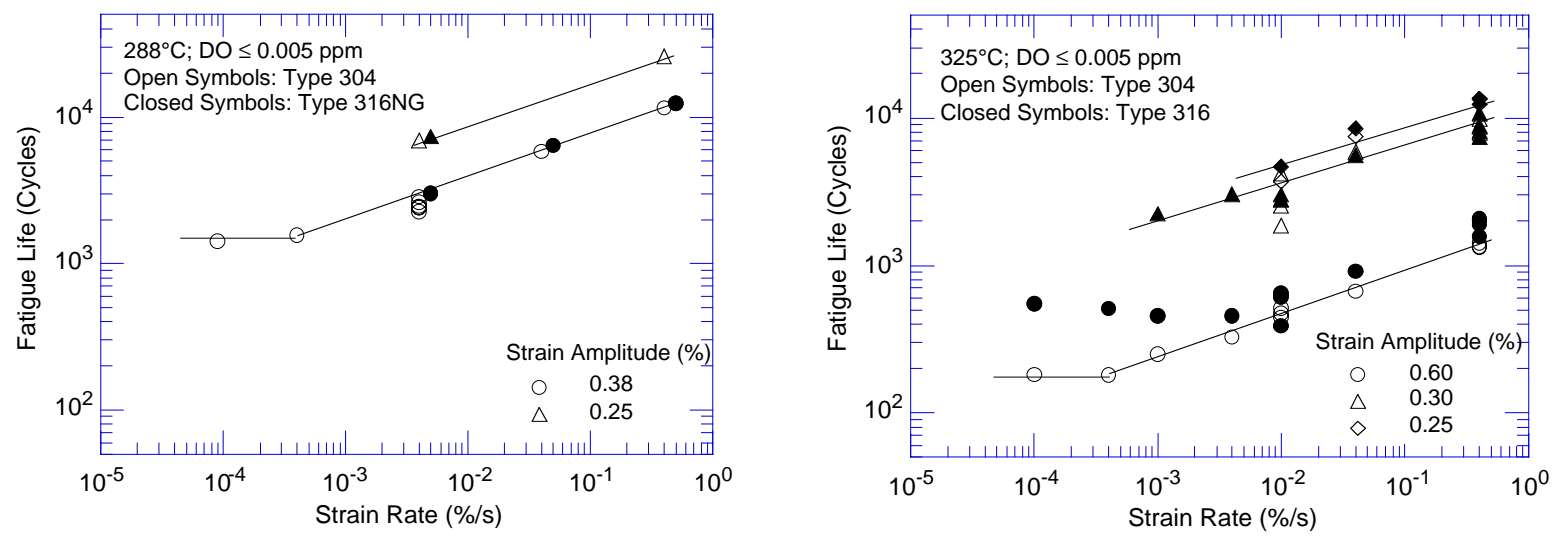

Figure 10. Dependence of fatigue life of austenitic stainless steels on strain rate in low-DO water (Refs. 26,27).

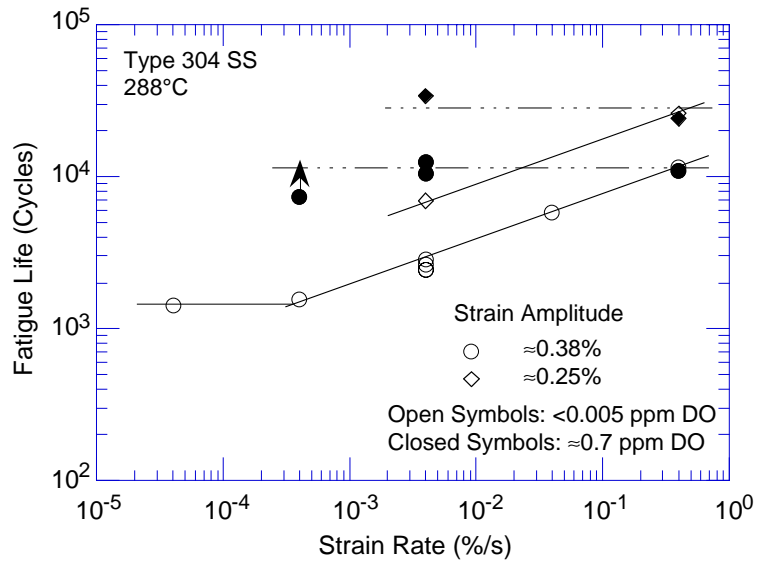

(a)

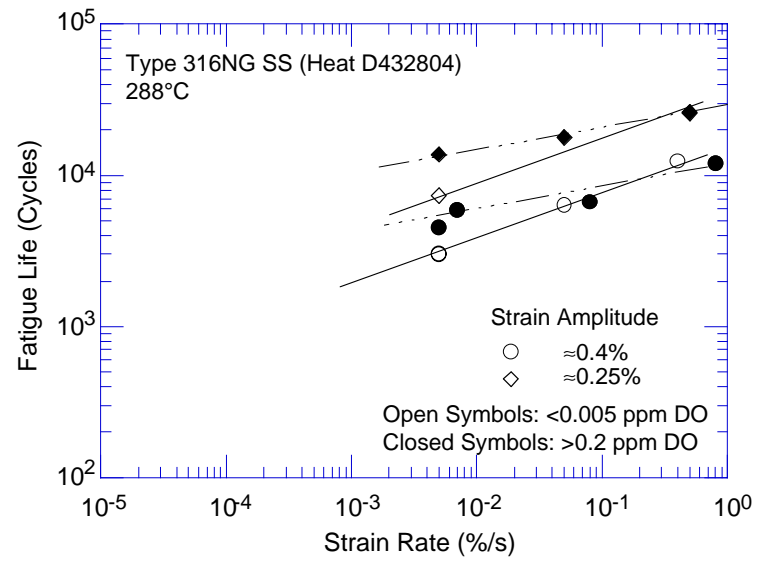

(b)

Figure 11. Dependence of fatigue life of Types (a) 304 and (b) $316 N G$ stainless steel on strain rate in high- and low-DO water at $288^{\circ} \mathrm{C}$ (Ref. 27). 
SSs, the effect of strain rate on fatigue life is the same in low- and high-DO water and is comparable to that observed for the wrought SSs in low-DO water. ${ }^{21,22}$

Dissolved Oxygen in Water: In contrast to the behavior of carbon and low-alloy steels, the fatigue lives of nonsensitized wrought and cast austenitic SSs are decreased significantly even in low-DO (i.e., $<0.01 \mathrm{ppm}$ DO) water. The decrease in life is greater at low strain rates and high temperatures. ${ }^{17-26}$ Environmental effects on the fatigue lives of these steels in high-DO water may be influenced by the composition and heat treatment of the steel. At temperatures above $150^{\circ} \mathrm{C}$, the fatigue lives of wrought SSs in high-DO water are either comparable to 21,22 or, in some cases, smaller ${ }^{26}$ than those in low-DO water.

In high-DO water, only moderate environmental effects were observed for a heat of Type $304 \mathrm{SS}$ when the conductivity of the water was maintained at $<0.1 \mu \mathrm{S} / \mathrm{cm}$ and the ECP of the steel was above $150 \mathrm{mV} .{ }^{17}$ During laboratory tests, the time to reach these stable environmental conditions depends on test parameters such as the autoclave volume, flow rate, etc. In the ANL test facility, fatigue tests on austenitic SSs in high-DO water required a soaking period of 5-6 days for the ECP of the steel to stabilize. The steel ECPs increased from zero or negative values to above $150 \mathrm{mV}$ during this period. The fatigue lives of Type $304 \mathrm{SS}$ specimens, soaked for $\approx 5$ days in high-DO water before testing in high-DO water at $289^{\circ} \mathrm{C}$ and $\approx 0.38$ and $0.25 \%$ strain amplitude, are plotted as a function of strain rate in Fig. 11a. For this heat, fatigue life decreases linearly with decreasing strain rate in low-DO water, whereas in high-DO water, strain rate has no effect on fatigue life. For example, the fatigue life at $\approx 0.38 \%$ strain amplitude and $0.0004 \% / \mathrm{s}$ strain rate is $\approx 1500$ cycles in low-DO water and $>7300$ cycles in high-DO water. At all strain rates, the fatigue life of Type $304 \mathrm{SS}$ is $30 \%$ lower in high-DO water than in air. However, the results obtained at MHI, Japan, on Types 304 and 316 SS show a different behavior; environmental effects are observed to be the same in high- and low-DO water. ${ }^{21-23}$ As discussed below the different behavior is most likely due to differences in the steel composition or heat treatment.

For a heat of Type 316NG (Heat D432804), some effect of strain rate is observed in high-DO water, although it is smaller than that in low-DO water (Fig. 11b). The Type 316NG specimens were soaked for only $24 \mathrm{~h}$ before testing, thus, environmental conditions may not have been stable for these tests. To determine the possible influence of the shorter soak-period, additional tests were conducted on another heat of Type 316NG (Heat P91576); these specimens were soaked for $\approx 10$ days before testing to achieve stable values for the ECP of

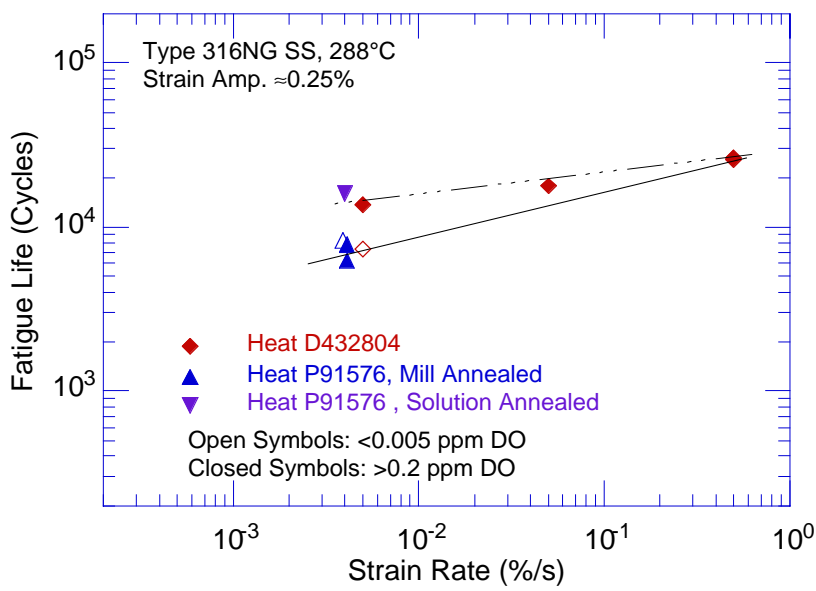

Figure 12.

Dependence of fatigue life of two heats of Type 316NG SS on strain rate in high- and low-DO water at $288^{\circ} \mathrm{C}$. 
the steel. The results are shown in Fig. 12. Unlike the data obtained earlier on Heat D432804 (diamond symbols), the results for Heat P91576 (triangle symbols) indicate that the fatigue life of this heat is the same in low- and high-DO water. These results indicate that, in high-DO water, material heat treatment may influence the fatigue life of austenitic SSs.

In low-DO water, the fatigue lives of cast SSs are comparable to those of wrought austenitic SSs. ${ }^{21-26}$ Limited data suggest that the fatigue lives of cast SSs in high-DO water are approximately the same as those in low-DO water. ${ }^{26}$

Water Conductivity: The effect of the conductivity of water and the ECP of the steel on the fatigue life of austenitic SSs is shown in Fig. 13. In high-DO water, fatigue life is decreased by a factor of $\approx 2$ when the conductivity of water is increased from $\approx 0.07$ to $0.4 \mu \mathrm{S} / \mathrm{cm}$. Note that environmental effects appear more significant for the specimens that were soaked for only $24 \mathrm{~h}$. For these tests, the ECP of steel was initially very low and increased during the test.

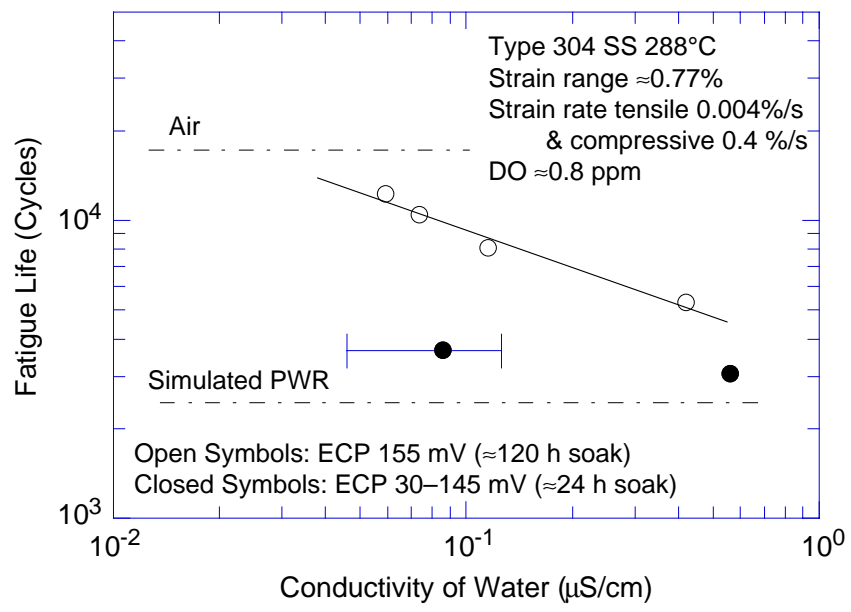

Figure 13.

Effects of conductivity of water and soaking period on fatigue life of Type 304 SS in high-DO water (Ref. 17).

Temperature: The data suggest a lower threshold temperature of $150^{\circ} \mathrm{C}$ (Fig. 14). Above this temperature, the environment decreases fatigue life in low-DO water if the strain rate is below the threshold of $0.4 \% / \mathrm{s}{ }^{11,19}$ In the range of $150-325^{\circ} \mathrm{C}$, the logarithm of fatigue life decreases linearly with temperature. Only a moderate decrease in life is observed in water at temperatures below the threshold value of $150^{\circ} \mathrm{C}$.

The results of fatigue tests on Type 316 SS under combined mechanical and thermal cycling are presented in Fig. 15 with the data obtained from tests at constant temperature. Two temperature cycling sequences were examined: an in-phase sequence, in which temperature cycling was synchronized with mechanical strain cycling, and an out-of-phase sequence in which temperature and strain were out of phase, i.e., maximum temperature occurred at minimum strain level and vice versa. ${ }^{20}$ Two temperature ranges, $100-325^{\circ} \mathrm{C}$ and $200-325^{\circ} \mathrm{C}$, were selected for the tests.

As discussed earlier, the tensile load cycle is primarily responsible for environmentally assisted reduction of fatigue life, and the applied strain and temperature must be above a minimum threshold value for environmental effects to occur. Thus, life should be longer for out-of-phase tests than for in-phase tests, because applied strains above the threshold strain occur at high temperatures for in-phase tests, whereas applied strains above the threshold strain occur only at low temperatures for out-of-phase tests. In Fig. 15, the data for the 

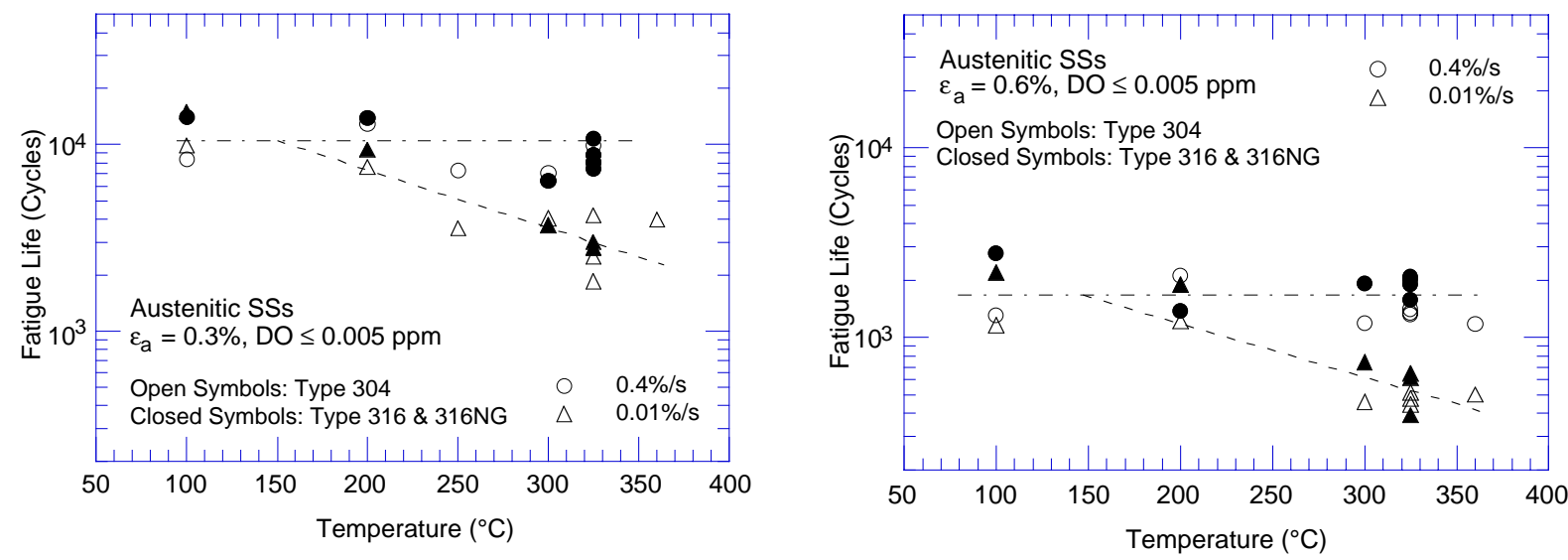

Figure 14. Change in fatigue lives of austenitic stainless steels in low-DO water with temperature (Refs. 17,19-22,26,27).

thermal cycling tests are plotted in terms of an average temperature, i.e., the average of the temperature at peak strain and the temperature at threshold strain or $150^{\circ} \mathrm{C}$ (whichever is higher). From Eq. 3, the threshold strain for this test is $0.46 \%$. Thus, for the temperature range of $100-325^{\circ} \mathrm{C}$, the temperature plotted in Fig. 15 is the average of 239 and $150^{\circ} \mathrm{C}$ for the out-of-phase test and the average of 186 and $325^{\circ} \mathrm{C}$ for the in-phase test. For the temperature range of $200-325^{\circ} \mathrm{C}$, the temperature plotted in Fig. 15 is the average of 277 and $200^{\circ} \mathrm{C}$ for the out-of-phase test and the average of 248 and $325^{\circ} \mathrm{C}$ for the in-phase test. With this choice of average temperatures, the results from thermal cycling tests agree well with those from constant-temperature tests (open circles in Fig. 15). The data suggest a linear decrease in logarithmic life at temperatures above $150^{\circ} \mathrm{C}$.

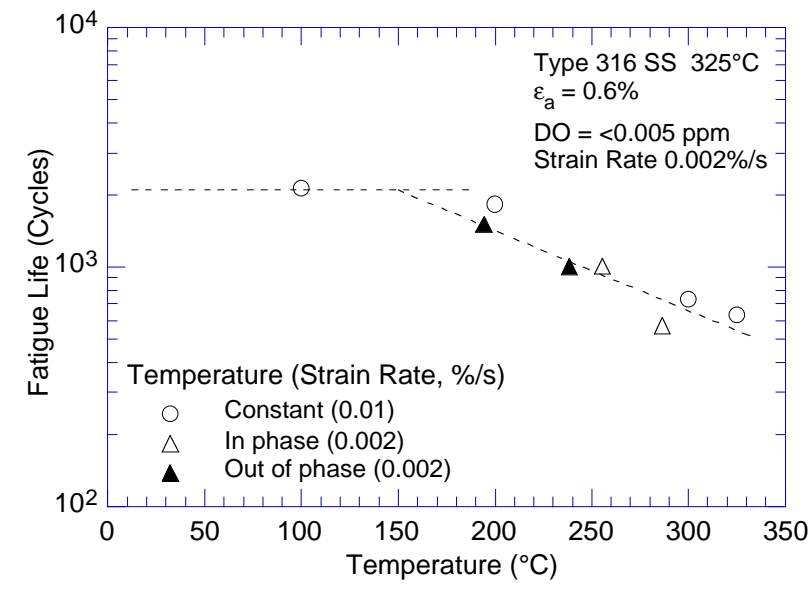

Figure 15.

Fatigue life of Type 316 stainless steel under constant and varying test temperature (Ref. 20).

Sensitization Anneal: In low-DO water, a sensitization anneal has no effect on the fatigue life of Types 304 and 316 SS, whereas, in high-DO water, environmental effects in sensitized steels are enhanced. For example, the fatigue life of sensitized steel is a factor of $\approx 2$ lower than that of solution-annealed material in high-DO water. ${ }^{21,22}$ Sensitization has little or no effect on the fatigue life of Type 316NG SS in low- and high-DO water.

To investigate the effect of heat treatment, a specimen of Heat P91576 was solution annealed in the laboratory and tested in high-DO water at $289^{\circ} \mathrm{C}$. The fatigue life of the 
solution-annealed specimen (inverted triangle symbol in Fig. 12) is a factor of $\approx 2$ higher than that of the mill-annealed specimens. These results indicate that, in high-DO water, material heat treatment has a strong effect on the fatigue life of austenitic SSs, e.g., environmental effects may be significant even for mill-annealed steel where no sensitization is apparent.

Flow Rate: Limited data indicate that the water flow rate has no effect on the fatigue life of austenitic SSs in high-purity water at $289^{\circ} \mathrm{C}$. The fatigue lives of Type $316 \mathrm{NG}$ at $0.6 \%$ strain amplitude and $0.001 \% / \mathrm{s}$ strain rate, in high-purity water with 0.2 or $0.05 \mathrm{ppm} \mathrm{DO}$ at $289^{\circ} \mathrm{C}$, showed little or no change when the flow rate was increased from $\approx 10^{-5}$ to $10 \mathrm{~m} / \mathrm{s} .^{51}$ The results at $0.3 \%$ strain amplitude and $0.01 \% / \mathrm{s}$ strain rate show slight decrease in fatigue lives with increasing flow rate. Because the mechanism of fatigue crack initiation in LWR environments appears to be different in SSs than in carbon steels, the effect of flow rate is also likely to be different.

\subsection{Effects of Surface Finish}

Several fatigue tests have been conducted on rough specimens at $288^{\circ} \mathrm{C}$ in air and highand low-DO water environments. The results of these tests and data obtained earlier on smooth specimens are presented in Table 2.

Table 2. Fatigue test results for smooth and rough specimens of austenitic SSs and carbon and low-alloy steels in air and LWR environments at $288^{\circ} \mathrm{C}$

\begin{tabular}{|c|c|c|c|c|c|c|c|c|c|c|c|c|}
\hline $\begin{array}{l}\text { Test } \\
\text { No. }\end{array}$ & $\begin{array}{l}\text { Dis. } \\
\text { Oxygena } \\
\text { (ppb) }\end{array}$ & $\begin{array}{l}\text { Specimen } \\
\text { Type }\end{array}$ & $\begin{array}{c}\text { Dis. } \\
\text { Hydrogen } \\
\text { (cc/kg) }\end{array}$ & $\begin{array}{c}\mathrm{Li} \\
(\mathrm{ppm})\end{array}$ & $\begin{array}{l}\text { Boron } \\
\text { (ppm) }\end{array}$ & $\begin{array}{c}\mathrm{pH} \\
\text { at } \mathrm{RT}\end{array}$ & $\begin{array}{l}\text { Conduc } \\
\text {-tivityb } \\
(\mu \mathrm{S} / \mathrm{cm})\end{array}$ & $\begin{array}{c}\text { ECP SSa } \\
\text { mV } \\
(\mathrm{SHE})\end{array}$ & $\begin{array}{l}\text { Ten. } \\
\text { Ratec } \\
(\% / s)\end{array}$ & $\begin{array}{l}\text { Stress } \\
\text { Amp. } \\
(\mathrm{MPa})\end{array}$ & $\begin{array}{l}\text { Strain } \\
\text { Amp. } \\
(\%)\end{array}$ & $\begin{array}{c}\text { Life } \\
\text { N25 } \\
\text { (Cycles) }\end{array}$ \\
\hline \multicolumn{13}{|c|}{ A106-Gr B Carbon Steel (Heat J-7201) } \\
\hline 1621 & Air Env. & Smooth & - & - & - & - & - & - & $1.0 \mathrm{E}-2$ & 393.5 & 0.20 & 38,128 \\
\hline 1876 & Air Env. & Rough & - & - & - & - & - & - & $1.0 \mathrm{E}-2$ & 388.9 & 0.20 & 11,270 \\
\hline 1679 & 3 & Smooth & 23 & 2 & 1000 & 6.5 & 20.41 & -690 & $4.0 \mathrm{E}-3$ & 502.9 & 0.38 & 2,141 \\
\hline 1886 & 5 & Rough & - & - & - & 7.3 & 0.06 & -645 & $4.0 \mathrm{E}-3$ & 492.4 & 0.39 & 1,765 \\
\hline 1614 & 400 & Smooth & - & - & - & 5.9 & 0.11 & 84 & $4.0 \mathrm{E}-3$ & 465.2 & 0.39 & 303 \\
\hline 1682 & 700 & Smooth & - & - & - & 6.0 & 0.09 & 185 & $4.0 \mathrm{E}-3$ & 460.5 & 0.37 & 469 \\
\hline 1885 & 740 & Rough & - & - & - & 6.0 & 0.06 & 112 & $4.0 \mathrm{E}-3$ & 467.0 & 0.39 & 390 \\
\hline 1624 & 800 & Smooth & - & - & - & 5.9 & 0.10 & 189 & $4.0 \mathrm{E}-3$ & 387.9 & 0.23 & 2,276 \\
\hline 1877 & 780 & Rough & - & - & - & 6.5 & 0.06 & 138 & $4.0 \mathrm{E}-3$ & 381.7 & 0.22 & 2,350 \\
\hline 1884 & 920 & Rough & - & - & - & 6.8 & 0.06 & 96 & $4.0 \mathrm{E}-3$ & 391.2 & 0.21 & 2,320 \\
\hline \multicolumn{13}{|c|}{ A533-Gr B Low-Alloy Steel (Midland Reactor) } \\
\hline 1627 & 800 & Smooth & - & - & - & 5.9 & 0.10 & 214 & $4.0 \mathrm{E}-3$ & 413.4 & 0.27 & 769 \\
\hline 1887 & 750 & Rough & - & - & - & 6.6 & 0.06 & 153 & $4.0 \mathrm{E}-3$ & 404.0 & 0.26 & 842 \\
\hline \multicolumn{13}{|c|}{ Type 304 Stainless Steel (Heat 30956) } \\
\hline 1817 & Air Env. & Smooth & - & - & - & - & - & - & $4.0 \mathrm{E}-3$ & 215.8 & 0.25 & 42,180 \\
\hline 1874 & Air Env. & Rough & - & - & - & - & - & - & $4.0 \mathrm{E}-3$ & 206.5 & 0.25 & 13,900 \\
\hline 1823 & 3 & Smooth & 23 & 2 & 1000 & 6.6 & 23.06 & -699 & $4.0 \mathrm{E}-3$ & 204.1 & 0.25 & 6,900 \\
\hline 1875 & 2 & Rough & - & - & - & 5.8 & 0.06 & -595 & $4.0 \mathrm{E}-3$ & 199.5 & 0.26 & 2,280 \\
\hline \multicolumn{13}{|c|}{ Type 316NG Stainless Steel (Heat P91576) } \\
\hline 1878 & Air Env. & Smooth & - & - & - & - & - & - & $4.0 \mathrm{E}-3$ & 200.5 & 0.25 & 58,300 \\
\hline 1890 & Air Env. & Rough & - & - & - & - & - & - & $4.0 \mathrm{E}-3$ & 195.6 & 0.25 & 15,570 \\
\hline 1879 & 4 & Smooth & - & - & - & - & 0.06 & -591 & $4.0 \mathrm{E}-3$ & 190.1 & 0.25 & 8,310 \\
\hline 1889 & 5 & Rough & - & - & - & - & 0.06 & -672 & $4.0 \mathrm{E}-3$ & 186.3 & 0.25 & 3,230 \\
\hline 1881 & 830 & Smooth & - & - & - & 6.5 & 0.06 & 130 & $4.0 \mathrm{E}-3$ & 188.3 & 0.25 & 6,200 \\
\hline 1882 & 760 & Smooth & - & - & - & 6.5 & 0.06 & 140 & $4.0 \mathrm{E}-3$ & 190.8 & 0.25 & 7,780 \\
\hline 1888 & 690 & Rough & - & - & - & 6.7 & 0.06 & 116 & $4.0 \mathrm{E}-3$ & 190.5 & 0.25 & 8,040 \\
\hline
\end{tabular}

aMeasured in effluent.

${ }^{b}$ Measured in feedwater supply tank.

cStrain rate during tensile half of the cycle; rates during compressive half were $0.4 \% / \mathrm{s}$ for all tests. 


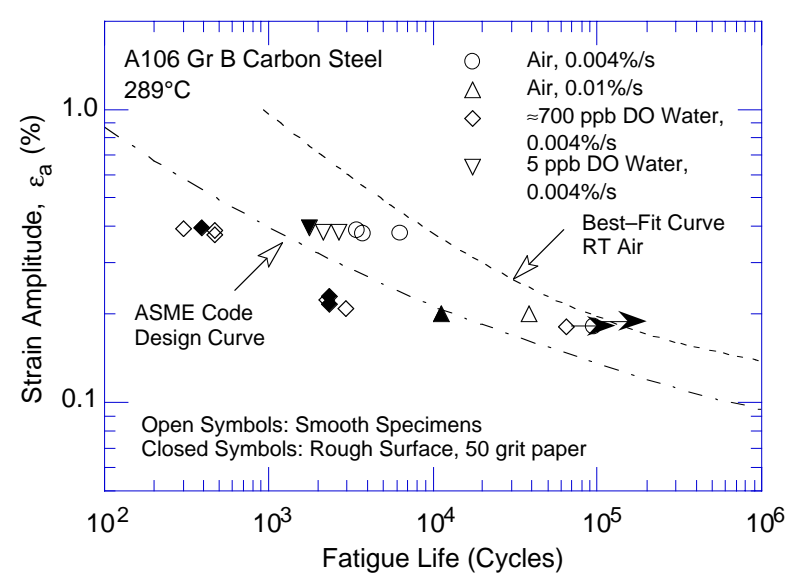

(a)

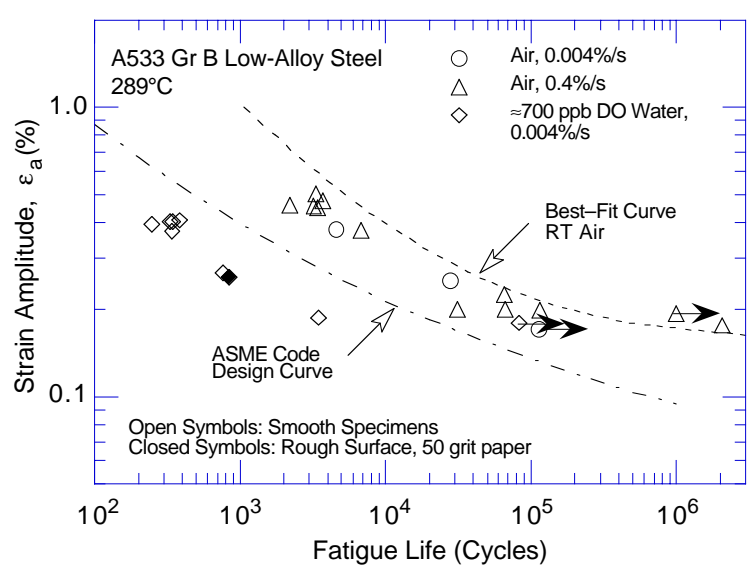

(b)

Figure 16. Effect of surface roughness on fatigue life of (a) A106-Gr B carbon steel and (b) A533 low-alloy steel in air and high-purity water at $289^{\circ} \mathrm{C}$.

The results for A106-Gr B carbon steel and A533-Gr B low-alloy steel are shown in Figs. 16a and b, respectively. In air, the fatigue life of rough A106-Gr B specimens is a factor of 3 lower than that of smooth specimens, and, in high-DO water, it is the same as that of smooth specimens. In low-DO water, the fatigue life of the roughened A106-Gr B specimen is slightly lower than that of smooth specimens. The effect of surface roughness on the fatigue life of A533-Gr B low-alloy steel is similar to that for A106-Gr B carbon steel; in high-DO water, the fatigue lives of both rough and smooth specimens are the same. The results for carbon and low-alloy steels are consistent with a mechanism of growth by a slip oxidation/dissolution process, which seems unlikely to be affected by surface finish. Because environmental effects are moderate in low-DO water, surface roughness would be expected to influence fatigue life.

The results for Types 316NG and 304 SS are shown in Figs. 17a and b, respectively. For both steels, the fatigue life of roughened specimens is lower than that of the smooth specimens in air and low-DO water environments. In high-DO water, the fatigue life is the same for rough and smooth specimens.

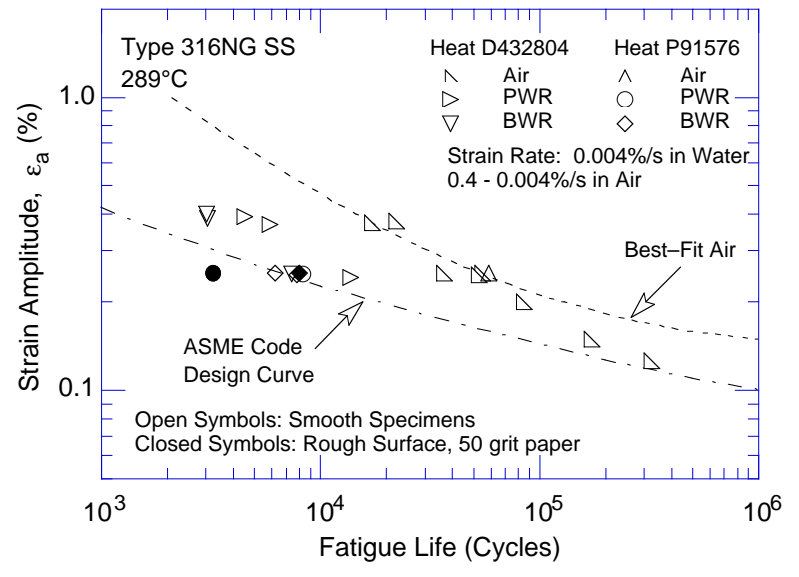

(a)

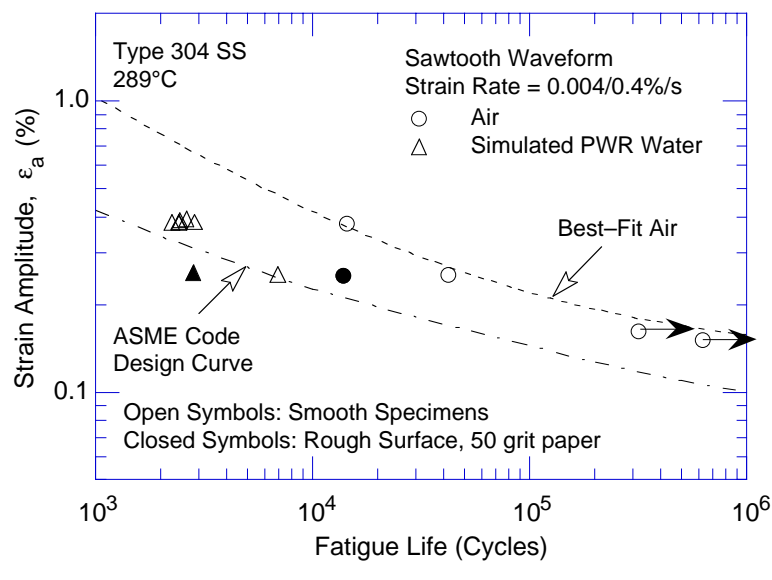

(b)

Figure 17. Effect of surface roughness on fatigue life of (a) Type 316NG and (b) Type 304 stainless steels in air and high-purity water at $289^{\circ} \mathrm{C}$. 
The cyclic stress response of smooth and roughened specimens of A106-Gr B carbon steel, A533-Gr B low-alloy steel, and Types 316NG and 304 SS in air and LWR environments is shown in Figs. 18a-d. For all of the steels, the cyclic strain hardening behavior of the specimens in air and LWR environments and that of smooth and roughened specimens is identical.

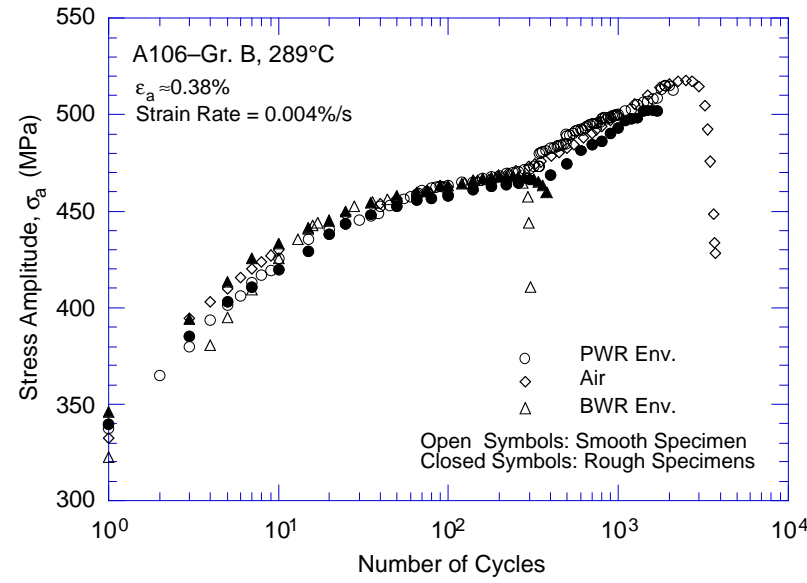

(a)

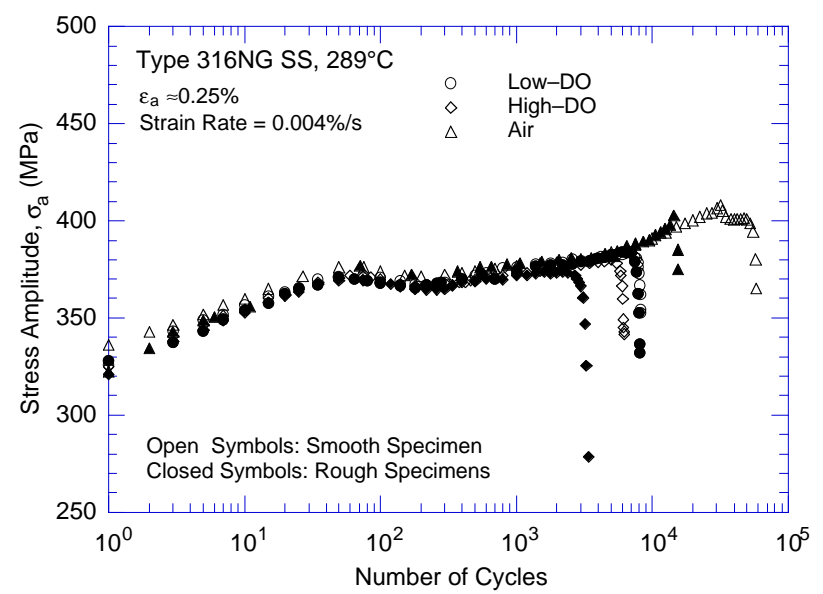

(c)

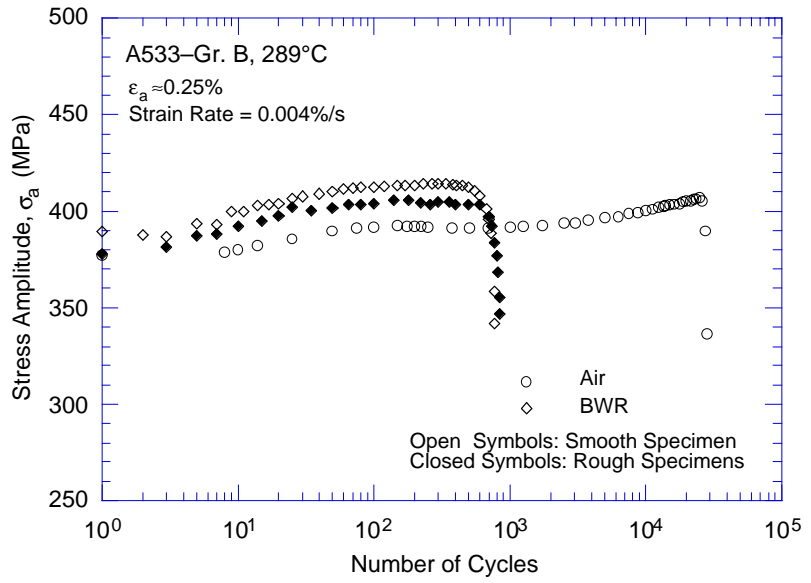

(b)

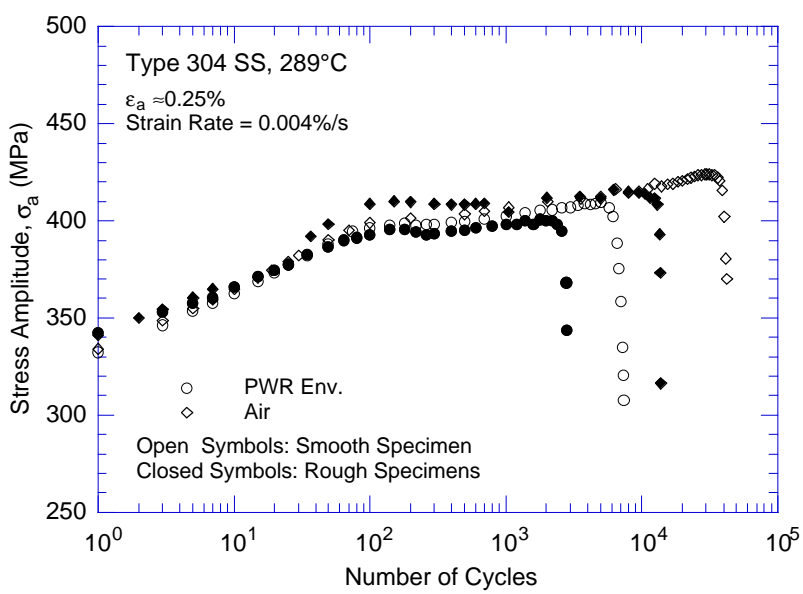

(d)

Figure 18. Cyclic stress response of (a) A106-Gr B carbon steel, (b) A533-Gr B low-alloy steel, (c) Type $316 \mathrm{NG}$, and (d) Type $304 \mathrm{SS}$, in air and LWR environments at $289^{\circ} \mathrm{C}$. 


\section{Statistical Models}

Statistical models based on the existing fatigue $\varepsilon-\mathrm{N}$ data have been developed at ANL for estimating the fatigue lives of carbon and low-alloy steels and wrought and cast austenitic SSs in air and LWR environments. ${ }^{14,17,26,28}$ In room-temperature air, the fatigue life $\mathrm{N}$ of carbon steels is represented by

$$
\ln (\mathrm{N})=6.564-1.975 \ln \left(\varepsilon_{\mathrm{a}}-0.113\right)
$$

and that of low-alloy steels, by

$$
\ln (\mathrm{N})=6.627-1.808 \ln \left(\varepsilon_{\mathrm{a}}-0.151\right)
$$

where $\varepsilon_{\mathrm{a}}$ is applied strain amplitude (\%). In LWR environments, the fatigue life of carbon steels is represented by

$$
\ln (\mathrm{N})=6.010-1.975 \ln \left(\varepsilon_{\mathrm{a}}-0.113\right)+0.101 \mathrm{~S}^{*} \mathrm{~T}^{*} \mathrm{O}^{*} \dot{\varepsilon}^{*}
$$

and that of low-alloy steels, by

$$
\ln (\mathrm{N})=5.729-1.808 \ln \left(\varepsilon_{\mathrm{a}}-0.151\right)+0.101 \mathrm{~S}^{*} \mathrm{~T}^{*} \mathrm{O}^{*} \dot{\varepsilon}^{*},
$$

where $\mathrm{S}^{*}, \mathrm{~T}^{*}, \mathrm{O}^{*}$, and $\dot{\varepsilon}^{*}$ are transformed $\mathrm{S}$ content, temperature, DO level, and strain rate, respectively, defined as:

$$
\begin{aligned}
& \mathrm{S}^{*}=0.015 \\
& \mathrm{~S}^{*}=\mathrm{S} \\
& \mathrm{S}^{*}=0.015 \\
& \mathrm{~T}^{*}=0 \\
& \mathrm{~T}^{*}=\mathrm{T}-150 \\
& \mathrm{O}^{*}=0 \\
& \mathrm{O}^{*}=\ln (\mathrm{DO} / 0.04) \\
& \mathrm{O}^{*}=\ln (12.5) \\
& \dot{\varepsilon}^{*}=0 \\
& \dot{\varepsilon}^{*}=\ln (\dot{\varepsilon}) \\
& \dot{\varepsilon}^{*}=\ln (0.001)
\end{aligned}
$$

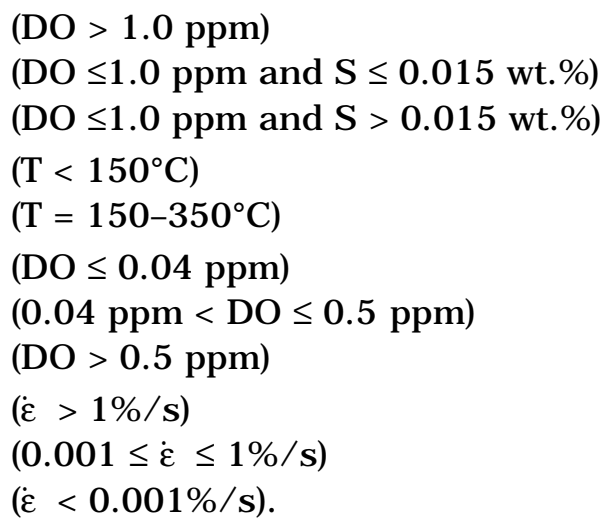

In air at temperatures up to $400^{\circ} \mathrm{C}$, the fatigue data for Types 304 and 316 SS are best represented by

$$
\ln (\mathrm{N})=6.703-2.030 \ln \left(\varepsilon_{\mathrm{a}}-0.126\right)
$$

and those for Type $316 \mathrm{NG}$, by

$$
\ln (\mathrm{N})=7.433-1.782 \ln \left(\varepsilon_{\mathrm{a}}-0.126\right) .
$$

The results indicate that, in LWR environments, the fatigue data for Types 304 and 316 SS are best represented by 


$$
\ln (\mathrm{N})=5.768-2.030 \ln \left(\varepsilon_{\mathrm{a}}-0.126\right)+\mathrm{T}^{\prime} \dot{\varepsilon}^{\prime} \mathrm{O}^{\prime}
$$

and those of Type $316 \mathrm{NG}$, by

$$
\ln (\mathrm{N})=6.913-1.671 \ln \left(\varepsilon_{\mathrm{a}}-0.126\right)+\mathrm{T}^{\prime} \dot{\varepsilon}^{\prime} \mathrm{O}^{\prime}
$$

where $\mathrm{T}^{\prime}, \dot{\varepsilon}$ ', and $\mathrm{O}^{\prime}$ are transformed temperature, strain rate, and DO level, respectively, defined as:

$$
\begin{aligned}
& \mathrm{T}^{\prime}=0 \\
& \mathrm{~T}^{\prime}=(\mathrm{T}-150) / 175 \\
& \mathrm{~T}^{\prime}=1 \\
& \dot{\varepsilon}=0 \\
& \dot{\varepsilon}=\ln (\dot{\varepsilon} / 0.4) \\
& \dot{\varepsilon}=\ln (0.0004 / 0.4) \\
& \mathrm{O}^{\prime}=0.26
\end{aligned}
$$

$$
\begin{aligned}
& \left(\mathrm{T}<150^{\circ} \mathrm{C}\right) \\
& \left(150 \leq \mathrm{T}<325^{\circ} \mathrm{C}\right) \\
& \left(\mathrm{T} \geq 325^{\circ} \mathrm{C}\right) \\
& (\dot{\varepsilon}>0.4 \% / \mathrm{s}) \\
& (0.0004 \leq \dot{\varepsilon} \leq 0.4 \% / \mathrm{s}) \\
& (\dot{\varepsilon}<0.0004 \% / \mathrm{s}) \\
& \text { (all DO levels). }
\end{aligned}
$$

These models are recommended for predicted fatigue lives $\leq 10^{6}$ cycles. Note that, in the above equations, the fatigue life $\mathrm{N}$ represents the number of cycles needed to form an $\approx 3$-mm-deep crack. Equations 13 and 15-17 should also be used for cast austenitic SSs such as $\mathrm{CF}-3, \mathrm{CF}-8$, and $\mathrm{CF}-8 \mathrm{M}$. Although the statistical models do not include the effects of flow rate on fatigue life, the limited data available on flow rate effects have been discussed in Sections 3.1 and 3.2. Under the conditions typical of operating BWRs, environmental effects on the fatigue life of carbon and low-alloy steels are a factor of $\approx 2$ lower at high flow rates $(7 \mathrm{~m} / \mathrm{s})$ than at very low flow rates $(0.3 \mathrm{~m} / \mathrm{s}$ or lower $) .50-52$ Flow rate appears to have little effect on the fatigue life of austenitic SSs. ${ }^{51}$ Also, as noted earlier, because the influence of DO level on the fatigue life of austenitic SSs is not well understood, these models may be conservative for some SSs in high-DO water. Also, because the effect of S on the fatigue life of carbon and low-alloy steels appears to depend on the DO level in water, Eqs. 1-10 may yield conservative estimates of fatigue life for low-S $(<0.007 \mathrm{wt} . \%)$ steels in high-temperature water with $>1$ ppm DO.

The best-fit mean curve expressed in terms of stress amplitude $\mathrm{S}_{\mathrm{a}}(\mathrm{MPa})$ can be obtained by multiplying Eqs. 3-6 and 11-14 by the elastic modulus at room temperature, e.g., 206.8 GPa for carbon and low-alloy steels and 195.1 GPa for austenitic SSs. The current ASME Code mean curve for carbon steel is expressed as

$$
\mathrm{S}_{\mathrm{a}}=59734(\mathrm{~N})^{-0.5}+149.2,
$$

for low-alloy steel, as

$$
\mathrm{S}_{\mathrm{a}}=49222(\mathrm{~N})^{-0.5}+265.4 \text {, }
$$

and for austenitic SS, as

$$
\mathrm{S}_{\mathrm{a}}=58020(\mathrm{~N})^{-0.5}+299.9 \text {. }
$$




\section{Incorporating Environmental Effects into Fatigue Evaluations}

Two methods have been proposed for incorporating the effects of LWR coolant environments into the ASME Section III fatigue evaluations. In one case, new, environmentally adjusted fatigue design curves are developed; ${ }^{14-17,26,28}$ in the other, fatigue life correction factors $F_{e n}$ are used to adjust the fatigue usage values for environmental effects. ${ }^{11,28,54,55}$ Estimates of fatigue life based on the two approaches can differ somewhat because of differences between the ASME mean curves used to develop the current design curves and the best-fit curves to the current data that are used to develop the environmentally adjusted curves. However, both methods provide an acceptable approach to account for environmental effects.

\subsection{Fatigue Design Curves}

Fatigue design curves, represented by Eqs. 3-10 for carbon and low-alloy steels, and by Eqs. 11,13, and 15-17 for austenitic SSs, have been obtained. To be consistent with the current ASME Code philosophy, the best-fit curves were first adjusted for the effect of mean stress by using the modified Goodman relationship. The adjusted curves were then decreased by a factor of 2 on stress and 20 on cycles to obtain design curves. Although the current Code fatigue design curve for austenitic SSs does not include a mean stress correction, the new design curve does. The mean stress correction was included for the design curve for austenitic SSs because the fatigue strength at $10^{6}$ cycles is greater than the monotonic yield strength of austenitic SSs. Studies by Wire et al. ${ }^{56}$ indicate an apparent reduction of up to $26 \%$ in strain amplitude in the low- and intermediate-cycle regime (i.e., $<10^{6}$ cycles) for a mean stress of $138 \mathrm{MPa}$.

Examples of fatigue design curves for carbon and low-alloy steels and austenitic SS in air and LWR environments are shown in Figs. 19-21. Because the fatigue life of Type 316NG is superior to that of Types 304 or 316 SS at high strain amplitudes, the design curves in Fig. 21 are somewhat conservative for Type 316NG SS. Also, Fig. 21 a indicates that, even in air at room temperature, the current ASME Code design curve for austenitic SSs is nonconservative with respect to the design curve based on the statistical model. The margins

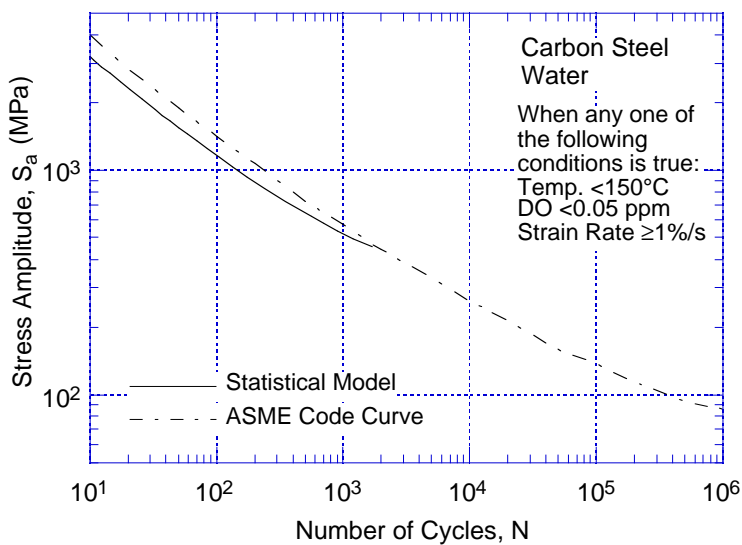

(a)

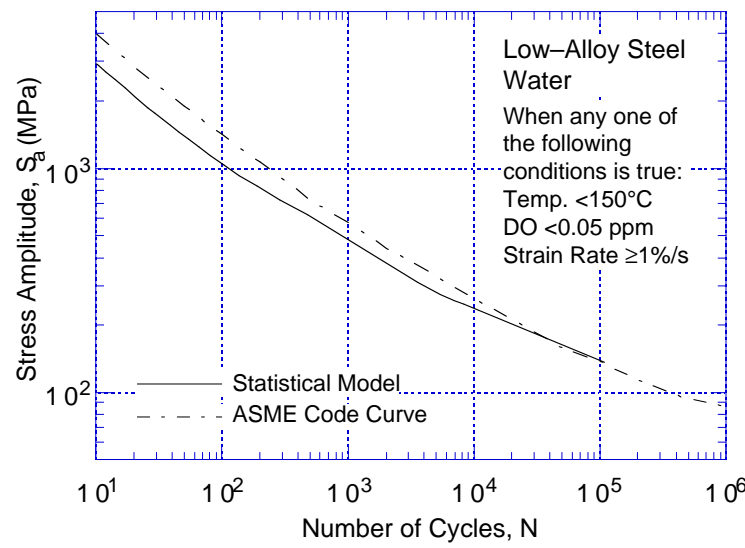

(b)

Figure 19. Fatigue design curves developed from statistical model for (a) carbon steels and (b) low-alloy steels under service conditions where one or more critical threshold values are not satisfied. 


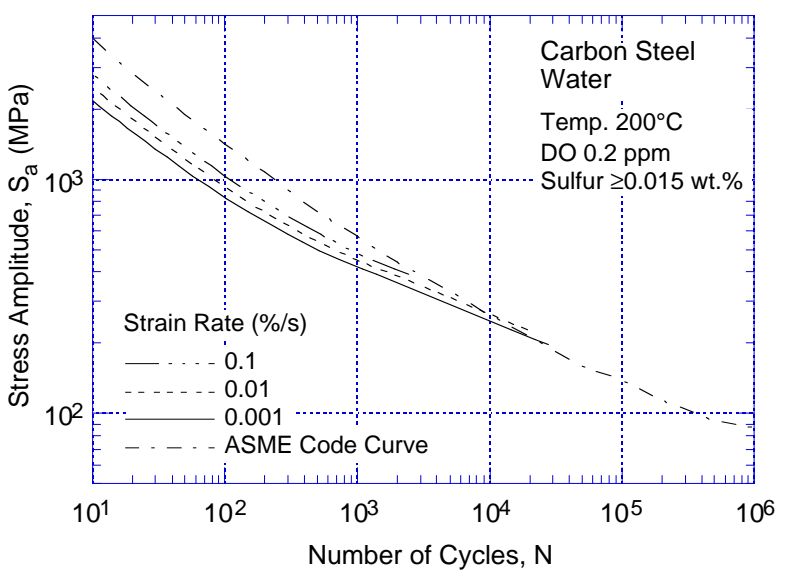

(a)

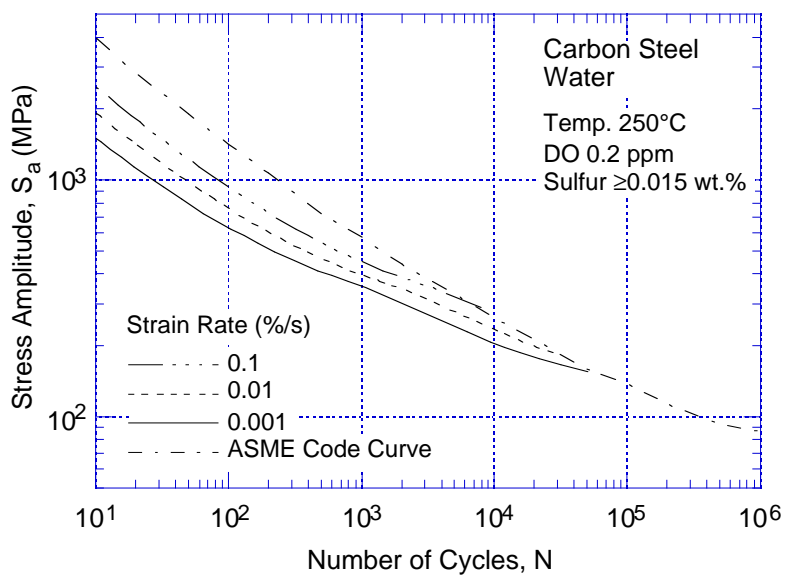

(c)

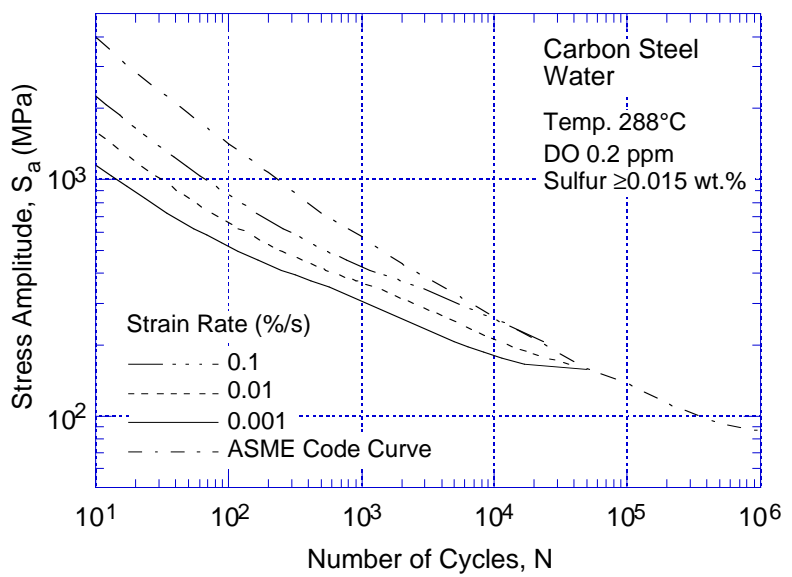

(e)

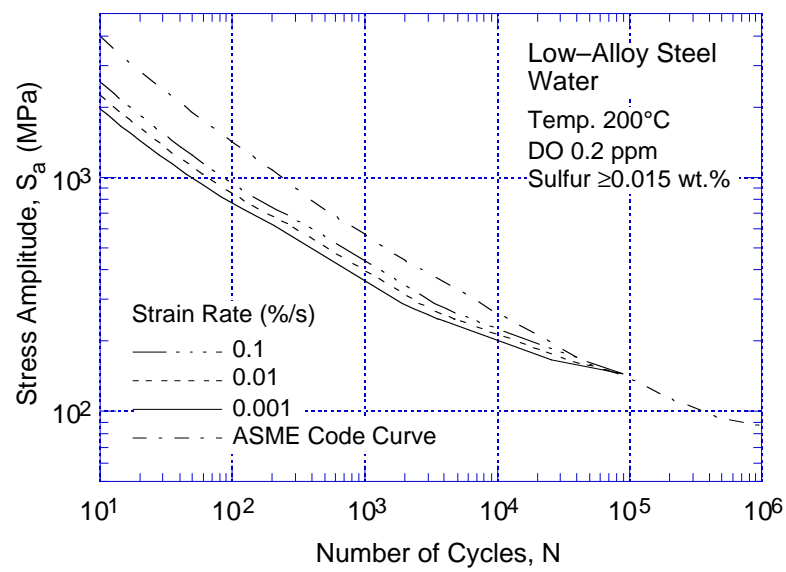

(b)

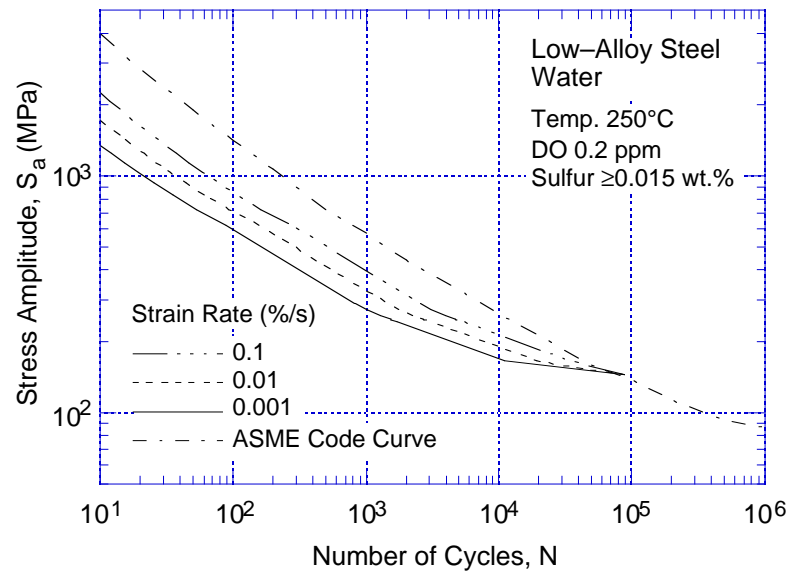

(d)

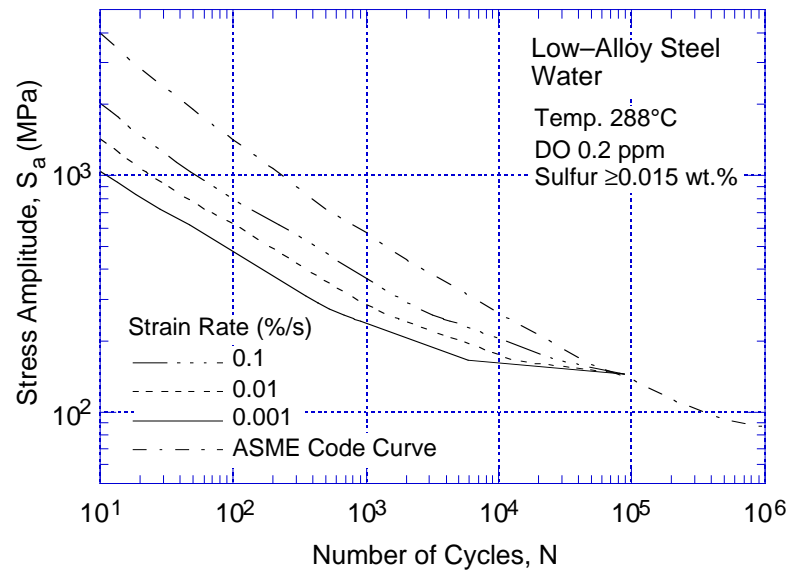

(f)

Figure 20. Fatigue design curves developed from statistical model for carbon steels and low-alloy steels in high-DO water at 200,250 , and $288^{\circ} \mathrm{C}$ and under service conditions where all other threshold values are satisfied. 


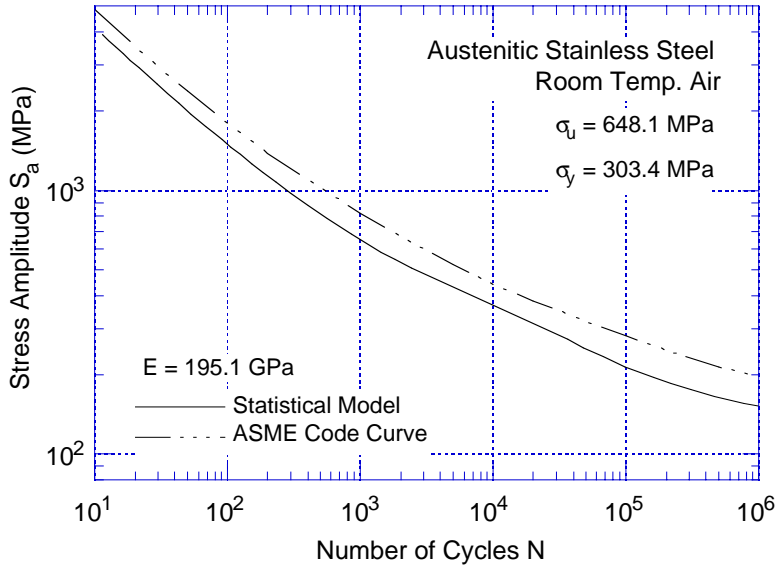

(a)

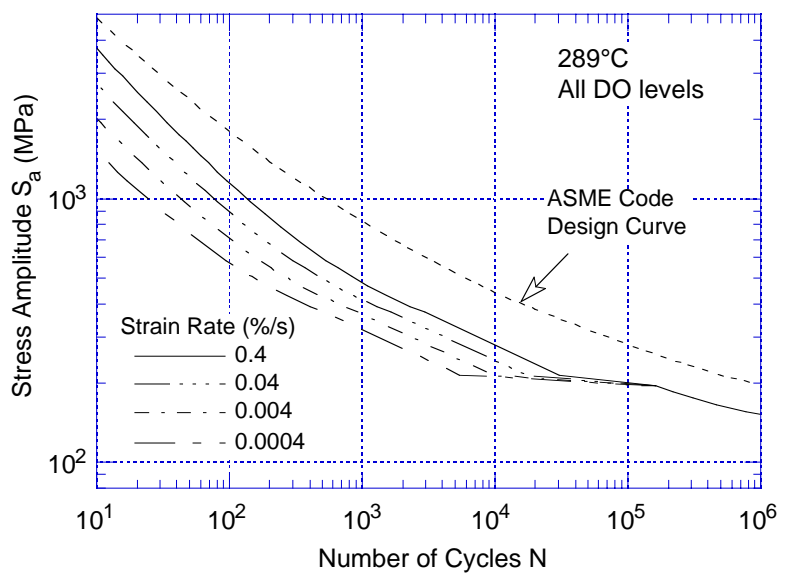

(c)

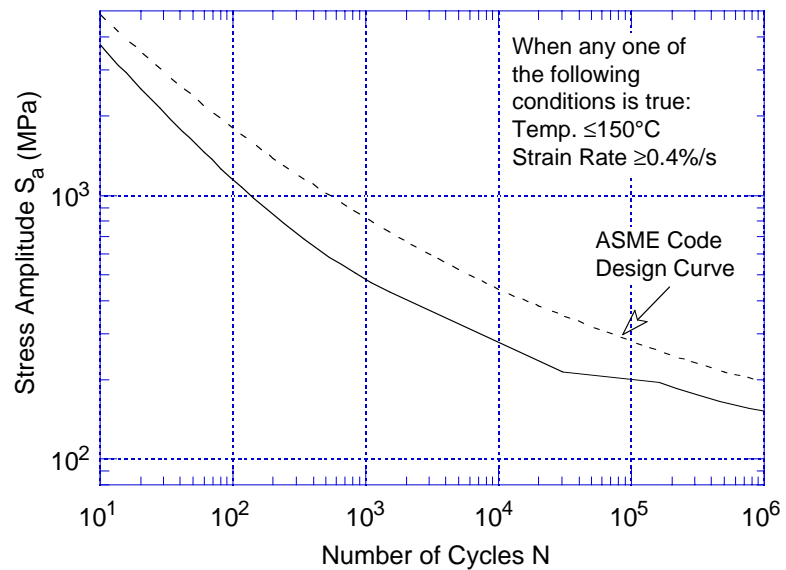

(b)

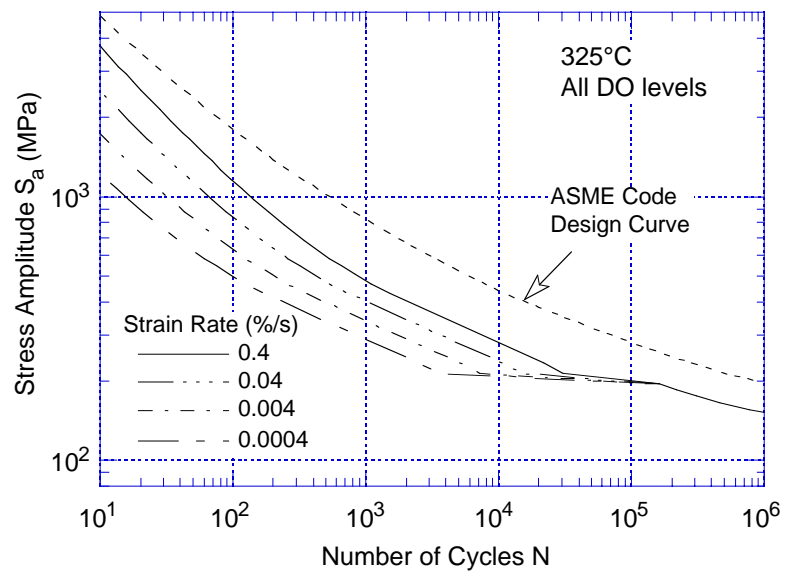

(d)

Figure 21. Fatigue design curves developed from the statistical model for austenitic stainless steels in (a) air at room temperature, (b) LWR environment under service conditions where one or more critical threshold values are not satisfied, and (c) and (d) LWR environments under service conditions where all threshold values are satisfied.

between the current Code curve and experimental data are $\approx 1.5$ on stress and $10-16$ on cycles instead of the 2 and 20 originally intended.

For the environmentally adjusted fatigue design curves, a minimum threshold strain is defined, below which environmental effects are modest. Based on the experimental data, the PVRC steering committee for cyclic life environmental effects ${ }^{52}$ has proposed a linear variation for the threshold strain; i.e., a lower strain amplitude, below which environmental effects are insignificant; a slightly higher strain amplitude, above which environmental effects decrease fatigue life; and a linear variation of environmental effects between these two values. The two strain amplitudes are 0.07 and $0.08 \%$ for carbon and low-alloy steels, and 0.10 and $0.11 \%$ for austenitic SSs (both wrought and cast SS). These threshold values were used to develop Figs. 20 and 21 . 


\subsection{Fatigue Life Correction Factor}

The effects of reactor coolant environments on fatigue life have also been expressed in terms of a fatigue life correction factor $\mathrm{F}_{\mathrm{en}}$, which is defined as the ratio of life in air at room temperature to that in water at the service temperature. Values of $\mathrm{F}_{\mathrm{en}}$ can be obtained from the statistical model, where

$$
\ln \left(\mathrm{F}_{\text {en }}\right)=\ln \left(\mathrm{N}_{\mathrm{RTair}}\right)-\ln \left(\mathrm{N}_{\text {water }}\right)
$$

The fatigue life correction factor for carbon steels is given by

$$
\mathrm{F}_{\mathrm{en}}=\exp \left(0.554-0.101 \mathrm{~S}^{*} \mathrm{~T}^{*} \mathrm{O}^{*} \dot{\varepsilon}^{*}\right),
$$

for low-alloy steels, by

$$
\mathrm{F}_{\mathrm{en}}=\exp \left(0.898-0.101 \mathrm{~S}^{*} \mathrm{~T}^{*} \mathrm{O}^{*} \dot{\varepsilon}^{*}\right) \text {, }
$$

and for austenitic SSs, by

$$
\mathrm{Fen}=\exp \left(0.935-\mathrm{T}^{\prime} \varepsilon^{\prime} \mathrm{O}^{\prime}\right)
$$

where the constants $\mathrm{S}^{*}, \mathrm{~T}^{*}, \dot{\varepsilon}^{*}$, and $\mathrm{O}^{*}$ are defined in Eqs. 7-10, and $\mathrm{T}^{\prime}, \dot{\varepsilon}$ ', and $\mathrm{O}^{\prime}$ are defined in Eqs. 15-17. A strain threshold is also defined, below which environmental effects are modest. The strain threshold is represented by a ramp, i.e., a lower strain amplitude below which environmental effects are insignificant, a slightly higher strain amplitude above which environmental effects are significant, and a ramp between the two values. Thus, the negative terms in Eqs. 22-24 are scaled from zero to their actual values between the two strain thresholds. The two strain amplitudes are 0.07 and $0.08 \%$ for carbon and low-alloy steels, and 0.10 and $0.11 \%$ for wrought and cast austenitic SSs. To incorporate environmental effects into a Section III fatigue evaluation, the fatigue usage for a specific stress cycle based on the current Code fatigue design curve is multiplied by the correction factor. 


\section{Margins in ASME Code Fatigue Design Curves}

Conservatism in the ASME Code fatigue evaluations may arise from (a) the fatigue evaluation procedures and/or (b) the fatigue design curves. The overall conservatism in ASME Code fatigue evaluations has been demonstrated in fatigue tests on components. ${ }^{57,58}$ Mayfield et al. ${ }^{57}$ have shown that, in air, the margins on the number of cycles to failure for elbows and tees were 40-310 and 104-510, respectively, for austenitic SS, and 118-2500 and 123-1700, respectively, for carbon steel. The margins for girth butt welds were significantly lower, at 6-77 for SS and 14-128 for carbon steel. Data obtained by Heald and Kiss ${ }^{58}$ on 26 piping components at room temperature and $288^{\circ} \mathrm{C}$ showed that the design margin for cracking exceeds 20, and for most of the components it is $>100$. In these tests, fatigue life was expressed as the number of cycles for the crack to penetrate through the wall, which ranged in thickness from 6 to $18 \mathrm{~mm}$. Consequently, depending on wall thickness, the actual margins to form a $3-\mathrm{mm}$ crack may be lower by a factor of more than 2 .

Deardorff and Smith ${ }^{59}$ discussed the types and extent of conservatism present in the ASME Section III fatigue evaluation procedures and the effects of LWR environments on fatigue margins. The sources of conservatism in the procedures include the use of design transients that are significantly more severe than those experienced in service, conservative grouping of transients, and use of simplified elastic-plastic analyses that lead to higher stresses. The authors estimated that the ratio of the cumulative usage factors (CUFs) computed with the mean experimental curve for test specimen data in air and more accurate values of the stress to the CUFs computed with the Code fatigue design curve were $\approx 60$ and 90 , respectively, for PWR and BWR nozzles. The reductions in these margins due to environmental effects were estimated to be factors of 5.2 and 4.6 for PWR and BWR nozzles, respectively. Thus, Deardorff and Smith ${ }^{59}$ argue that, after accounting for environmental effects, factors of 12 and 20 on life for PWR and BWR nozzles, respectively, account for uncertainties due to material variability, surface finish, size, mean stress, and loading sequence.

However, other studies on piping and components indicate that the Code fatigue design procedures do not always ensure large margins of safety. 60,61 Southwest Research Institute performed fatigue tests in room-temperature water on 0.914-m-diameter carbon and low-alloy steel vessels with $19-\mathrm{mm}$ walls. ${ }^{60}$ In the low-cycle regime, $\approx 5-\mathrm{mm}$-deep cracks were initiated slightly above (a factor of $<2$ ) the number of cycles predicted by the ASME Code design curve (Fig. 22a). Battelle-Columbus conducted tests on 203-mm or 914-mm carbon steel pipe welds at room temperature in an inert environment, and Oak Ridge National Laboratory (ORNL) performed four-point bend tests on 406-mm-diameter Type 304 SS pipe removed from the C-reactor at the Savannah River site. ${ }^{61}$ The results showed that the number of cycles to produce a leak was lower, and in some cases significantly lower, than that expected from the ASME Code fatigue design curves (Fig. 22a and b). The most striking results are for the ORNL "tie-in" and flawed "test" weld; these specimens cracked completely through the 12.7-mm-thick wall in a life 6 or 7 times shorter than would be expected from the Code curve. Note that the Battelle and ORNL results represent a through-wall crack; the number of cycles to initiate a 3-mm crack may be a factor of 2 lower.

Much of the margin in the current evaluations arises from design procedures (e.g., stress analysis rules and cycle counting) that, as discussed by Deardorff and Smith, ${ }^{59}$ are quite conservative. However, the ASME Code permits new and improved approaches to fatigue 


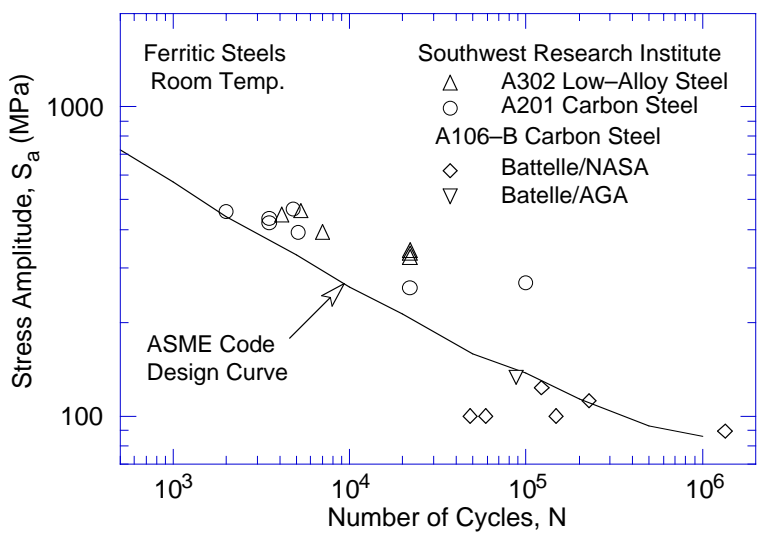

(a)

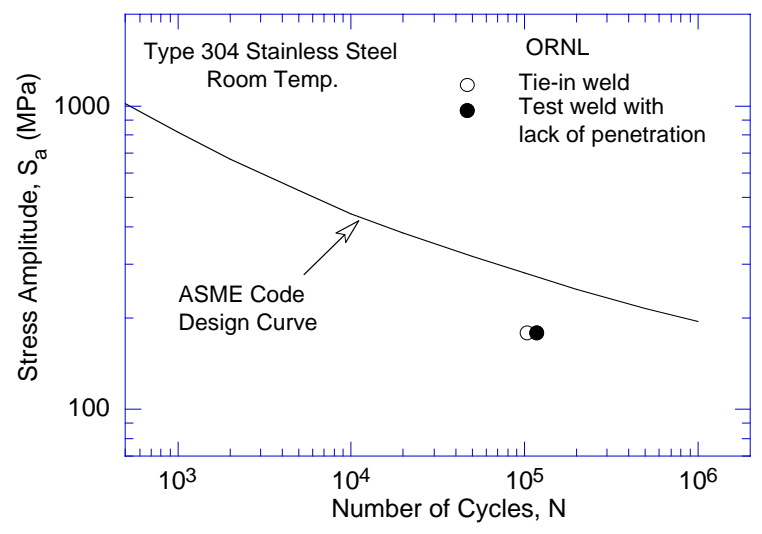

(b)

Figure 22. Fatigue data for (a) carbon and low-alloy steel and (b) Type 304 stainless steel components (Refs. 60,61).

evaluations (e.g., finite-element analyses, fatigue monitoring, and improved $\mathrm{K}_{\mathrm{e}}$ factors) that can significantly decrease the conservatism in the current fatigue evaluation procedures.

The factors of 2 on stress and 20 on cycles used in the Code were intended to cover the effects of variables that can influence fatigue life but were not investigated in the tests that provided the data for the curves. It is not clear whether the particular values of 2 and 20 that were chosen include possible conservatism. A study sponsored by the PVRC to assess the margins of 2 and 20 in fatigue design curves concluded that these margins could not be changed. 62

The variables that can affect fatigue life in air and LWR environments can be broadly classified into three groups:

(a) Material

(i) Composition

(ii) Metallurgy: grain size, inclusions, orientation within a forging or plate

(iii) Processing: cold work, heat treatment

(iv) Size and geometry

(v) Surface finish: fabrication surface condition

(vi) Surface preparation: surface work hardening

(b) Loading

(i) Strain rate: rise time

(ii) Sequence: linear damage summation or Miner's rule

(iii) Mean stress

(iv) Biaxial effects: constraints

(c) Environment

(i) Water chemistry: DO, lithium hydroxide, boric acid concentrations

(ii) Temperature

(iii) Flow rate

The existing fatigue $\varepsilon-\mathrm{N}$ database covers an adequate range of material parameters (i-iii), a loading parameter (i), and environment parameters (i-ii); therefore, the variability and uncertainty in fatigue life due to these parameters have been incorporated into the model. The 
existing data are most likely conservative with respect to the effects of surface preparation because the fatigue $\varepsilon-\mathrm{N}$ data are obtained for specimens that are free of surface cold work. Fabrication procedures for fatigue test specimens generally follow ASTM guidelines, which require that the final polishing of the specimens avoid surface work-hardening. Biaxial effects are covered by design procedures and need not be considered in the fatigue design curves. As discussed earlier, under the conditions typical of operating BWRs, environmental effects on the fatigue life of carbon and low-alloy steels are a factor of $\approx 2$ lower at high flow rates $(7 \mathrm{~m} / \mathrm{s})$ than those at very low flow rates $\left(0.3 \mathrm{~m} / \mathrm{s}\right.$ or lower). ${ }^{50-52}$ Also, existing data indicate that flow rate has no effect on the fatigue life of austenitic SSs. ${ }^{51}$

Thus, the contributions of four groups of variables, namely, material variability and data scatter, specimen size and geometry, surface finish, and loading sequence (Miner's rule), must be considered in developing the fatigue design curves that are applicable to components. Data available in the literature have been reviewed in NUREG/CR-6717 to determine the effect of these variables on the fatigue life of components. ${ }^{7}$

\subsection{Material variability and data scatter}

The effects of material variability and data scatter must be included to ensure that the design curves not only describe the available test data well, but also adequately describe the fatigue lives of the much larger number of heats of material that are found in the field. The effects of material variability and data scatter are often evaluated by comparing the experimental data to a specific model for fatigue crack initiation, e.g., the best-fit (in some sense) to the data. The adequacy of the evaluation will then depend on the nature of the sample of data used in the analysis. For example, if most of the data have been obtained from a heat of material that has poor resistance to fatigue damage or under loading conditions that show significant environmental effects, the results may be conservative for most of the materials or service conditions of interest. Conversely, if most data are from a heat of material with a high resistance to fatigue damage, the results could be nonconservative for many heats in service.

Another method to assess the effect of material variability and data scatter is by considering the best-fit curves determined from tests on individual heats of materials or loading conditions as samples of the much larger population of heats of materials and service conditions of interest. The fatigue behavior of each of the heats or loading conditions is characterized by the value of the constant term in the statistical models (e.g., Eq. 3), denoted as $\mathrm{A}$. The values of $\mathrm{A}$ for the various data sets are ordered, and median ranks are used to estimate the cumulative distribution of $A$ for the population. ${ }^{63,64}$ The distributions were fit to lognormal curves. No rigorous statistical evaluation was performed, but the fits seem reasonable and describe the observed variability adequately. Results for carbon and low-alloy steels and austenitic SSs in air and water environments are shown in Fig. 23. Note that the mean values of A in Fig. 23 are slightly different from the values in Eqs. 3-6, 11, and 13, because they are based on a larger database. The statistical model expressions were obtained from Ref. 17 and have not been updated with the larger database. Such an update is planned after the final form of the model is established.

The values of $A$ that describe the 5 th percentile of these distributions give fatigue $\varepsilon-\mathrm{N}$ curves that are expected to bound the fatigue lives of $95 \%$ of the heats of the material. The 


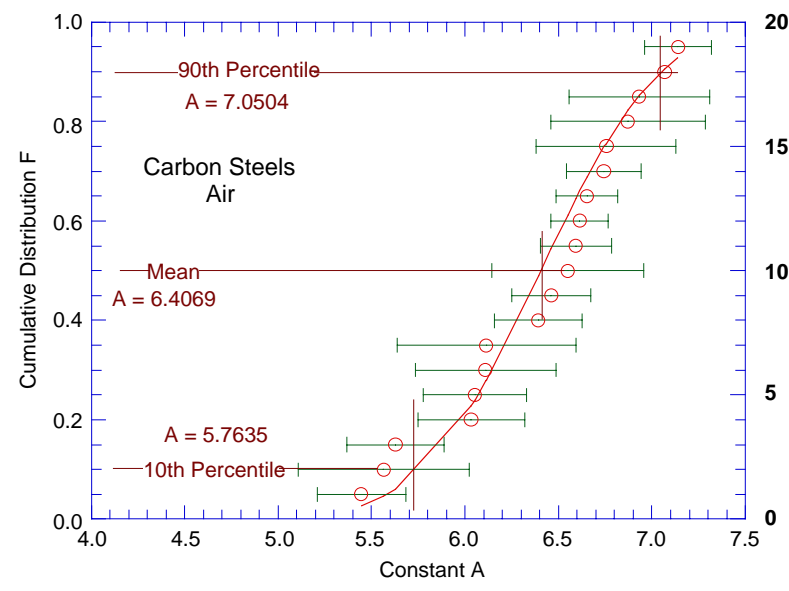

Carbon steel in air

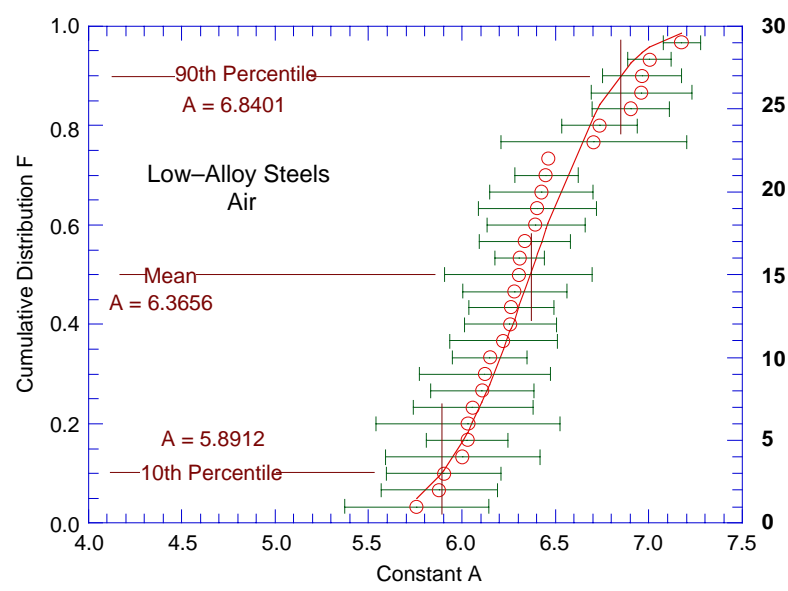

Low-alloy steel in air

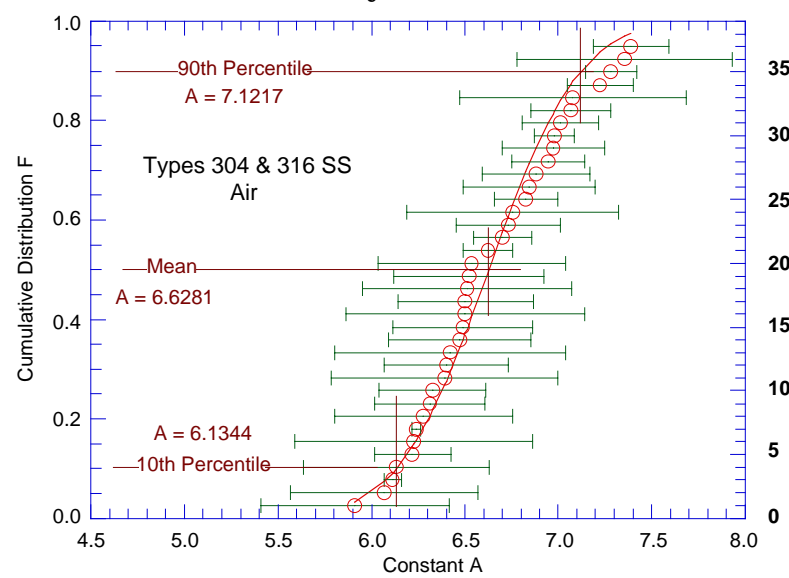

Austenitic SS in air

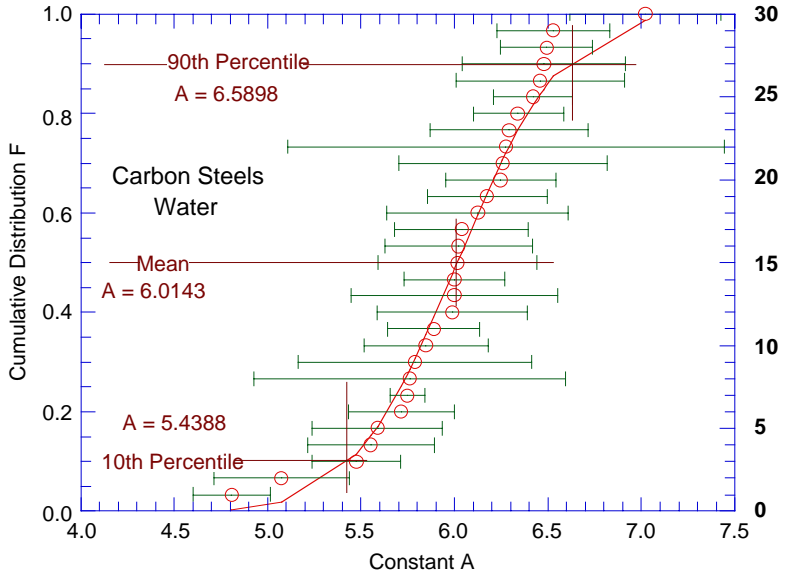

Carbon steel in water

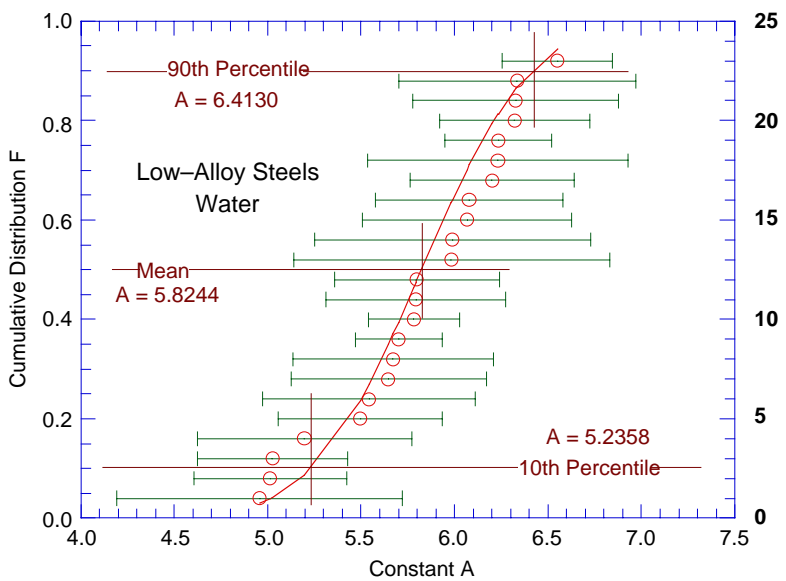

Low-alloy steel in water

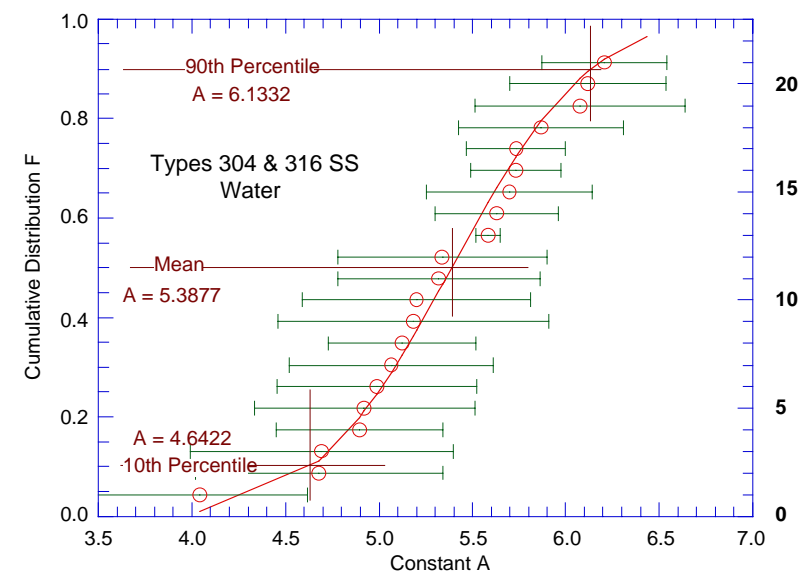

Austenitic SS in water

Figure 23. Estimated cumulative distribution of Parameter A in statistical models for fatigue life for heats of carbon and low-alloy steels and austenitic SSs in air and water environments.

distributions shown in Fig. 23 contain two sources of error. The mean and standard deviation of the population must be estimated from the mean and standard deviation of the sample, ${ }^{65}$ and confidence bounds can then be obtained on the population mean and standard deviation in terms of the sample mean and standard deviation. Secondly, even this does not fully 
Table 3. Values of Parameter A in statistical model for carbon steels as a function of confidence level and percentage of population bounded

\begin{tabular}{|c|c|c|c|c|c|}
\hline \multirow{2}{*}{$\begin{array}{c}\text { Confidence } \\
\text { Level }\end{array}$} & \multicolumn{5}{|c|}{ Percentage of Population Bounded (Percentile Distribution of A) } \\
\hline & $95(5)$ & $90(10)$ & $75(25)$ & $67(33)$ & $50(50)$ \\
\hline & \multicolumn{5}{|c|}{ Air Environment } \\
\hline 50 & 5.930 & 6.019 & 6.212 & 6.278 & 6.400 \\
\hline 75 & 5.572 & 5.670 & 5.867 & 5.936 & 6.065 \\
\hline 90 & 5.251 & 5.356 & 5.555 & 5.627 & 5.764 \\
\hline \multirow[t]{2}{*}{95} & 5.058 & 5.168 & 5.369 & 5.443 & 5.583 \\
\hline & \multicolumn{5}{|c|}{ LWR Environments } \\
\hline 50 & 5.300 & 5.444 & 5.675 & 5.767 & 5.948 \\
\hline 75 & 4.959 & 5.119 & 5.370 & 5.466 & 5.652 \\
\hline 90 & 4.652 & 4.836 & 5.095 & 5.195 & 5.386 \\
\hline 95 & 4.468 & 4.651 & 4.931 & 5.033 & 5.227 \\
\hline
\end{tabular}

Table 4. Values of Parameter A in statistical model for low-alloy steels as a function of confidence level and percentage of population bounded

\begin{tabular}{|c|c|c|c|c|c|}
\hline \multirow{2}{*}{$\begin{array}{c}\text { Confidence } \\
\text { Level }\end{array}$} & \multicolumn{5}{|c|}{ Percentage of Population Bounded (Percentile Distribution of A) } \\
\hline & $95(5)$ & $90(10)$ & $75(25)$ & $67(33)$ & $50 \quad(50)$ \\
\hline \multicolumn{6}{|c|}{ Air Environment } \\
\hline 50 & 5.912 & 6.000 & 6.180 & 6.242 & 6.370 \\
\hline 75 & 5.640 & 5.738 & 5.927 & 5.992 & 6.119 \\
\hline 90 & 5.395 & 5.503 & 5.700 & 5.768 & 5.893 \\
\hline 95 & 5.249 & 5.362 & 5.563 & 5.633 & 5.758 \\
\hline \multicolumn{6}{|c|}{ LWR Environments } \\
\hline 50 & 5.049 & 5.210 & 5.496 & 5.623 & 5.820 \\
\hline 75 & 4.699 & 4.876 & 5.182 & 5.315 & 5.508 \\
\hline 90 & 4.383 & 4.575 & 4.898 & 5.037 & 5.227 \\
\hline 95 & 4.194 & 4.396 & 4.729 & 4.871 & 5.059 \\
\hline
\end{tabular}

Table 5. Values of Parameter A in statistical model for austenitic stainless steels as a function of confidence level and percentage of population bounded

\begin{tabular}{|c|c|c|c|c|c|}
\hline \multirow{2}{*}{$\begin{array}{c}\text { Confidence } \\
\text { Level }\end{array}$} & \multicolumn{5}{|c|}{ Percentage of Population Bounded (Percentile Distribution of A) } \\
\hline & $95(5)$ & $90(10)$ & $75(25)$ & $67(33)$ & $50(50)$ \\
\hline & \multicolumn{5}{|c|}{ Air Environment } \\
\hline 50 & 6.044 & 6.173 & 6.376 & 6.481 & 6.631 \\
\hline 75 & 5.721 & 5.878 & 6.102 & 6.217 & 6.371 \\
\hline 90 & 5.429 & 5.612 & 5.855 & 5.978 & 6.137 \\
\hline \multirow[t]{2}{*}{95} & 5.255 & 5.453 & 5.707 & 5.836 & 5.997 \\
\hline & \multicolumn{5}{|c|}{ LWR Environments } \\
\hline 50 & 4.563 & 4.749 & 5.048 & 5.160 & 5.380 \\
\hline 75 & 4.132 & 4.328 & 4.650 & 4.767 & 4.988 \\
\hline 90 & 3.745 & 3.950 & 4.291 & 4.412 & 4.636 \\
\hline 95 & 3.513 & 3.723 & 4.077 & 4.200 & 4.425 \\
\hline
\end{tabular}

address the uncertainty in the distribution, because of the large uncertainties in the sample values themselves, i.e., the "horizontal" uncertainty in the actual value of A for a heat of material, as indicated by the error bars in Fig. 23. A Monte Carlo analysis was used to address both sources of uncertainty. The results of the Monte Carlo analyses for various steels are summarized in Tables 3-5 in terms of values for A that provide bounds for the portion of the population and the confidence that is desired in the estimates of the bounds. Note that, with small samples, demanding too high a confidence level can lead to very conservative estimates of 
Table 6. Margins on life for carbon steels corresponding to various confidence levels and percentile values of Parameter A

\begin{tabular}{|c|c|c|c|c|c|}
\hline \multirow{2}{*}{$\begin{array}{c}\text { Confidence } \\
\text { Level }\end{array}$} & \multicolumn{5}{|c|}{ Percentage of Population Bounded (Percentile Distribution of A) } \\
\hline & $95(5)$ & $90(10)$ & $75(25)$ & $67(33)$ & $50(50)$ \\
\hline & \multicolumn{5}{|c|}{ Air Environment } \\
\hline 50 & 1.6 & 1.5 & 1.2 & 1.1 & 1.0 \\
\hline 75 & 2.3 & 2.1 & 1.7 & 1.6 & 1.4 \\
\hline 90 & 3.2 & 2.9 & 2.3 & 2.2 & 1.9 \\
\hline \multirow[t]{2}{*}{95} & 3.9 & 3.5 & 2.8 & 2.6 & 2.3 \\
\hline & \multicolumn{5}{|c|}{ LWR Environments } \\
\hline 50 & 2.0 & 1.8 & 1.4 & 1.3 & 1.0 \\
\hline 75 & 2.9 & 2.4 & 1.9 & 1.7 & 1.4 \\
\hline 90 & 3.9 & 3.3 & 2.5 & 2.3 & 1.9 \\
\hline 95 & 4.7 & 3.9 & 3.0 & 2.7 & 2.2 \\
\hline
\end{tabular}

Table 7. Margins on life for low-alloy steels corresponding to various confidence levels and percentile values of Parameter A

\begin{tabular}{|c|c|c|c|c|c|}
\hline \multirow{2}{*}{$\begin{array}{c}\text { Confidence } \\
\text { Level }\end{array}$} & \multicolumn{5}{|c|}{ Percentage of Population Bounded (Percentile Distribution of A) } \\
\hline & $95(5)$ & $90(10)$ & $75(25)$ & $67(33)$ & $50(50)$ \\
\hline & \multicolumn{5}{|c|}{ Air Environment } \\
\hline 50 & 1.6 & 1.4 & 1.2 & 1.1 & 1.0 \\
\hline 75 & 2.1 & 1.9 & 1.6 & 1.5 & 1.3 \\
\hline 90 & 2.6 & 2.4 & 1.9 & 1.8 & 1.6 \\
\hline \multirow[t]{2}{*}{95} & 3.1 & 2.7 & 2.2 & 2.1 & 1.8 \\
\hline & \multicolumn{5}{|c|}{ LWR Environments } \\
\hline 50 & 2.2 & 1.8 & 1.4 & 1.2 & 1.0 \\
\hline 75 & 3.1 & 2.6 & 1.9 & 1.7 & 1.4 \\
\hline 90 & 4.2 & 3.5 & 2.5 & 2.2 & 1.8 \\
\hline 95 & 5.1 & 4.2 & 3.0 & 2.6 & 2.1 \\
\hline
\end{tabular}

Table 8. Margins on life for austenitic stainless steels corresponding to various confidence levels and percentile values of Parameter $A$

\begin{tabular}{|c|c|c|c|c|c|}
\hline \multirow{2}{*}{$\begin{array}{c}\text { Confidence } \\
\text { Level }\end{array}$} & \multicolumn{5}{|c|}{ Percentage of Population Bounded (Percentile Distribution of A) } \\
\hline & $95(5)$ & $90(10)$ & $75(25)$ & $67(33)$ & $50(50)$ \\
\hline & \multicolumn{5}{|c|}{ Air Environment } \\
\hline 50 & 1.8 & 1.6 & 1.3 & 1.2 & 1.0 \\
\hline 75 & 2.5 & 2.1 & 1.7 & 1.5 & 1.3 \\
\hline 90 & 3.3 & 2.8 & 2.2 & 1.9 & 1.6 \\
\hline \multirow[t]{2}{*}{95} & 3.9 & 3.2 & 2.5 & 2.2 & 1.9 \\
\hline & \multicolumn{5}{|c|}{ LWR Environments } \\
\hline 50 & 2.3 & 1.9 & 1.4 & 1.3 & 1.0 \\
\hline 75 & 3.5 & 2.9 & 2.1 & 1.9 & 1.5 \\
\hline 90 & 5.2 & 4.2 & 3.0 & 2.7 & 2.1 \\
\hline 95 & 6.5 & 5.3 & 3.7 & 3.3 & 2.6 \\
\hline
\end{tabular}

the percentile values. Because the cumulative distributions in Fig. 23 do not properly account for all uncertainties, they should only be considered as a qualitative description of expected variation. Tables 3-5 should be used for quantitative estimates. For low-alloy steels, the 5th percentile value of Parameter A at a 75\% confidence level is 5.640 in air and 4.699 in LWR environments. From Fig. 23, the mean value of A for the sample is 6.366 and 5.824, respectively, in the two environments. Thus, for low-alloy steels, the 95/75 value of the margin to account for material variability and data scatter is 2.1 and 3.1 on life in air and water environments, respectively. The corresponding margins in air and water environments, 
respectively, are 2.3 and 2.9 for carbon steels, and 2.5 and 3.5 for SSs. Thus, average values of 2 and 3 on life in air and water environments, respectively, may be used to account for uncertainties due to material variability and data scatter. The estimated margins for these steels for various percentile and confidence levels are given in Tables 6-8. These margins are needed to provide reasonable confidence that the resultant life will be greater than that observed for $95 \%$ of the materials of interest.

\subsection{Size and Geometry}

The effect of specimen size on the fatigue life has been investigated for smooth specimens of various diameters in the range of 2-60 mm. ${ }^{66-69}$ No intrinsic size effect has been observed for smooth specimens tested in axial loading or plain bending. However, a size effect does occur in specimens tested in rotating bending; the fatigue endurance limit decreases by $\approx 25 \%$ by increasing the specimen size from 2 to $16 \mathrm{~mm}$ but does not decrease further with larger sizes. ${ }^{69}$ In addition, some effect of size and geometry has been observed on small-scale-vessel tests conducted at the Ecole Polytechnique in conjunction with the large-size-pressure-vessel tests carried out by the Southwest Research Institute. ${ }^{60}$ The tests at the Ecole Polytechnique were conducted in room-temperature water on $\approx 305$-mm-inner-diameter, 19 -mm-thick shells with nozzles made of machined bar stock. The results indicate that the number of cycles needed to form a 3-mm-deep crack in a 19-mm-thick shell may be 30-50\% lower than that needed for a small test specimen. Thus, a factor of $\approx 1.4$ on cycles and a factor of $\approx 1.25$ on strain can be used to account for size and geometry.

\subsection{Surface Finish}

Fatigue life is sensitive to surface finish; cracks can initiate at surface irregularities that are normal to the stress axis. The height, spacing, shape, and distribution of surface irregularities are important for crack initiation. The most common measure of roughness is average surface roughness $\mathrm{R}_{\mathrm{a}}$, which is a measure of the height of irregularities that are present. Investigations of the effects of surface roughness on the low-cycle fatigue of Type 304 SS in air at $593^{\circ} \mathrm{C}$ indicate that fatigue life decreases as surface roughness increases. ${ }^{70,71}$ The effect of roughness on crack initiation $\mathrm{N}_{\mathrm{i}}(\mathrm{R})$ is given by

$$
\mathrm{N}_{\mathrm{i}}\left(\mathrm{R}_{\mathrm{q}}\right)=1012 \mathrm{R}_{\mathrm{q}}^{-0.21}
$$

where the RMS value of surface roughness $\left(R_{q}\right)$ is in micrometers. Studies indicate that an $R_{a}$ of $3 \mu \mathrm{m}$ (or an $\mathrm{R}_{\mathrm{q}}$ of $4 \mu \mathrm{m}$ ) represents the maximum surface roughness for drawing/extrusion, grinding, honing, and polishing processes and a mean value for the roughness range for milling or turning processes. ${ }^{72}$ For SSs, an $\mathrm{R}_{\mathrm{q}}$ of $4 \mu \mathrm{m}$ in Eq. $25\left(\mathrm{R}_{\mathrm{q}}\right.$ of a smooth polished specimen is $\approx 0.0075 \mu \mathrm{m}$ ) would decrease fatigue life by a factor of 3.7.70 A study of the effect of surface finish on the fatigue life of carbon steel in room-temperature air showed a factor of 2 decrease in life when $\mathrm{R}_{\mathrm{a}}$ is increased from 0.3 to $5.3 \mu \mathrm{m} .{ }^{73}$ The experimental results from the present study are consistent with Eq. 25. From Eq. 25, an $\mathrm{R}_{\mathrm{q}}$ of $1.6 \mu \mathrm{m}$ corresponds to a factor of 3.1 decrease in fatigue life for the roughened specimen.

The experimental results suggest that factors of $\approx 3$ on cycles would account for effects of surface finish on the fatigue life of austenitic SSs in both air and water environments and for carbon and low-alloy steels in air. A factor of 3 decrease in life corresponds to a factor of $\approx 1.3$ on strain (Considering the factor of 20 on cycles to be equivalent to the factor of 2 on strain, 
the factor applied on strain $\left(\mathrm{K}_{\mathrm{S}}\right)$ is obtained from the factor applied on cycles $\left(\mathrm{K}_{\mathrm{N}}\right)$ by using the relationship $\mathrm{K}_{\mathrm{S}}=\left(\mathrm{K}_{\mathrm{N}}\right)^{0.2326}$. For carbon and low-alloy steels, the effect of surface finish is lower in LWR environments; most likely, the moderate environmental effects (when any one threshold condition is not satisfied) are primarily due to surface roughness effects.

In earlier reports, Chopra and Shack ${ }^{15}$ and Chopra ${ }^{26}$ argued that the effects of surface finish may not be significant in LWR environments, because carbon and low-alloy steels and austenitic SSs develop a rough corrosion scale. They further argued that the factor on life to account for the surface finish effect could be as low as 1.5 or perhaps eliminated completely in LWR environments. The results from the present study indicate that this argument is not valid for austenitic SSs, although the effect of surface roughness is small for carbon and low-alloy steels in LWR environments.

The decrease in fatigue life of both carbon and low-alloy steels and austenitic SSs is caused primarily by the effect of the environment on the growth of microstructurally small cracks and, to a lesser extent, on the growth of mechanically small cracks. ${ }^{43,44}$ The observed effects of surface finish on the fatigue life of SSs and carbon and low-alloy steels in LWR environments appear to be consistent with the hypothesis that the mechanisms of the growth of microstructurally small cracks are different in austenitic SSs and carbon or low-alloy steels, although other explanations are also possible. The fact that the fatigue life of carbon and low-alloy steels is unaffected by surface finish is consistent with the possibility of a mechanism like slip/dissolution which is less dependent on the stress level. The reduction in life of SSs is consistent with a hydrogen-enhanced crack growth mechanism, which seems more likely to be influenced by surface roughness.

\subsection{Loading Sequence}

The effects of variable amplitude loading of smooth specimens are well known. ${ }^{74-78}$ The presence in a loading sequence of a few cycles at high strain amplitude causes the fatigue life at smaller strain amplitude to be significantly lower than that at constant-amplitude loading. As discussed in Section 3.1, growth of mechanically small cracks can occur at strain levels below the fatigue limit of the material. Fatigue life has conventionally been divided into two stages: initiation, expressed as the cycles required to form microcracks on the surface; and propagation, expressed as cycles required to propagate the surface cracks to engineering size. During cyclic loading of smooth test specimens, surface cracks $10 \mu \mathrm{m}$ or longer form quite early in life (i.e., $<10 \%$ of life) at surface irregularities or discontinuities either already in existence or produced by slip bands, grain boundaries, second-phase particles, etc. ${ }^{14,43,79-82}$ Consequently, fatigue life may be considered to be composed entirely of propagation of cracks from 10 to $3000 \mu \mathrm{m}$ long. 83

A schematic illustration of the two stages, i.e., initiation and propagation, of fatigue life is shown in Fig. 24. The initiation stage involves growth of microstructurally small cracks (MSCs), characterized by decelerating crack growth (Region AB in Fig. 24a). The propagation stage involves growth of mechanically small cracks, characterized by accelerating crack growth (Region BC in Fig. 24a). The growth of MSCs is very sensitive to microstructure. ${ }^{43,80}$ Fatigue cracks greater than the critical length of MSCs show little or no influence of microstructure, and are called mechanically small cracks, and they correspond to Stage II (tensile) cracks, which are characterized by striated crack growth, with a fracture surface normal to the maximum principal stress. Various criteria, summarized in Ref. 17, have been used to define 


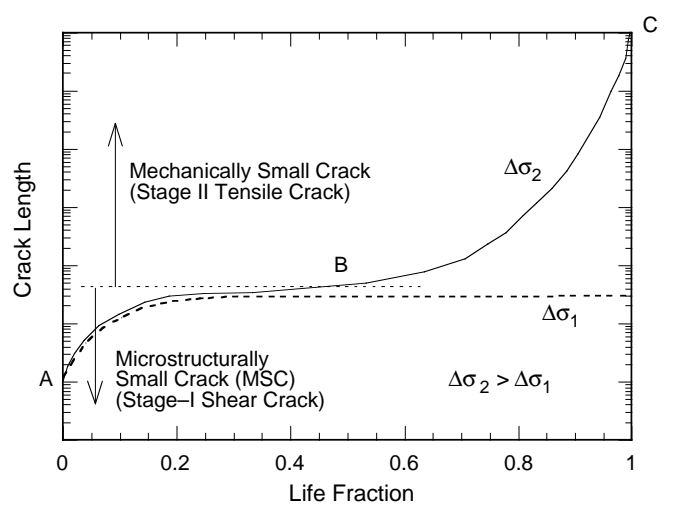

(a)

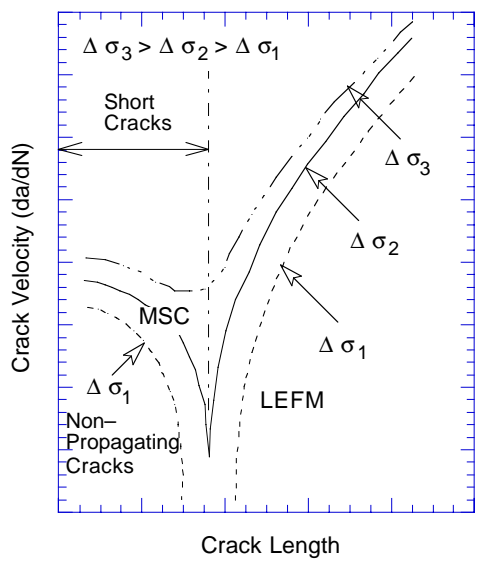

(b)

Figure 24. Schematic illustration of (a) growth of short cracks in smooth specimens as a function of fatigue life fraction and (b) crack velocity as a function of crack length. LEFM = linear elastic fracture mechanics.

the crack length for transition from microstructurally to mechanically small crack; the transition crack length is a function of applied stress and microstructure of the material; actual values may range from 150 to $250 \mu \mathrm{m}$.

At low stress levels $\left(\Delta \sigma_{1}\right)$, the transition from MSC growth to accelerating crack growth does not occur. This circumstance represents the fatigue limit for the smooth specimen. Although cracks can form below the fatigue limit, they can grow to engineering size only at stresses greater than the fatigue limit. Note that the fatigue limit for a material is applicable only for constant loading conditions. Under variable loading conditions encountered during service of power plants, cracks created by growth of MSCs at high stresses $\left(\Delta \sigma_{3}\right)$ to lengths larger than the transition crack length can increase at stress levels below the fatigue limit $\left(\Delta \sigma_{1}\right)$.

Studies on fatigue damage in Type 304 SS under complex loading histories ${ }^{78}$ indicate that the loading sequence of decreasing strain levels (i.e., high strain level followed by low strain level) is more damaging than that of increasing strain levels. The fatigue life of the steel decreased by a factor of 2-4 under a decreasing-strain sequence. In another study, the fatigue limit of medium carbon steels was lowered even after low-stress high-cycle fatigue; the higher the stress, the greater the decrease in fatigue threshold. ${ }^{84}$ In general, the mean fatigue $\varepsilon-\mathrm{N}$ curves are lowered to account for damaging cycles that occur below the constant-amplitude fatigue limit of the material. ${ }^{85}$ A factor of 1.5-2.5 on cycles and 1.3-1.6 on strain may be used to incorporate the effects of load histories on fatigue life.

\subsection{Moderate or Acceptable Environmental Effects}

A working group of the PVRC has been compiling and evaluating data on the effects of LWR coolant environments on the fatigue life of pressure boundary materials. ${ }^{31}$ One of the tasks in the PVRC activity was to define a set of values for material, loading, and environmental variables that lead to moderate or acceptable effects of environment on fatigue life. A factor of 4 on the ASME mean life was chosen as a working definition of "moderate" or "acceptable" effects of environment, i.e., up to a factor of 4 decrease in fatigue life due to the environment is considered acceptable and does not require further fatigue evaluation. ${ }^{31}$ The basis for this 
criterion was the discussion presented by Cooper ${ }^{3}$ on the initial scope and intent of the Section III fatigue design procedures, and has been discussed in Section 1 of this report.

The criterion for "acceptable" effects of the environment developed by the PVRC working group was based on the assumption that the current Code design curve includes a factor of 4 (i.e., the third subfactor listed by Cooper) to account for the effects of environment. The third subfactor, however, also was intended to include the effect of surface finish on fatigue life. As discussed in Section 5.3, surface finish can decrease the fatigue life of structural steels by up to a factor of 3 in air and, for austenitic SSs, also in water environments. Therefore, assuming surface effects were maximized, the PVRC criterion of a factor of 4 for "acceptable" effects of environment, will only provide a factor of 1.3 to account for the environment.

\subsection{Fatigue Design Curve Margins Summarized}

The subfactors that are needed to account for the effects of various material, loading, and environmental variables on fatigue life are summarized in Table 9. As shown by "total adjustment," a factor of at least 12.5 on cycles with respect to the mean $\varepsilon-\mathrm{N}$ curve for laboratory test specimens in air is needed to account for the effects of data scatter, material variability, component size, surface finish, and loading history. In LWR environments, a factor of at least 19 on cycles with respect to the mean $\varepsilon-\mathrm{N}$ curve for laboratory test specimens is needed for austenitic SSs and at least 10 on cycles for carbon and low-alloy steels.

The factors on strain are needed primarily to account for the variation in the fatigue limit of the material caused by material variability, component size and surface finish, and load history. Because these variables affect life through their influence on the growth of short cracks $(<100 \mu \mathrm{m})$, the adjustment on strain to account for such variations is typically not cumulative, i.e., the portion of the life can only be reduced by a finite amount. Thus, it is controlled by the variable that has the largest effect on life. In relating the fatigue lives of laboratory test specimens to those of actual reactor components, a factor of $\approx 1.7$ on strain with respect to the mean $\varepsilon-\mathrm{N}$ curve for laboratory test specimens is needed to account for the uncertainties associated with material variability, component size, surface finish, and load history. These results suggest that the current ASME Code requirements of a factor of 2 on stress and 20 on cycle to account for differences and uncertainties in fatigue life that are associated with material and loading conditions are quite reasonable, but do not contain excess conservatism that can be assumed to account for the effects of LWR environments. They thus provide appropriate margins for the development of design curves from mean data curves for small specimens in LWR environments.

Table 9. Factors on cycles and strain or stress to be applied to mean $\varepsilon-\mathrm{N}$ curve

\begin{tabular}{|c|c|c|c|c|}
\hline \multirow[b]{2}{*}{ Parameter } & \multirow{2}{*}{$\begin{array}{l}\text { Factor } \\
\text { on Life } \\
\text { (Air) }\end{array}$} & \multicolumn{2}{|c|}{ Factor on Life (Water) } & \multirow{2}{*}{$\begin{array}{c}\text { Factor } \\
\text { on Strain } \\
\text { or Stress }\end{array}$} \\
\hline & & $\begin{array}{l}\text { Stainless } \\
\text { Steels }\end{array}$ & $\begin{array}{l}\text { Carbon \& Low- } \\
\text { Alloy Steels }\end{array}$ & \\
\hline $\begin{array}{l}\text { Material variability \& } \\
\text { experimental scatter }\end{array}$ & 2.0 & 3.0 & 3.0 & $1.2-1.7$ \\
\hline Size effect & 1.4 & 1.4 & 1.4 & 1.25 \\
\hline Surface finish & 3.0 & 3.0 & 1.6 & 1.6 \\
\hline Loading history & $1.5-2.5$ & $1.5-2.5$ & $1.5-2.5$ & $1.3-1.6$ \\
\hline Total adjustment & $12.5-21.0$ & $19.0-31.0$ & $10.0-17.0$ & $1.6-1.7$ \\
\hline
\end{tabular}




\section{Summary}

The existing fatigue $\varepsilon-\mathrm{N}$ data for carbon and low-alloy steels and wrought and cast austenitic SSs have been evaluated to define the effects of key material, loading, and environmental parameters on the fatigue lives of these steels. The fatigue lives of carbon and low-alloy steels and austenitic SSs are decreased in LWR environments; the magnitude of the reduction depends on temperature, strain rate, DO level in water, and, for carbon and low-alloy steels, the S content of the steel. For all steels, environmental effects on fatigue life are significant only when critical parameters (temperature, strain rate, DO level, and strain amplitude) meet certain threshold values. Environmental effects are moderate, e.g., less than a factor of 2 decrease in life, when any one of the threshold conditions is not satisfied. The threshold values of the critical parameters and the effects of other parameters (such as water conductivity, water flow rate, and material heat treatment) on the fatigue life of the steels are summarized.

Experimental data are presented on the effects of surface roughness on the fatigue life of carbon and low-alloy steels and austenitic SSs in air and LWR environments. Tests were conducted on specimens that were intentionally roughened under controlled conditions to an RMS surface roughness of $1.6 \mu \mathrm{m}$. For austenitic SSs, the fatigue life of roughened specimens is a factor of $\approx 3$ lower than that of the smooth specimens in both air and low-DO water. In high-DO water, fatigue lives are comparable for smooth and roughened specimens. For carbon and low-alloy steels, the fatigue life of roughened specimens is lower than that of smooth specimens in air but, in high-DO water, it is the same. In low-DO water, the fatigue life of the roughened specimens is slightly lower than that of smooth specimens. Because environmental effects on carbon and low-alloy steels are moderate in low-DO water, surface roughness is expected to influence fatigue life.

Statistical models are presented for estimating the fatigue life of carbon and low-alloy steels and wrought and cast austenitic SSs as a function of material, loading, and environmental parameters. Functional form and bounding values of these parameters are based on experimental observations and data trends. The models are recommended for predicted fatigue lives of $\leq 10^{6}$ cycles.

Two approaches are presented for incorporating the effects of LWR environments into ASME Section III fatigue evaluations. Both approaches are based on the best-fit curves to the experimental fatigue $\varepsilon-\mathrm{N}$ data in LWR environments. In the first approach, environmentally adjusted fatigue design curves have been developed by adjusting the best-fit experimental curve for the effect of mean stress and by setting margins of 20 on cycles and 2 on strain to account for uncertainties in life associated with material and loading conditions. These curves provide allowable cycles for fatigue crack initiation in LWR coolant environments. The second approach considers the effects of reactor coolant environments on fatigue life in terms of an environmental correction factor $\mathrm{F}_{\mathrm{en}}$, which is the ratio of fatigue life in air at room temperature to that in water under reactor operating conditions. To incorporate environmental effects into the ASME Code fatigue evaluations, a fatigue usage factor for a specific load set, based on the current Code design curves, is multiplied by the correction factor.

Data available in the literature have been reviewed to evaluate the conservatism in the existing ASME Code fatigue evaluations. Much of the conservatism in these evaluations arises 
from current design procedures, e.g., stress analysis rules and cycle counting. However, the ASME Code permits alternative approaches, such as finite-element analyses, fatigue monitoring, and improved $\mathrm{K}_{\mathrm{e}}$ factors, that can significantly decrease the conservatism in the current fatigue evaluation procedures.

Because of material variability, data scatter, and component size and surface, the fatigue life of actual components differ from that of laboratory test specimens under a similar loading history, and the mean $\varepsilon-\mathrm{N}$ curves for laboratory test specimens must be adjusted to obtain design curves for components. These design margins are another source of possible conservatism. The factors of 2 on stress and 20 on cycles used in the Code were intended to cover the effects of variables that can influence fatigue life but were not investigated in the tests that provided the data for the curves. Although these factors were intended to be somewhat conservative, they should not be considered safety margins because they were intended to account for variables that are known to affect fatigue life. Data available in the literature have been reviewed to evaluate the margins on cycles and stress that are needed to account for the differences and uncertainties. In air, a factor of at least 12.5 on cycles with respect to the mean $\varepsilon-\mathrm{N}$ curve for laboratory test specimens is needed to account for the effects of data scatter and material variability, component size, surface finish, and loading sequence. In LWR environments, a factor of at least 19 on cycles with respect to the mean $\varepsilon-\mathrm{N}$ curve for laboratory test specimens is needed for austenitic SSs and at least 10 on cycles for carbon and low-alloy steels. Also, in air and LWR environments, a factor of 1.7 on stress is needed to account for the various differences and uncertainties. The results indicate that the current ASME Code requirements of a factor of 2 on stress and 20 on cycles are quite reasonable, but do not contain excess conservatism that can be assumed to account for the effects of LWR environments. They thus provide appropriate design margins for the development of design curves from mean data curves for small specimens in LWR environments.. 


\section{References}

1. B. F. Langer, "Design of Pressure Vessels for Low-Cycle Fatigue," ASME J. Basic Eng. 84, 389-402 (1962).

2. Criteria of the ASME Boiler and Pressure Vessel Code for Design by Analysis in Sections III and VIII, Division 2, The American Society of Mechanical Engineers, New York (1969).

3. W. E. Cooper, "The Initial Scope and Intent of the Section III Fatigue Design Procedure," in Welding Research Council, Inc., Technical Information from Workshop on Cyclic Life and Environmental Effects in Nuclear Applications, Clearwater, Florida, January 20-21, 1992.

4. S. Ranganath, J. N. Kass, and J. D. Heald, "Fatigue Behavior of Carbon Steel Components in High-Temperature Water Environments," BWR Environmental Cracking Margins for Carbon Steel Piping, EPRI NP-2406, Electric Power Research Institute, Palo Alto, CA, Appendix 3 (1982).

5. M. Higuchi and K. Iida, "Fatigue Strength Correction Factors for Carbon and Low-Alloy Steels in Oxygen-Containing High-Temperature Water," Nucl. Eng. Des. 129, 293-306 (1991).

6. N. Nagata, S. Sato, and Y. Katada, "Low-Cycle Fatigue Behavior of Pressure Vessel Steels in High-Temperature Pressurized Water," ISIJ Intl. 31 (1), 106-1 14 (1991).

7. Y. Katada, N. Nagata, and S. Sato, "Effect of Dissolved Oxygen Concentration on Fatigue Crack Growth Behavior of A533 B Steel in High-Temperature Water," ISIJ Intl. 33 (8), 877-883 (1993).

8. H. Kanasaki, M. Hayashi, K. Iida, and Y. Asada, "Effects of Temperature Change on Fatigue Life of Carbon Steel in High Temperature Water," in Fatigue and Crack Growth: Environmental Effects, Modeling Studies, and Design Considerations, PVP Vol. 306, S. Yukawa, ed., American Society of Mechanical Engineers, New York, pp. 117-122 (1995).

9. G. Nakao, H. Kanasaki, M. Higuchi, K. Iida, and Y. Asada, "Effects of Temperature and Dissolved Oxygen Content on Fatigue Life of Carbon and Low-Alloy Steels in LWR Water Environment," in Fatigue and Crack Growth: Environmental Effects, Modeling Studies, and Design Considerations, PVP Vol. 306, S. Yukawa, ed., American Society of Mechanical Engineers, New York, pp. 123-128 (1995).

10. M. Higuchi, K. Iida, and Y. Asada, "Effects of Strain Rate Change on Fatigue Life of Carbon Steel in High-Temperature Water," in Effects of the Environment on the Initiation of Crack Growth, ASTM STP 1298, W. A. Van Der Sluys, R. S. Piascik, and R. Zawierucha, eds., American Society for Testing and Materials, Philadelphia, pp. 216-231 (1997). 
11. K. Iida, T. Bannai, M. Higuchi, K. Tsutsumi, and K. Sakaguchi, "Comparison of Japanese MITI Guideline and Other Methods for Evaluation of Environmental Fatigue Life Reduction," in Pressure Vessel and Piping Codes and Standards, PVP Vol. 419, M. D. Rana, ed., American Society of Mechanical Engineers, New York, pp. 73-82 (2001).

12. O. K. Chopra and W. J. Shack, "Evaluation of Effects of LWR Coolant Environments on Fatigue Life of Carbon and Low-Alloy Steels," in Effects of the Environment on the Initiation of Crack Growth, ASTM STP 1298, W. A. Van Der Sluys, R. S. Piascik, and R. Zawierucha, eds., American Society for Testing and Materials, Philadelphia, pp. 247-266 (1997).

13. O. K. Chopra and W. J. Shack, "Low-Cycle Fatigue of Piping and Pressure Vessel Steels in LWR Environments,” Nucl. Eng. Des. 184, 49-76 (1998).

14. O. K. Chopra and W. J. Shack, "Effects of LWR Coolant Environments on Fatigue Design Curves of Carbon and Low-Alloy Steels," NUREG/CR-6583, ANL-97/18 (March 1998).

15. O. K. Chopra and W. J. Shack, "Overview of Fatigue Crack Initiation in Carbon and Low-Alloy Steels in Light Water Reactor Environments," J. Pressure Vessel Technol. 121, 49-60 (1999).

16. O. K. Chopra and J. Muscara, "Effects of Light Water Reactor Coolant Environments on Fatigue Crack Initiation in Piping and Pressure Vessel Steels," in Proc. $8^{\text {th }}$ Intl. Conference on Nuclear Engineering, 2.08 LWR Materials Issue, Paper 8300, American Society of Mechanical Engineers, New York (2000).

17. O. K. Chopra and W. J. Shack, "Environmental Effects on Fatigue Crack Initiation in Piping and Pressure Vessel Steels,” NUREG/CR-6717, ANL-00/27 (May 2001).

18. M. Fujiwara, T. Endo, and H. Kanasaki, "Strain Rate Effects on the Low-Cycle Fatigue Strength of 304 Stainless Steel in High-Temperature Water Environment; Fatigue Life: Analysis and Prediction," in Proc. Intl. Conf. and Exposition on Fatigue, Corrosion Cracking, Fracture Mechanics, and Failure Analysis, ASM, Metals Park, OH, pp. 309-313 (1986).

19. M. Higuchi and K. Iida, "Reduction in Low-Cycle Fatigue Life of Austenitic Stainless Steels in High-Temperature Water," in Pressure Vessel and Piping Codes and Standards, PVP Vol. 353, D. P. Jones, B. R. Newton, W. J. O'Donnell, R. Vecchio, G. A. Antaki, D. Bhavani, N. G. Cofie, and G. L. Hollinger, eds., American Society of Mechanical Engineers, New York, pp. 79-86 (1997).

20. H. Kanasaki, R. Umehara, H. Mizuta, and T. Suyama, "Effect of Strain Rate and Temperature Change on the Fatigue Life of Stainless Steel in PWR Primary Water," Trans. 14th Intl. Conf. on Structural Mechanics in Reactor Technology (SMiRT 14), Lyon, France, pp. 485-493 (1997).

21. H. Kanasaki, R. Umehara, H. Mizuta, and T. Suyama, "Fatigue Lives of Stainless Steels in PWR Primary Water," Trans. 14th Intl. Conf. on Structural Mechanics in Reactor Technology (SMiRT 14), Lyon, France, pp. 473-483 (1997). 
22. K. Tsutsumi, H. Kanasaki, T. Umakoshi, T. Nakamura, S. Urata, H. Mizuta, and S. Nomoto, "Fatigue Life Reduction in PWR Water Environment for Stainless Steels," in Assessment Methodologies for Preventing Failure: Service Experience and Environmental Considerations, PVP Vol. 410-2, R. Mohan, ed., American Society of Mechanical Engineers, New York, pp. 23-34 (2000).

23. K. Tsutsumi, T. Dodo, H. Kanasaki, S. Nomoto, Y. Minami, and T. Nakamura, "Fatigue Behavior of Stainless Steel under Conditions of Changing Strain Rate in PWR Primary Water," in Pressure Vessel and Piping Codes and Standards, PVP Vol. 419, M. D. Rana, ed., American Society of Mechanical Engineers, New York, pp. 135-141 (2001).

24. O. K. Chopra and D. J. Gavenda, "Effects of LWR Coolant Environments on Fatigue Lives of Austenitic Stainless Steels,” J. Pressure Vessel Technol. 120, 116-121 (1998).

25. O. K. Chopra and J. L. Smith, "Estimation of Fatigue Strain-Life Curves for Austenitic Stainless Steels in Light Water Reactor Environments," in Fatigue, Environmental Factors, and New Materials, PVP Vol. 374, H. S. Mehta, R. W. Swindeman, J. A. Todd, S. Yukawa, M. Zako, W. H. Bamford, M. Higuchi, E. Jones, H. Nickel, and S. Rahman, eds., American Society of Mechanical Engineers, New York, pp. 249-259 (1998).

26. O. K. Chopra, "Effects of LWR Coolant Environments on Fatigue Design Curves of Austenitic Stainless Steels,” NUREG/CR-5704, ANL-98/31 (1999).

27. O. K. Chopra, "Mechanism and Estimation of Fatigue Crack Initiation in Austenitic Stainless Steels in LWR Environments,” NUREG/CR-6787, ANL-01/25 (2002).

28. O. K. Chopra, "Development of Fatigue Design Curve for Austenitic Stainless Steels in LWR Environments: A Review," in Pressure Vessel and Piping Codes and Standards 2002, PVP Vol. 439, R. D. Rana, ed., American Society of Mechanical Engineers, New York, pp. 119-132 (2002).

29. S. Majumdar, O. K. Chopra, and W. J. Shack, "Interim Fatigue Design Curves for Carbon, Low-Alloy, and Austenitic Stainless Steels in LWR Environments," NUREG/CR-5999, ANL-93/3 (1993).

30. J. Keisler, O. K. Chopra, and W. J. Shack, "Fatigue Strain-Life Behavior of Carbon and Low-Alloy Steels, Austenitic Stainless Steels, and Alloy 600 in LWR Environments," NUREG/CR-6335, ANL-95/15 (1995).

31. W. A. Van Der Sluys and S. Yukawa, "Status of PVRC Evaluation of LWR Coolant Environmental Effects on the S-N Fatigue Properties of Pressure Boundary Materials," in Fatigue and Crack Growth: Environmental Effects, Modeling Studies, and Design Considerations, PVP Vol. 306, S. Yukawa, ed., American Society of Mechanical Engineers, New York, pp. 47-58 (1995).

32. J. L. Smith, O. K. Chopra, and W. J. Shack, "Effect of Water Chemistry on the Fatigue Life of Austenitic Stainless Steels in LWR Environments," in Environmentally Assisted Cracking in Light Water Reactors, Semiannual Report, January 1999-June 1999, NUREG/CR-4667, Vol. 28, ANL-00/7, pp. 13-27 (July 2000). 
33. D. A. Hale, S. A. Wilson, E. Kiss, and A. J. Gianuzzi, "Low Cycle Fatigue Evaluation of Primary Piping Materials in a BWR Environment," GEAP-20244, U.S. Nuclear Regulatory Commission (1977).

34. D. A. Hale, S. A. Wilson, J. N. Kass, and E. Kiss, "Low Cycle Fatigue Behavior of Commercial Piping Materials in a BWR Environment," J. Eng. Mater. Technol. 103, 15-25 (1981).

35. S. Ranganath, J. N. Kass, and J. D. Heald, "Fatigue Behavior of Carbon Steel Components in High-Temperature Water Environments," in Low-Cycle Fatigue and Life Prediction, ASTM STP 770, C. Amzallag, B. N. Leis, and P. Rabbe, eds., American Society for Testing and Materials, Philadelphia, pp. 436-459 (1982).

36. J. B. Terrell, "Fatigue Life Characterization of Smooth and Notched Piping Steel Specimens in $288^{\circ} \mathrm{C}$ Air Environments," NUREG/CR-5013, EM-2232 Materials Engineering Associates, Inc., Lanham, MD (1988).

37. J. B. Terrell, "Fatigue Strength of Smooth and Notched Specimens of ASME SA 106-B Steel in PWR Environments," NUREG/CR-5136, MEA-2289, Materials Engineering Associates, Inc., Lanham, MD (1988).

38. C. E. Jaske and W. J. O'Donnell, "Fatigue Design Criteria for Pressure Vessel Alloys," Trans. ASME J. Pressure Vessel Technol. 99, 584-592 (1977).

39. J. B. Conway, R. H. Stentz, and J. T. Berling, "Fatigue, Tensile, and Relaxation Behavior of Stainless Steels," TID-26135, U.S. Atomic Energy Commission, Washington, DC (1975).

40. D. L. Keller, "Progress on LMFBR Cladding, Structural, and Component Materials Studies during July, 1971 through June, 1972, Final Report," Task 32, Battelle-Columbus Laboratories, BMI-1928 (1977).

41. M. Hayashi, "Thermal Fatigue Strength of Type 304 Stainless Steel in Simulated BWR Environment," Nucl. Eng. Des. 184, 135-144 (1998).

42. M. Hayashi, K. Enomoto, T. Saito, and T. Miyagawa, "Development of Thermal Fatigue Testing with BWR Water Environment and Thermal Fatigue Strength of Austenitic Stainless Steels," Nucl. Eng. Des. 184, 113-122 (1998).

43. D. J. Gavenda, P. R. Luebbers, and O. K. Chopra, "Crack Initiation and Crack Growth Behavior of Carbon and Low-Alloy Steels," in Fatigue and Fracture 1, Vol. 350, S. Rahman, K. K. Yoon, S. Bhandari, R. Warke, and J. M. Bloom, eds., American Society of Mechanical Engineers, New York, pp. 243-255 (1997).

44. O. K. Chopra, "Mechanism of Fatigue Crack Initiation in Austenitic Stainless Steels in LWR Environments," in Pressure Vessel and Piping Codes and Standards - 2002, PVP Vol. 439, R. D. Rana, ed., American Society of Mechanical Engineers, New York, pp. 133-142 (2002). 
45. T. T. Pleune and O. K. Chopra, "Artificial Neural Networks and Effects of Loading Conditions on Fatigue Life of Carbon and Low-Alloy Steels," in Fatigue and Fracture 1, Vol. 350, S. Rahman, K. K. Yoon, S. Bhandari, R. Warke, and J. M. Bloom, eds., American Society of Mechanical Engineers, New York, pp. 413-423 (1997).

46. G. L. Wire and Y. Y. Li, "Initiation of Environmentally-Assisted Cracking in Low-Alloy Steels," in Fatigue and Fracture Volume 1, PVP Vol. 323, H. S. Mehta, ed., American Society of Mechanical Engineers, New York, pp. 269-289 (1996).

47. J. Hickling, "Strain-Induced Corrosion Cracking of Low-Alloy Reactor Pressure Vessel Steels under BWR Conditions," in Proc. of the Tenth Intl. Symp. on Environmental Degradation of Materials in Nuclear Power Systems-Water Reactors, F. P. Ford, S. M. Bruemmer, and G. S. Was, eds., The Minerals, Metals, and Materials Society, Warrendale, PA, CD-ROM, Paper 0156 (2001).

48. H. D. Solomon, R. E. DeLair, and A. D. Unruh, "Crack Initiation in Low-Alloy Steel in High-Temperature Water," in Effects of the Environment on the Initiation of Crack Growth, ASTM STP 1298, W. A. Van Der Sluys, R. S. Piascik, and R. Zawierucha, eds., American Society for Testing and Materials, Philadelphia, pp. 135-149 (1997).

49. H. D. Solomon, R. E. DeLair, and E. Tolksdorf, "LCF Crack Initiation in WB36 in High Temperature Water," in Proc. of the Ninth Intl. Symp. on Environmental Degradation of Materials in Nuclear Power Systems-Water Reactors, F. P. Ford, S. M. Bruemmer, and G. S. Was, eds., The Minerals, Metals, and Materials Society, Warrendale, PA, pp. 865-872 (1999).

50. A. Hirano, M. Yamamoto, K. Sakaguchi, K. Iida, and T. Shoji, "Effects of Water Flow Rate on Fatigue Life of Carbon Steel in High-Temperature Pure Water Environment," in Assessment Methodologies for Predicting Failure: Service Experience and Environmental Considerations, PVP Vol. 410-2, R. Mohan, ed., American Society of Mechanical Engineers, New York, pp. 13-18 (2000).

51. A. Hirano, M. Yamamoto, K. Sakaguchi, T. Shoji, and K. Iida, "Effects of Water Flow Rate on Fatigue Life of Ferritic and Austenitic Steels in Simulated LWR Environment," in Pressure Vessel and Piping Codes and Standards - 2002, PVP Vol. 439, R. D. Rana, ed., American Society of Mechanical Engineers, New York, pp. 143-150 (2002).

52. E. Lenz, N. Wieling, and H. Muenster, "Influence of Variation of Flow Rates and Temperature on the Cyclic Crack Growth Rate under BWR Conditions," in Environmental Degradation of Materials in Nuclear Power Systems - Water Reactors, The Metallurgical Society, Warrendale, PA (1988).

53. C. Amzallag, P. Rabbe, G. Gallet, H. -P. Lieurade, "Influence des Conditions de Sollicitation Sur le Comportement en Fatigue Oligocyclique D'aciers Inoxydables Austénitiques,” Memoires Scientifiques Revue Metallurgie Mars, pp. 161-173 (1978).

54. H. S. Mehta and S. R. Gosselin, "Environmental Factor Approach to Account for Water Effects in Pressure Vessel and Piping Fatigue Evaluations," Nucl. Eng. Des. 181, 175-197 (1998). 
55. H. S. Mehta, "An Update on the EPRI/GE Environmental Fatigue Evaluation Methodology and its Applications," in Probabilistic and Environmental Aspects of Fracture and Fatigues, PVP Vol. 386, S. Rahman, ed., American Society of Mechanical Engineers, New York, pp. 183-193 (1999).

56. G. L. Wire, T. R. Leax, and J. T. Kandra, "Mean Stress and Environmental Effects on Fatigue in Type 304 Stainless Steel," in Probabilistic and Environmental Aspects of Fracture and Fatigues, PVP Vol. 386, S. Rahman, ed., American Society of Mechanical Engineers, New York, pp. 213-228 (1999).

57. M. E. Mayfield, E. C. Rodabaugh, and R. J. Eiber, "A Comparison of Fatigue Test Data on Piping with the ASME Code Fatigue Evaluation Procedure," ASME Paper 79-PVP-92, American Society of Mechanical Engineers, New York (1979).

58. J. D. Heald and E. Kiss, "Low Cycle Fatigue of Nuclear Pipe Components," J. Pressure Vessel Technol. 74, PVP-5, 1-6 (1974).

59. A. F. Deardorff and J. K. Smith, "Evaluation of Conservatisms and Environmental Effects in ASME Code, Section III, Class 1 Fatigue Analysis," SAND94-0187, prepared by Structural Integrity Associates, San Jose, CA, under contract to Sandia National Laboratories, Albuquerque, NM (1994).

60. L. F. Kooistra, E. A. Lange, and A. G. Pickett, "Full-Size Pressure Vessel Testing and Its Application to Design,” J. Eng. Power 86, 419-428 (1964).

61. P. M. Scott and G. M. Wilkowski, "A Comparison of Recent Full-Scale Component Fatigue Data with the ASME Section III Fatigue Design Curves," in Fatigue and Crack Growth: Environmental Effects, Modeling Studies, and Design Considerations, PVP Vol. 306, S. Yukawa, ed., American Society of Mechanical Engineers, New York, pp. 129-138 (1995).

62. J. Hechmer, "Evaluation Methods for Fatigue - A PVRC Project," in Fatigue, Environmental Factors, and New Materials, PVP Vol. 374, H. S. Mehta, R. W. Swindeman, J. A. Todd, S. Yukawa, M. Zako, W. H. Bamford, M. Higuchi, E. Jones, H. Nickel, and S. Rahman, eds., American Society of Mechanical Engineers, New York, pp. 191-199 (1998).

63. L. G. Johnson, "The Median Ranks of Sample Values in Their Population with an Application to Certain Fatigue Studies," Ind. Math. 2, 1-9 (1951).

64. C. Lipson and N. J. Sheth, Statistical Design and Analysis of Engineering Experiments, McGraw Hill, New York (1973).

65. J. Beck and K. Arnold, Parameter Estimation in Engineering and Science, J. Wiley, New York (1977).

66. R. E. Peterson, "Fatigue Tests of Small Specimens with Particular Reference to Size Effect,” Trans. Amer. Soc. Steel Testing 18, 1041-1053 (1930).

67. D. Morkovin and H. F. Moore, "Third Progress Report on the Effect of Size of Specimen on Fatigue Strength of Three Types of Steel," Proc. Amer. Soc. Test. Mater. 44, 137-158 (1944). 
68. C. E. Philips and R. B. Heywood, "The Size Effect in Fatigue of Plain and Notched Steel Specimens Loaded under Reversed Direct Stress," Proc. Inst. Mech. Eng. 165, 113-124 (1951).

69. C. Massonnet, "The Effect of Size, Shape, and Grain Size on the Fatigue Strength of Medium Carbon Steel,” Proc. Amer. Soc. Test. Mater. 56, 954-978 (1956).

70. P. S. Maiya and D. E. Busch, "Effect of Surface Roughness on Low-Cycle Fatigue Behavior of Type 304 Stainless Steel,” Met. Trans. 6A, 1761-1766 (1975).

71. P. S. Maiya, "Effect of Surface Roughness and Strain Range on Low-Cycle Fatigue Behavior of Type 304 Stainless Steel," Scripta Metall. 9, 1277-1282 (1975).

72. K. J. Stout, "Surface Roughness - Measurement, Interpretation, and Significance of Data," Mater. Eng. 2, 287-295 (1981).

73. K. Iida, "A Study of Surface Finish Effect Factor in ASME B \& PV Code Section III," in Pressure Vessel Technology, Vol. 2, L. Cengdian and R. W. Nichols, eds., Pergamon Press, New York, pp. 727-734 (1989).

74. M. A. Pompetzki, T. H. Topper, and D. L. DuQuesnay, "The Effect of Compressive Underloads and Tensile Overloads on Fatigue Damage Accumulation in SAE 1045 Steel," Int. J. Fatigue 12 (3), 207-213 (1990).

75. A. Conle and T. H. Topper, "Evaluation of Small Cycle Omission Criteria for Shortening of Fatigue Service Histories,” Int. J. Fatigue 1, 23-28 (1979).

76. A. Conle and T. H. Topper, "Overstrain Effects During Variable Amplitude Service History Testing,” Int. J. Fatigue 2, 130-136 (1980).

77. Li Nian and Du Bai-Ping, "Effect of Monotonic and Cyclic Prestrain on the Fatigue Threshold in Medium-Carbon Steels,” Int. J. Fatigue 14 (1), 41-44 (1992).

78. M. J. Manjoine, "Fatigue Damage Models for Annealed Type 304 Stainless Steel under Complex Strain Histories," Trans. 6th Intl. Conf. on Structural Mechanics in Reactor Technology (SMiRT), Vol. L, 8/1, North-Holland Publishing Co., pp. 1-13 (1981).

79. K. J Miller, "Initiation and Growth Rates of Short Fatigue Cracks," Fundamentals of Deformation and Fracture, Eshelby Memorial Symposium, Cambridge University Press, Cambridge, U.K., pp. 477-500 (1985).

80. K. Tokaji, T. Ogawa, and S. Osaka, "The Growth of Microstructurally Small Fatigue Cracks in a Ferrite-Pearlite Steel,” Fatigue Fract. Eng. Mater. Struct. 11, 311-342 (1988).

81. K. Obrtlik, J. Polák, M. Hájek, and A. Vasek, "Short Fatigue Crack Behaviour in 316L Stainless Steel,” Intl. J. Fatigue 19, 471-475 (1997).

82. S. G. Sundara Raman, D. Argence, and A. Pineau, "High-Temperature Short Fatigue Crack Behaviour in a Stainless Steel,” Fatigue Fract. Eng. Mater. Struct. 20, 1015-1031 (1997). 
83. K. J. Miller, "Damage in Fatigue: A New Outlook," in International Pressure Vessels and Piping Codes and Standards: Volume 1 - Current Applications, PVP Vol. 313-1, K. R. Rao and Y. Asada, eds., American Society of Mechanical Engineers, New York, pp. 191-192 (1995).

84. Li Nian and Du Bai-Ping, "The Effect of Low-Stress High-Cycle Fatigue on the Microstructure and Fatigue Threshold of a 40Cr Steel," Int. J. Fatigue 17 (1), 43-48 (1995).

85. E. Haibach and D. Schutz, "Fatigue Life Evaluation with Particular Attention to Local Strain and Stress Time Histories," Proc. Inst. Mech. Eng. (1974). 